\title{
Landscape Development in Mountain Regions
}

Proceedings of the ForumAlpinum 2007

18. - 21. April, Engelberg / Switzerland

\section{Wiscar}

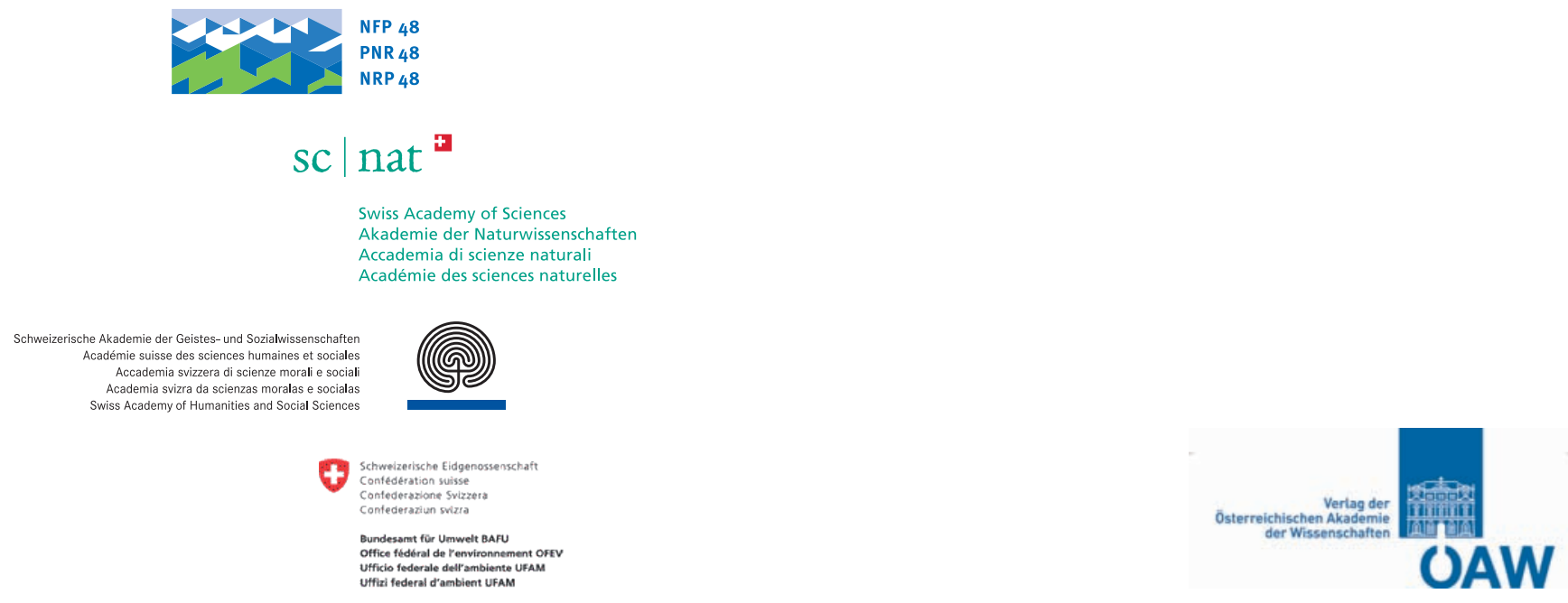




\section{Imprint}

\section{Distributor}

Austrian Academy of Sciences Press, Vienna

\section{Editors}

Prof. Heinz Veit, Dr. Thomas Scheurer, Dr. Günter Köck

International Scientific Committee on Research in the Alps IsCAR, www.iscar-alpineresearch.org

ISBN Online: 978-3-7001-3940-9

doi: 10.1553/forumalpinum

\section{Local scientific committee}

Prof. Heinz Veit (ICAS / IsCAR / University of Berne), chair, Susanne Grieder (ISCAR / Swiss Alpine Museum), Dr. Christian Gysi (Schweizer Alpen-Club SAC), Dr. Stefan Husi (National Research Programme NRP 48), Sylvia Martinez (Swiss Biodiversity Forum). Prof. Jon Mathieu (ICAS / University of Lucerne), Prof. em. Bruno Messerli (University of Berne), Christian Preiswerk (Swiss Academy of Sciences Scnat), Dr. Raimund Rodewald (Stiftung Landschaftsschutz Schweiz), Dr. Engelbert Ruoss (IcAs / IscaR / Unesco Biosphere Entlebuch UBE), Dr. Thomas Scheurer (ICAS / IsCAR), Andreas Stalder (Federal Office for the Environment Foen), Urs Steiger (Swiss National Research Programme NRP 48), Marlis Zbinden (Swiss Academy of Humanities and Social Sciences SHS)

\section{Partners:}

Swiss Academy of Sciences ScnAt, Swiss Academy of Humanities and Social Sciences SHS, Swiss National Research Programme NRP 48 Federal Office for the Environment Foen

\section{International scientific committee}

International Scientific Committee on Research in the Alps IscaR:

Prof. Heinz Veit (University of Berne, chair 2005-2006), Dr. Loredana Alfaré (IMONT, Rome), Prof. Axel Borsdorf (University of Innsbruck), Prof. Philippe Bourdeau (University Joseph Fourier, Grenoble), Dr. Anton Brancelj (Slovenian National Institute of Biology, Ljubljana), Dr. Jean-Jacques Brun (Cemagref, Grenoble, chair 2007-2008), Susanne Grieder (Swiss Alpine Museum, Berne), Prof. Horst Hagedorn (University of Würzburg), Prof. Dietrich Herm (University of Munich), Dr. Günter Köck (Austrian Academy of Sciences, Vienna, guest), Ivan Kreft (University of Ljubljana;), Dr. Massimo Pecci (IMONT), Dr. Christian Preiswerk (Swiss Academy of Sciences Scnat, guest), Prof. Roland Psenner (University of Innsbruck), Dr. Engelbert Ruoss (Unesco Biosphere Entlebuch UBE), Dr. Thomas Scheurer (Iscar office, Berne), Marlis Zbinden (Swiss Academy of Humanities and Social Sciences SHS, guest)

\section{Editorial staff and production}

Dr. Günter Köck (Austrian Academy of Sciences, Vienna)

Dr. Thomas Scheurer (Iscar office, Berne)

DI (FH) Vittorio Muth (Austrian Academy of Sciences, Vienna)

Mag. Herwig Stöger (Austrian Academy of Sciences, Vienna)

Vera Kaufmann (Iscar office, Berne)

\section{Layout}

Vera Kaufmann (Iscar office, Berne)

\section{Translation \& Proof-Reading}

Margret Powell-Joss, Berne

Veit H., Scheurer T., Köck G. (Ed's.) 2007: Landscape Development in Mountain Regions. Proceedings of the ForumAlpinum 2007, 18. - 21. April, Engelberg / Switzerland - International Scientific Committee on Research in the Alps Iscar. - Vienna, Austrian Academy of Sciences Press. Digital Edition.

ISBN Online: 978-3-7001-3940-9; doi: 10.1553/forumalpinum 


\section{Contents}

\section{Foreword}

\section{Plenary Session 1: Values and valuation}

1.1. Pecci M., Weck-Hannemann H.: summary

1.2. Key input contributions to Plenary Session 1: extended summaries 7

1.2.1. Walter F.: The Alps as both matrix and model of European perception of the landscape 7

1.2.2. Hunziker M.: What values, needs and expectations do future alpine landscapes have to meet?Results of representative preference studies in Switzerland

1.2.3. Pruckner G.: Use and non-use values of landscapes - economic valuation 9

1.2.4. Panizza M.: Cultural Geomorphology in Mountain Regions 10

1.3. Workshops Plenary Session 1: summaries 12

1.3.1. Backhaus N., Stremlow M.: Alpine views: from imagination to action Workshop 1/1 (NRP 48 synthesis 1) 12

$\begin{array}{ll}\text { 1.3.2. Grêt-Regamey A.: Economic valuation of alpine landscapes } & 13 \\ & \text { Workshop 1/2 (NRP } 48 \text { synthesis 4) }\end{array}$

1.3.3. Sgard A.: Landscape and identity

1.3.4. Hausner I., Reynard E.: Toponymy and Geoheritage in the Alps - cultural approaches in geoheritage research

Workshop $1 / 4$

\section{Plenary Session 2: Transformation processes}

2.1. Brun J.-J., Golobič M.: summary 19

2.2. Key input contributions to Plenary Session 2: extended summaries 21

2.2.1. Tappeiner U.: Land-use change in the European Alps: effects of historical and future scenarios of landscape development on ecosystem services

2.2.2. Bolliger J., Kienast F.: Observed and simulated transformation of Alpine landscapes: driving forces and potential impact on landscape functions

2.2.3. Bertrand N., Vanpeene S.: Landscape under urban pressure: agreement or divergence between socio-economical and ecological approaches

2.2.4. Vancutsem D.: Shaping our future urban landscapes - experiences from Bavaria 26

2.3. Workshops Plenary Session 2: summaries 27

$\begin{array}{ll}\text { 2.3.1. Perlik M.: Urbanisation: changes of the built environment } & 27\end{array}$

$\begin{array}{ll}\text { 2.3.2. Stöcklin J.: Agriculture, Alpine landscapes and biodiversity } & 29 \\ & \text { Workshop 2/2 (NRP } 48 \text { synthesis 2) }\end{array}$

$\begin{array}{ll}\text { 2.3.3. Probst T.: Changing climate - changing landscape } & 30\end{array}$

2.3.4. Kozak J., Petek F.: Land-use changes in the Carpathians and in the Alps
Workshop 2/4

2.3.5. Alewell Ch., Spehn E.: Soil system services in mountain environments
Workshop $2 / 5$ 


\section{Plenary Session 3: Cooperation and decision-making in}

landscape management

3.1. Luque S., Weixlbaumer N.: summary

3.2. Key input contributions to Plenary Session 3: extended summaries 37

3.2.1. Wiesinger G.: The importance of social capital in rural development, networking and decision-making in rural areas

3.2.2. Coy M.: The perception of landscape management - the example of the Großes Walsertal Biosphere Reserve

3.2.3. Hirschmugl M., Zebisch M.: How can remote sensing support landscape planning and landscape management in mountain regions?

3.3. Workshops Plenary Session 3: summaries

3.3.1. Heeb J.: Shaping future landscapes: negotiation processes and best practices Workshop 3/1 (NRP 48 Synthesis 3)

3.3.2. Lange E.: Virtual worlds - real decisions: modelling the Alps Workshop 3/2 (NRP 48 Synthesis 5)

3.3.3. Castiglioni B., De Marchi M.:Strategic Environmental Assessment and Alpine landscape development Workshop $3 / 3$

3.3.4. Egerer H.: Cooperation in European mountains - the example of the Alpine and Carpathian Conventions

Workshop 3/4

\section{Plenary Session 4: Landscape's role in a changing society 47}

4.1. Wytrzens H. K.: summary 47

4.2. Key input contributions to Plenary Session 4: extended summaries 49

4.2.1. Debarbieux B.: Social demand for landscapes 49

4.2.2. Lehmann B.: Landscapes: from by-product to resource - selected conclusions
from the Swiss NRP 48 „Landscapes and Habitats of the Alps"

4.2.3. Helming K., Kräuchi N.: Assessing land-use impacts on landscape goods and

5. Project \& Programme Fairs $\quad 55$

5.1. Borsdorf A.: Project networking in European Mountains (FP 6, INTERREG III and COST) Project \& Programme Fair 1

5.2. Björnsen Gurung A., Scheurer T., Veit H.: Global change research in European mountains: Implementation of the GLOCHAMORE Research Strategy and Research Agenda in the multi-annual working programme of the Alpine Convention among the scientific community Project \& Programme Fair 2

5.3. Bose L.: Ecological networks within and into the Alps: from concepts to actions Project \& Programme Fair 3

5.4. Jost S., Kirchgesser M.: The Alpine Space Programme: A successful approach to transnational cooperation in the Alpine Space Project \& Programme Fair 4

\section{Poster presentations}




\section{Foreword}

After Disentis (CH 1994), Chamonix (F 1996), GarmischPartenkirchen (D 1998), Bergamo and Castione della Presolana (I 2000), Alpbach (A 2002) and Kranjska Gora (SI 2004), the seventh ForumAlpinum was hosted again by Switzerland from April $18^{\text {th }}-21^{\text {st }}, 2007$. As in 1994, the Swiss venue was Engelberg, a historic location famous for its monastery. Some 230 scientists, stakeholders, politicians and interested laypeople responded to the invitation to discuss various aspects of "Landscape Development in Mountain Regions" at this year's ForumAlpinum, extended by the International Scientific Committee for Alpine Research IsCAR, the Swiss Academy of Sciences ScNAT and the Swiss Academy of Humanities and Social Sciences SHS. The choice of topic was related to the Swiss national research programme "Landscapes and habitats of the Alps" (NRP 48), realized between 2001 and 2007, but to be discussed in a broader alpine and European context.

Four plenary sessions dealt with "values and valuation", "transformation processes", „cooperation and decisionmaking in landscape management" and "the role of landscape in a changing society". The plenary sessions with talks by various speakers were complemented by thirteen workshops, a poster presentation, four project \& programme fairs, film presentations and two excursions. Participants and invited guests spent the official evening on the Titlis (3020 $\mathrm{m}$ asl), an impressive peak on which Edwin Bernbaum, Head of the Sacred Mountains Programme of The Mountain Institute, Berkeley, USA, enhanced our awareness of sacred mountains around the world.

These proceedings summarize the results of the $7^{\text {th }}$ ForumAlpinum. I trust that issues addressed at Engelberg will encourage further research and programmes to provide our society with greater knowledge in managing mountain landscape as a cultural heritage and resource for development.

The next ForumAlpinum will be integrated into Alpweek 2008 and focus on innovation processes in the Alps. Alpweek 2008 will be held from June $11^{\text {th }}-14^{\text {st }}, 2008$ at L'Argentière-la Bessée, France, in the south-western Alps.

Heinz Veit,

Chair of the ForumAlpinum 2007 


\section{Plenary Session 1: Values and valuation}

\subsection{Summary}

Moderators:

Hannnelore Weck-Hannemann (Institut für Finanzwissenschaft, Universität Innsbruck, Austria)

\section{Massimo Pecci (Imont, Rome, Italy)}

Mountain landscapes represent symbolic and cultural values, which are a part of driving factors for landscape development in mountain regions, such as scenery, amenity, identity, authenticity, naturalness, wildlife, seclusion, or sacredness. This first Plenary Session asked (1) how such values are recognised, valuated and used by policy-makers, society and the private economic sector, (2) what issues concerning landscape development need to be addressed, and (3) what appropriate concepts of landscape development or efficient instruments exist to preserve, improve or create such values.

The presentations of the Plenary Session emphasized cultural, historical, political, social and economic dimensions in the use of landscape values and debated on questions as:

- How are landscapes valuated by society and different "user groups"?

- What landscape for which users?

- Are landscapes a public (national or regional) good?

- Use (economic) and non-use (cultural, ethical) values of landscapes?

- Do we need landscapes for identity?

- Will future mountain tourism depend on landscape?

- Do value changes precede landscape changes - or vice versa?

- How to create new values in / of landscapes?

The four Keynote Speakers represented different approaches to these issues. François Walter from the Département d'Histoire générale of the University of Geneva (Switzerland) questioned the perception of Alpine landscapes from a historical perspective. He was followed by Marcel Hunziker, from the Social Sciences in Landscape Research Group of the Swiss Federal Research Institute WSL in Birmersdorf (Switzerland), who further explored the question of what objectives and preferences the Swiss population has with respect to landscapes in the Alps in the future. Gerald Pruckner from the Department of Economics at the University of Linz (Austria) focussed on the valuation of landscape amenities in monetary terms and as revealed by local compensation schemes based on political negotiations. Finally, Mario Panizza from the Dipartmento di Scienze della Terra at the Universitá di Mo- dena e Reggio Emilia (Italy) supplemented the discussion by illustrating his concept of cultural geomorphology in mountain regions.

- François Walter (Département d'Histoire générale, Université de Genève, Switzerland) :

The Alps as both matrix and model of European landscape perception

The alpine mountain landscape has played an important role in European visual culture. Between the $18^{\text {th }}$ and the mid- $20^{\text {th }}$ centuries, this particular type of landscape was a must when it came to characterizing beautiful scenery. Beyond aesthetics, the political uses of the model deserve renewed attention. Reference to the alpine landscape has been used in very different contexts, most often totally unrelated to mountain topography, in order to affirm national specificities. More or less hybrid landscape types have thus been promoted to the status of cultural reference. Elsewhere, through rejection of the model and aesthetic sublimation of local qualities, reference to mountains helps found a more autonomous landscape image. These complex processes do not develop within an ideological vacuum. Understanding them might prevent the excessive naturalization of cultural references.

- Marcel Hunziker (Swiss Federal Research Institute WSL, Birmensdorf, Switzerland):

What values, needs and expectations do future landscapes in the Alps have to meet? Results of representative preference studies in Switzerland

One of the main goals of our project within the framework of the NRP 48 was to investigate the objectives of different parts of the (Swiss) population regarding the Alpine landscape and its development. In this context, the underlying dimensions of objectives and preferences such as values, needs and expectations were analysed. Furthermore, consensus-building measures to resolve conflicts of objectives were developed and experimentally evaluated. At the conference, the main results of a nationwide representative survey in Switzerland regarding landscape objectives and preferences were primarily presented, with special emphasis on the results of the statistical evaluation of an integrative theoretical preference model developed to comprehensively explain public assessment of future landscape changes by underlying dimensions. Three such underlying dimensions were identified through factor analysis. They can be described as need for security, stimulation and self-direction, and might also be interpreted as value-orientations. 
- Gerald J. Pruckner (Sozial- und wirtschaftswissenschaftliche Fakultät, Universität Linz, Austria): Use and non-use values of landscapes - economic valuation

The economic valuation of public goods such as landscape amenities is difficult due to market failure. To overcome obvious free-riding incentives, economists have developed specific tools for a monetary valuation of public (environmental) goods. Based on a contingent valuation study, it was possible to provide willingness-to-pay (WTP) figures by tourists in Austria for the provision of landscape-enhancing services by mountain farmers. These so-called non-commodity outputs of agriculture contribute to the pleasure of individuals, either as residents or as tourists on holiday in the relevant areas. Moreover, landscape-cultivating activities protect people, animals and infrastructure from avalanches, landslides, erosion and rockslides. Even though the potential of hypothetical benefits associated with landscape amenities seems substantial, it was argued that the monetary landscape values have not been sufficiently transformed into real payments for farmers. Since the preservation of a cultivated and open countryside in mountain regions will require the comprehensive internalization of all landscape values in the future, voluntary local compensation schemes based on political negotiations at the municipal level may arise, which was illustrated by a specific example.

- Mario Panizza (Dipartimento di Scienze della Terra, Università di Modena e Reggio Emilia, Italy): Cultural Geomorphology in mountain regions The author proposed a definition of cultural geomorphology, i.e. the study of the geomorphological component of a territory which embodies both a cultural feature of the landscape and its interactions with cultural heritage (archaeological, historical, architectural, etc.). Moreover, he illustrated in general terms and by selected examples from mountain regions that the relationships between geomorphology and cultural elements can be considered schematically according to two reciprocally integrated viewpoints: (1) geomorphology is intended as a component of a territory's cultural heritage (geomorphosites); (2) the relationships between some cultural components (in a strict sense) of a territory (archaeological, historical, architectural assets, etc.) and their geomorphological context. Finally, it was argued that this concept can be extended to all the fields of earth sciences (cultural geology) based on geodiversity and geohistory.

In sum, this first Plenary Session with input contributions from four speakers, and comments from the audience and the moderators, has contributed to a general overview of the complexity of landscape values and valuation, pre- senting different points of view. Starting from the initial coincidence of Alpine with Swiss landscape, the discussion provided important impulses for a more general view, but also presented problematic and unresolved landscape concepts and values from historical, sociological, economic, physical and cultural points of view.

Some of the aspects brought up in the Plenary Session were taken up and discussed in greater depth in the subsequent Workshops (see pages 12-17):

- Workshop 1/1: Alpine views: from imagination to action (Norman Backhaus, Matthias Stremlow)

- Workshop 1/2: Economic valuation of alpine landscapes (Adrienne Grêt-Regamey)

- Workshop 1/3: Landscape and Identity (Anne Sgard)

- Workshop 1/4: Toponyms and Geoheritage in the Alps (Isolde Hausner, Emmanuel Reynard) 


\subsection{Key input contributions to Plenary Session 1: extended summaries}

\subsubsection{The Alps as both matrix and model of European perception of the landscape}

François Walter (Département d'Histoire générale, Université de Genève, Switzerland)

\section{Keywords}

Landscape and ideology, national identity, perception and representation

The aim of this paper is to show how, throughout history, Europeans have symbolically invested the world of mountains, and have not merely transformed it into a marketable commodity, into something with an exchange value, as so often suggested by tourism today. The Alps have provided something more than an exceptional context for interchangeable leisure activities.

\section{The Alps as a landscape}

Today, it is difficult to measure the extraordinary enrichment of thought that has been brought about by the diffusion of the landscape concept. We have generally become used to the idea that Western civilisation "invented", or at least "discovered", the concept. The origin of the concept has frequently been discussed, as has its gradual emancipation from the strictly pictorial context where it first appeared. Alongside a few other emblematic landscapes, the alpine mountain landscape has been considered since the end of the $17^{\text {th }}$ century as the prototype of the aesthetic landscape. Its pictorial and artistic interpretation is expressed in every aesthetic code of perception, whether it be pastoral, georgic, exotic, or even sublime rather than picturesque, where each vision is non-exclusive of any other. Although the alpine mountain landscape is a sensitive manifestation of the environment that should not be reduced to its aesthetic dimensions, it does represent something more than a simple way of "seeing the world". It is a means for making it visible, which is more than a nuance of style.

\section{Resistance to an aesthetic model}

At first, it may seem surprising to find texts that show a sort of contempt for or resistance to the landscape, appearing to reflect a rejection of an intrusive landscape model. Certain authors denounce the partiality shown for grandiose high-mountain landscapes, which they consider as no more than a fashion trend.

It is true that the $19^{\text {th }}$ century saw a multiplication of so-called "Swiss" landscapes. The "signs" or symbols of the Swiss landscape became rapidly diffused thanks to photography and the graphic arts. Landscape designations with references to the Swiss model spread quickly throughout the world. Thus, 116 regions, scattered across the globe, have been identified as bearing the "Swiss" label. Through its mountains, Switzerland has become the canonical reference for beauty in Nature.

\section{The question of a national landscape}

Issues associated with a landscape model took on meaning in the nation-forming processes of the $19^{\text {th }}$ and $20^{\text {th }}$ centuries. The adoption of an aesthetic model, like that of the Alpine landscape, in a different context involves a complex system of cultural images. It is a question of explaining the social mechanisms of its trans-cultural appropriation and its reinterpretation in a different national context. The landscape of the Alps is used to develop a new definition of national culture.

Sometimes the model is integrated by hybridization (at the regional scale in neighbouring countries), while in other situations it is rejected through a refusal of domination, a step accompanied by a process of cultural sublimation of local qualities (Germany, Scandinavia). In yet other contexts, references of the model may be taken over, not with a view to adopting it but rather to become distinct from it and develop a counter model. Relations of similitude are inversed here. The metaphor helps to reveal an antonymic relationship while at the same time including the positive features of the model (Hungary, Russia).

These mechanisms are not found in nations that have a sufficiently strong historical base to assimilate the shock of comparison with the Alps or, better still, to ignore it (case of France).

\section{Political values}

The phenomenon of a narrow identity anchor is not exclusive to mountain areas. However, it expresses itself in the Alps with particular force when local populations defend their freedom and privileges as if the existence of their autonomy was written in Nature. This indicates that the mountain environment, more than any other, makes it possible to project values considered as universal, such as freedom, courage, authenticity and other ethical values. They transcend time or at least take on a permanent character. This is why we find the same references in other mountain areas (for example, in Portugal or Scandinavia), although temporal aspects are peculiar to the different regions and national circumstances.

At different periods in history and in different contexts, these models have been mobilised in order to express national identity through a series of signs, metaphors, semiophores, and accounts. The $19^{\text {th }}$ century was a key moment in this process. 


\subsubsection{What values, needs and expectations do future alpine landscapes have to meet? \\ Results of representative preference studies in Switzerland}

\section{Marcel Hunziker (Research Group Social Sciences in Landscape Research, Swiss Federal Research Institute WSL, Birmensdorf, Switzerland)}

\section{Keywords}

Landscape preferences, theories, models, surveys

Due to the high value of the landscape as an important resource of the Alps, in particular regarding tourism, society is called upon to consciously steer the future development of Alpine landscapes. Thus, it needs to be established what is expected from these landscapes, what values and needs they have to meet. Our project within the framework of the Swiss National Research Program "Landscapes and Habitats in the Alps" (NRP 48) aimed at providing such prerequisites for planning and realising future landscape development in the Alps.

A first main goal of our study was to investigate the objectives of different parts of the (Swiss) population regarding the Alpine landscape and its development. In this context, the driving forces of the objectives and preferences such as values, needs and expectations were analysed, as well as the reasons of conflicts of objectives. Special emphasis was also given to the analysis of the role of perceived quality of everyday landscape of (peri-)urban areas as a background of landscape objectives and preferences.

As the "landscape-objectives" of different groups may diverge, a second main goal was to develop, apply and evaluate suitable methods to foster consensus building regarding these objectives. Therefore, the influences of contextual and procedural factors on acceptance, handling and success as well as the outcome-effect of such procedures were investigated.

The project consisted of three parts with different methodological approaches:

1) The inductive part, i.e. the analysis of qualitative data collected in problem-centred interviews of representatives of different social groups, revealed deep insights into the (different) landscape objectives and their socio-cultural driving forces. Furthermore, conflicts resulting from diverging landscape objectives could be recognised, and consensus criteria established.

2) The deductive part primarily provided representative quantitative data regarding landscape objectives and their socio-cultural and psychological driving forces. It allowed the creation of models regarding the influence of values, needs and expectations on landscape preferences, and the inter-relationship between satisfaction with the daily environment, expectations from leisure landscapes, and leisure mobility. To this end, representative samples of different strata of the Swiss public as well as of tourists and residents of two investigation areas were surveyed by standardised questionnaires (with visualised scenarios of future landscape development in the Alps).

3) In the quasi-experimental part, consensus-building procedures were applied. This approach was understood as an intervention-experiment that is evaluated empirically. Procedural aspects were evaluated by process observation; effect was measured by surveys before and after the intervention.

At the conference, the focus was on the main results of the second research part. Special emphasis was therefore given to the results of the statistical evaluation of an integrative theoretical preference model, developed to comprehensively explain public assessments of future landscape developments by basic driving forces such as values, needs and expectations. This model combines two groups of approaches: (1) concepts of the so-called „biological perspective" (Bourassa 1991) such as Kaplan \& Kaplan's (1989) information-processing theory, or attention-restoration theory (e.g. Kaplan \& Kaplan, 1989; Hartig et al., 1997) and (2) concepts of „social perspective“, including place-attachment (e.g. Altman \& Low, 1992; Korpela et al. 2001), place-identity (e.g. Breakwell, 1986; TwiggerRoss \& Uzzell, 1996), familiarity (e.g. Hammit, 1981), time orientation (Stokols \& Jacoby, 1984), political, ecological and economical interests (e.g. van den Berg 1998; Hunziker 1995). Not only was it shown which factors have greatest influence on landscape preferences and objectives, but also which factors are suggested by statistical analyses to represent general underlying dimensions of (bundles of) preference predictors. Three such underlying dimensions were identified through factor analyses. They can be described as needs for security, stimulation and self-direction, and might also be interpreted as value-orientations in terms of Schwartz' (1992) theory of integrated value systems. The suggestion that "security", "stimulation" and "self-direction" form a shared, higher-order structure linking different theoretical approaches, and representing guiding dimensions in the human-landscape relationship is also supported by the finding that the three dimensions are also related to types of landscape preferences: the Arcadian type, the Utilitarian type and the Wilderness type. Each of these types assesses future potential landscape developments such as settlement development or reafforestation in another way. Furthermore, they are not equally distributed in Switzerland.

Thus, considerable differences were found in the assessment of future landscape scenarios, with landscape experts and decision makers as well as the local popula- 
tion of Alpine areas favouring conservation of traditional cultural landscapes, whereas the general public of the lowlands was more open towards re-wilding and reforestation. Nevertheless, a surprisingly strong consensus was found within the majority of the Swiss population that wilderness scenarios are not to be considered as (much) worse than conservation scenarios. However, regarding implementation strategies, one must bear in mind that there are considerable value differences between Alpine and non-Alpine populations. In addition, it must be taken into account that, at present, the amount of cultural landscapes is still quite high and wilderness areas represent a rather scarce good, which affects the current scenario assessments. These assessments, however, might change when, in turn, cultural landscapes become scarce.

\section{References}

Altman, I. \& Low, S.M., 1992: Place attachment. New York, Plenum Press.

Bourassa, S.C., 1991: The Aesthetics of Landscape. London and New York: Belhaven Press. 168p.

Hammit, W.E., 1981: The familiarity-preference component of on-site recreational experiences. Leisure Sciences 4/2: 177-193.

Hartig, T., Korpela, K., Evans, G.W., \& Gärling, T., 1997: A measure of restorative quality in environments. Scandinavian Housing and Planning Research 14: 175-194.

Hunziker, M., 1995: The spontaneous reafforestation in abandoned agricultural lands: perception and aesthetical assessment by locals and tourists. Landscape and Urban Planning 31: 399410

Kaplan, R. \& Kaplan, S., 1989: The experience of nature. A psychological Perspective. Cambridge University Press. 340p.

Korpela, K.M., Hartig, T., Kaiser, F.G. \& Fuhrer, U., 2001: Restorative experience and self-regulation in favorite places. Environment and Behavior 33/4: 572-589.

Schwartz, S. H., 1992: Universals in the content and structure of values: Theoretical advances and empirical tests in 20 countries. Advances in Experimental Social Psychology, 25, 1-65.

Stokols, D. \& Jacobi, M, 1984:. Traditional, present oriented, and futuristic modes of group-environment relations. In: K. J. Gergen and M. M. Gergen. Historical social psychology. Hillsdale, NJ, Erlbaum: 303-324.

Twigger-Ross, C.L., \& Uzzell, D.L., 1996: Place and identity processes. Journal of Environmental Psychology 16: 205-220.

Van den Berg, A.E., Vlek, C.A. \& Coeterier, J.F., 1998: Group differences in the aesthetic evaluation of nature development plans: A multilevel approach. Journal of Environmental Psychology 18/2: 141-157.

\subsubsection{Use and non-use values of landscapes - economic valuation}

Gerald J. Pruckner (Sozial- und wirtschaftswissenschaftliche Fakultät, Universität Linz, Austria)

\section{Keywords}

Use and non-use values of landscape, contingent valuation, willingness to pay, agricultural externalities, noncommodity output of agriculture, local compensation payments

\section{Environmental Valuation}

One important principle of environmental economics is that individuals face a trade-off between income (wealth) and environmental quality. Therefore, it is theoretically possible to elicit people's willingness to pay (WTP) for an increase in environmental quality in monetary terms.

However, environmental quality (landscape quality) is a typical public good characterized by non-rivalry and non-excludability. We face valuation problems as private markets (demand and supply curves) do not exist.

Economists have developed non-market valuation techniques for environmental goods. These techniques capture different components of values:

- Use values

- Non-use values

$$
\begin{aligned}
& \text { - existence values } \\
& \text { - option values } \\
& \text { - bequest values }
\end{aligned}
$$

We distinguish indirect and direct valuation instruments:

- indirect instruments (revealed preferences): preference elicitation by observable behavior; hedonic pricing, travel cost method, etc.;

- direct instruments (stated preferences): preference elicitation by means of survey techniques; contingent valuation, etc.

\section{Landscape Valuation: Empirical Evidence from Alpine Regions}

Background: Apart from the production of food, feed and other raw materials sold on private markets, Austrian agriculture provides non-commodity outputs (NCOs), most of which represent external benefits of production. Austrian farmers (including the forest sector) cultivate more than 80 per cent of the national territory and are therefore in charge of creating an appropriate landscape across the nation - the multifunctional role of (mountain) agriculture. However, due to structural change in agriculture, mountain farms are no longer sufficiently competitive - policy measures have failed to keep farmers in mountain areas. Therefore, the provision of landscapeenhancing services and the openness of the countryside is 
threatened.

Agricultural landscape-enhancing services: NCOs have residential and/or recreational purposes. Certain types of agricultural activities (supplied jointly or separately with agricultural commodities) contribute to the pleasure of individuals, either as residents or as tourists who spend their holidays in the relevant areas. Whereas the beauty of the countryside seems indispensable to the tourist industry, protective measures provided by agriculture and in particular by forestry in alpine regions (the protection of people, animals, and the material infrastructure from avalanches, landslides, erosion and rockslides) also benefit local residents.

Several contingent valuation studies reveal the potential of WTP for landscape values of tourists [and residents] (Pruckner 1995, Hackl and Pruckner 1997, Hackl and Pruckner 1999). This evidence is supported by international studies. How do the WTP figures correspond to farmers' willingness to accept payment WTA (Glötzer and Pruckner 2007)?

\section{Landscape Amenities and Compensation}

Even if potential benefits associated with agricultural landscape services have been identified, the question remains as to how these monetary welfare measures can be translated into compensation payments to guarantee the provision of a well-kept mountain landscape.

We observe local voluntary compensation payments to farmers for their provision of landscape amenities in alpine Austrian tourist communities (for an interesting case study, see Pruckner 2005). These payments can be interpreted as the outcomes of a political bargaining process in municipalities. Based on a panel data analysis of local compensation schemes, Hackl, Halla and Pruckner (2007) identify underlying determinants of the negotiating process. The probability for a positive negotiation outcome depends on politico-economic factors such as the share of votes for distinct parties in parliamentary elections. Whereas benefits associated with landscape amenities also play an important role, transaction costs of bargaining are of minor relevance. If the variety of the countryside seems to be endangered, tourist communities start compensating their farmers for landscape-enhancing activities.

Compensation payments are "potentially" efficient as they internalise positive externalities. They supplement European Union and national policy measures in support of rural and/or less-favoured areas and contribute to farmers' incomes, especially in mountain regions. Whereas direct dependence of tourist profits on a well-kept landscape manifests itself in subsidy payments, we do not find similar evidence in non-tourist areas. However, the preservation of a cultivated and open countryside in mountain regions will require the comprehensive internalisation of all (intangible) landscape values in the future.

\subsubsection{Cultural Geomorphology in Mountain Regions}

Mario Panizza (Dipartimento di Scienze della Terra, Università di Modena e Reggio Emilia, Italy)

\section{Keywords}

Geomorphology, Culture, Geomorphosites, Mountain regions

The landscape is a "cultural" component of a territory, with all the "natural" and „anthropogenic" factors it contains; the relationships between the geomorphology and cultural elements of a specific territory can be considered schematically according to two reciprocally-integrated viewpoints

1) Geomorphology is then meant as a component of a territory's cultural heritage (in a broad sense), such as works of art, historical monuments, scientific assets, etc.

2) The relationships between some cultural components (in a strict sense) of a territory (archaeological, historical, architectonic assets etc.) and their geomorphological context.

As a result of these statements, a need was felt to propose a definition of Cultural Geomorphology (Panizza \& Piacente, 2003), i.e.

the discipline that studies the geomorphological component of a territory which embodies both a cultural feature of the landscape and its interactions with cultural heritage of the archaeological, historical, architectonic etc. type.

The concept of Cultural Geomorphology can be extended to all the fields of Earth Sciences and can therefore introduce the concept of Cultural Geology. This is based on the two concepts of Geodiversity and Geohistory. The former is considered as the substratum of unique landscapes and the basis of life varieties on Earth. The latter is considered in its spatial-temporal relationships with other cultural components and is a conditioning factor in the history of human society.

Everywhere on Earth there are elements to which these concepts can be applied. Therefore, in mountain regions, the two viewpoints mentioned above can also be identified.

The first viewpoint was considered as follows:

During the past ten years, these landscape aspects have been differently described and defined. The definition adopted here is the following: „Geomorphosite - a landform with particular and significant geomorphological attributions, which qualify it as a component of a territory's cultural heritage (in a broad sense)". 
The attributes that can confer value on a landform, making it a geomorphosite, are the following: scientific, cultural, socioeconomic, scenic.

The duties of Geomorphology in assessing the various attributes previously mentioned should be connected mainly to their scientific aspects.

The first phase of geomorphosite research usually aims to create a geomorphological map. From this map a map of geomorphological units will be derived, in which the units are grouped according to their morphogenetic characteristics (e.g., glacial, fluvial, karst, structural). Finally, geomorphological elements will have to be selected in order to produce a geomorphosite map.

Some examples in mountain regions were illustrated.

The second viewpoint was then considered as follows:

As regards a research methodology, five operative phases may be identified

- The first phase consists of the physical setting of the territory where the cultural asset (in a strict sense) is located (i.e., archaeological, historical or architectonic assets).

- The second phase consists of the geomorphological causes which conditioned the location of a given cultural element.

- The third phase consists of the possibility that a given cultural site might be affected by natural hazards (in our case geomorphological hazards) and consequently subject to risk.

- In the fourth phase the fruition of cultural assets will have to be considered, in particular for social or tourism initiatives which might have a negative effect on the natural environment, and geomorphological impacts should be taken into account.

- In the fifth phase one should also consider that the correct management of a cultural site cannot be separated from the knowledge of its integration with the surrounding environment. In this way, appropriate benefits can be promoted for both, with positive spin-offs in socio-economic terms, also with regard to conservation and improvement. Implementation of such an operation, together with all initiatives and activities aiming to promote and protect assets, requires interdisciplinary knowledge and multiple management of environmental education initiatives.

Some examples in mountain regions were illustrated.

Generally speaking, efforts should be made to respond to the ever-felt need for "neo-humanistic" culture, that is, for the integration of culture.

In conclusion, what should be emphasized, since it summarises the spirit guiding investigations in this field, is the fact that research approaches of an integrated, systemic type can become a very important opportunity for Geomorphology. Indeed, this Earth discipline can find in these topics further possibilities of development with new cultural and social vocations. 


\subsection{Workshops Plenary Session 1: summaries}

\subsubsection{Alpine views: from imagination to action (NRP 48 synthesis 1)}

Workshop 1/1

\section{Moderators:}

\section{Norman Backhaus (Geographisches Institut, Universität Zürich, Switzerland)}

\section{Matthias Stremlow (Federal Office for the Environment FoEN, Bern, Switzerland)}

A pristine and unaltered perception of landscapes and habitats of the Alps (and other mountain areas) does not exist. What does exist is a rich panoply of socially embedded images in the Alps that are used in culture, media, public relations but also in policy and planning. Not only do such images shape landscape experiences, they also play an important role in negotiations and conflicts in and around the Alps. To reveal such patterns of perception is a first step in order to find common grounds and to overcome obstacles in discussions. The thematic synthesis I of the NRP 48 addresses such issues, and - using the results from a dozen projects - forges a new concept of dealing with perceptions of landscape.

To see and experience landscapes and to talk about them reveals their inherent diversity. This includes both natural and built heritage and their anthropogenic depictions and symbols. Therefore, this natural and mental diversity is crucial to ascertain what landscapes can be.

Images of the Alps can be a symbolic capital for different purposes. They are often used in product advertisements. Here the Alps convey positive feelings. The product is seen as natural (vs. artificial), good (vs. bad) and in line with a harmonious cultural landscape (vs. industrial landscape). Especially in Switzerland, the Alps are used in political debates. They are often portrayed as the real and authentic Switzerland, or used in political campaigns. Also, of course, the Alps are a major tourist attraction in Switzerland. In line with notions of early Alpinists, the mountains are perceived as a sublime area that is removed from the squalors of the modern lowlands. Therefore, the Alps stand for recreation, leisure and being removed from the problems of everyday life. The Alps are also used to market cities and towns. Much has been written about the perceptual shift of the Alps as terra incognita (seen from far below) to the Alps as a modern sports arena. Therefore, we just briefly refer to aspects that can be regarded as outcomes of this historic development:

- To a certain extent there is an increasing polarisation between the Alps and the lowland. Moreover, this polarisation is superimposed onto the rural-urban divide that is an undercurrent of Swiss history.

- The cultural landscapes of the Alps are a consequence of traditional agriculture. In line with the glorification of pristine mountain peaks by the Alpinists of the $19^{\text {th }}$ and early $20^{\text {th }}$ centuries, the way of life of the Alpine population of that time is regarded as natural and authentic, including local customs and agricultural practices. Therefore, outsiders tend to regard people living in the Alps as peasants.

- Therefore, modernity is not associated with Alpine lifestyles or Alpine landscapes. Thus, it makes sense that the Alps are seen as something different from urban contexts and as something that is - and has to remain - unspoiled.

- In a nutshell, the image of the Alps has a lot to do with a Heidi-image of a free, untroubled, healthy and happy life. Also, in an unspoiled environment, special and different experiences can be made.

The core of the concept - four poles and six dimensions ${ }^{1}$

- The physical pole refers to the view of natural science, technology and environmental observation. It is therefore the pole of nature.

- The symbolic pole emphasises cultural values, representations and aesthetics of landscapes. It is the pole of cultural studies.

- The subjective pole is the point of view of individuals, and refers to people's individual and subjective experiences and perceptions of landscapes. It is associated with phenomenology, psychological and behavioural studies.

- Finally, the inter-subjective pole emphasises the social construction of landscapes, and is the pole of the social sciences.

Each pole is a centre of attraction and focuses on a knowledge base. Being focused on or attracted to one pole is a consequence of different scientific approaches and produces specific knowledge. However, there is the danger of losing sight of other poles. We regard landscape perception as occurring between these poles. Landscapes are more than the individual dimensions. Nevertheless, it is both important to go deep into details of landscapes and landscape perception and to look at the big picture of landscapes as space for recreation, production, nature protection and as a biosphere (fig. 1).

In order to describe the diversity and to be able to grasp it, we distinguish between six landscape dimensions.

The focus of the corporeal and sensory dimension are the sensations connected to landscape experiences. Thereby, landscape is not only seen or regarded, rather all senses

1 Backhaus, N., Reichler, C. \& Stremlow, M. 2007: Alpenlandschaften: Von der Vorstellung zur Handlung - Thematische Synthese zum Forschungsschwerpunkt I «Prozesse der Wahrnehmung» des NFP 48. vdf, Zürich. 
are addressed. Different expectations of a (beautiful) landscape and questions regarding pleasure and enjoyment are at the heart of the aesthetic dimension. Feelings of belonging are often connected with landscapes and therefore landscapes are connected with identity (dimension of identification). The fourth dimension we call the political dimension, in which stakeholders and interest groups enter negotiation processes. The economic dimension does not only concern values that can be expressed monetarily, but also values connected to security. The ecological dimension, finally, addresses different ecological concepts and their normative impact.

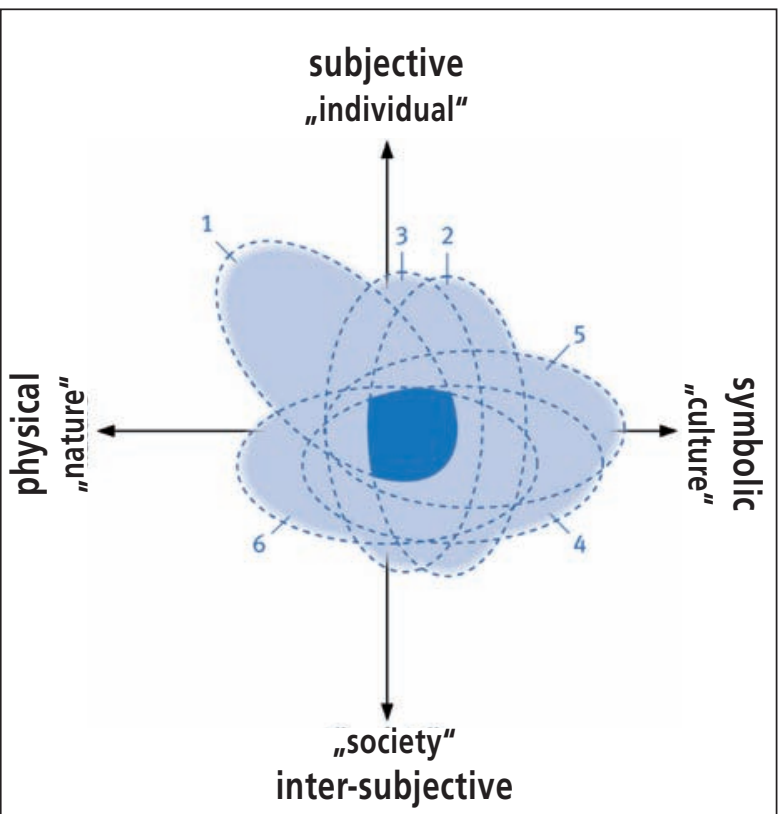

1. corporeal and sensory dimension

2. aesthetical dimension

3. identificatory dimension

4. political dimension

5. economic dimension

6. ecological dimension

Fig. 1: Landscapes connect people with nature

We can conclude that there are different ways to look at landscapes and that there is no landscape that everyone experiences the same way. Consequently, there is also no scientific, objectively valid landscape description.

The six dimensions show that landscapes are multi-layered and that people emphasise different aspects according to the context in which they regard or experience it.

But our model also shows that these dimensions or spheres overlap and merge with each other. The spheres can be regarded as frames or focal points through which researchers as well as laypeople regard landscapes. For the understanding of other people's landscape preferences and perceptions, it is important to at least acknowledge the existence of other ways of looking at them.

\section{Recommendations}

- Landscapes should be regarded as the combination of people and nature. Therefore, landscape is also an intermediary for people's spatial needs.

- Landscapes provide socio-spatial aspects of a changing world. Steering landscape development is a creative cultural task; it includes protection and education, and requires that we jettison traditional views of landscapes.

- Landscapes themselves cannot be lost (only their qualities and values).

- Landscape's potential not only includes ecological and economic aspects, but also emotional, aesthetic, social and ethical ones.

- Consequently, landscapes require a multidimensional view, considering also the fact that inside and outside views can differ (and change), that individual views are not always the same as socially accepted ones, and that the same person can look at a landscape differently.

- „Bargaining“ processes should be supported using knowledge about people's / groups' needs related to landscapes and acknowledging inside-outside and exper v. laypeople's views.

- Especially in large-scale participation processes, coordinators/moderators should be involved.

\section{Discussion}

- How do we translate the debate on multifunctionality into a viable planning instrument?

- The model could be adapted to other topics and be used as an evaluation tool.

- Participatory approaches can also imply threats due to limited resource; they are rarely practical, for if needs are expressed/created, they should be able to be met at least potentially.

\subsubsection{Economic valuation of alpine landscapes (NRP 48 synthesis 4) Workshop 1/2}

\section{Moderator:}

\section{Adrienne Grêt-Regamey (Landscape and Environmental Planning LEP, ETH Zürich, Switzerland)}

Alpine landscapes are often perceived as economically non-profitable regions. While $87 \%$ of the regional income of Alpine regions is produced by the market (Simmen et al., 2006), many goods and services provided by these 
regions are not marketed and thus do not command market values. The objective of the workshop was to discuss, (1) the economic potential of different strategies to make use of the public goods and services provided by Alpine landscapes; (2) the implementation of these strategies in different Alpine regions.

A comprehensive set of strategies to make use of landscape values was presented by Felix Walter (ECOPLAN, Berne, Switzerland). These include market strategies, valuation of public goods strategies, and mixed strategies (fig. 2). Their success is, however, dependent on regional implementation: as the economic potential of certain regions is large, selective "withdrawal" from other regions might be necessary. For decision-makers, this means that problems in areas with low economic potential should pro-actively be tackled, and that local landscape policy should take the function of resource policy.

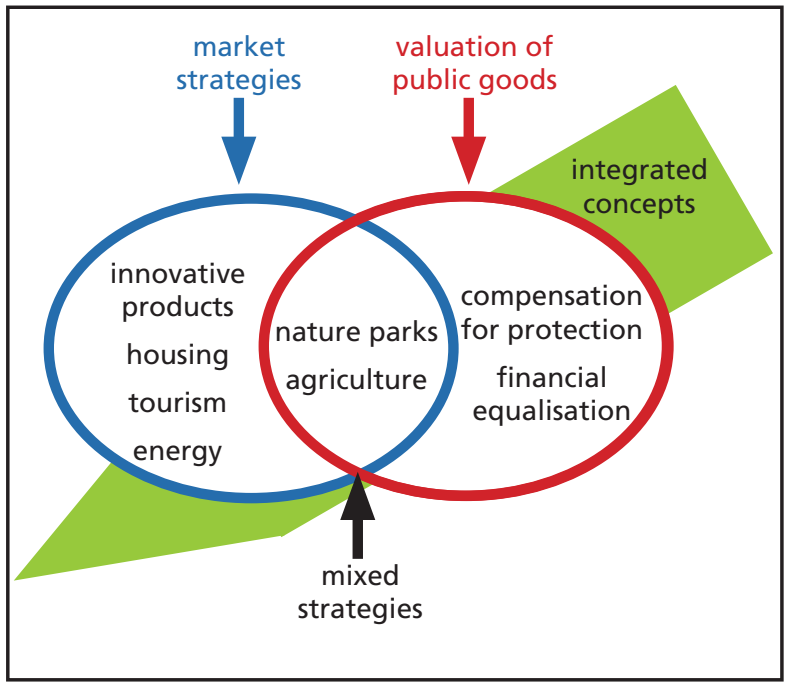

Fig. 2: Strategies to make use of landscape values (Simmen et al., 2007)

Payoffs and problems implementing a specific tourist strategy in a region in Switzerland were illustrated by Urs Wohler (head of Scuol Tourismus, Switzerland). The region offers spas, traditional events, objects of cultural heritage, and local products - the livelihood of 7'300 people. Yet, even though several innovative ideas have been implemented to exploit the values the landscape provides, other strategies have to be considered to remain competitive, especially considering rapid shifts in demand.

As the price of public goods only increases when they become scarce, users can consume more of the landscape values than their fair share. Such free-rider problems can threaten the income of Alpine regions in the long-term. Viewed in this light, valuation studies are essential to demonstrate the value of public goods and services to decision-makers. Several economic valuation studies have been conducted in the last years in the Alps. But the fact that these regionally studies are not released to the large public and that the resulting values are small compared to the regional income hinder their integration into strategic discussions. Yet, if economic estimates are assumed to be a valuable part of the information base for environmental decision-making, then a database summarizing the findings of these Alpine studies would help organize and express certain kinds of information on the range of alternative courses of action, and provide credible information to decision-makers.

\section{Reference}

Simmen, H., Walter, F., Marti, M., 2006: Den Wert der Alpenlandschaften nutzen - Thematische Synthese zum Forschungsschwerpunkt IV "Raumnutzung und Wertschöpfung", VDF Hochschulverlag AG, ETH Zürich, p. 212.

\subsubsection{Landscape and identity Workshop 1/3}

\section{Moderator:}

\section{Anne Sgard (Institut de Géographie Alpine, Grenoble, France)}

The purpose of this workshop was to explore the relationship between Landscape and Identity, or, more precisely, between landscape and identification processes.

The workshop proposed three steps:

- first a general framework, presenting the two key words: Landscape and Identity (by A. Sgard);

- followed by a presentation of the theme of sacred mountains with a series of landscapes from all over the world (by E. Bernbaum, The Mountain Institute, Berkeley, USA);

- finally a few examples introducing some of the main questions concerning the relationship between landscape, identification processes and mountain, and suggesting points of discussion.

The general presentation pointed out some elements of characterization of the landscape as a social and cultural construction, and focused on the fact that each person looking at a landscape has his or her own interpretative framework. Landscape is then the perceptible, emotional, aesthetical dimension of our relationship with a territory. From this point of view, landscape is a social and historic construction, and our perception of landscape depends on our cultural background. Each social group selects and codifies certain landscapes and attaches certain values to these landscapes: economical, aesthetic, symbolical, etc. How can we say that a landscape participates in the construction of identity, of feeling that one belongs to a territory? Many studies have shown that landscape can be 
used as „material“ and a medium for appropriation and attachment processes by populations, both at a national and local scale. Landscape is a kind of "cement" binding local communities, as well as a means of projecting a positive image of this society towards the outside world.

Three examples provoked discussion:

- The case of Mont Aiguille: an emblematic landscape showing a very unique and legendary mountain, which has been very well known since the $15^{\text {th }}$ century. It can be found on many brochures, packaging, postcards, etc. It certainly functions as an emblem and a source of attachment for the people of the nearest area (Trièves), for whom the peak is a feature of everyday environment. However, this is not true for all the inhabitants of the Vercors massif. Mont Aiguille is more a showcase, an "advertising landscape" for the Vercors, the Dauphiné, and even the North of the Alps. This example shows that identity-building capacity depends on scale.

- The case of Valchevrières (Vercors): this small village was destroyed by German troops in 1944 as a reprisal; since then, it has become a "memorial" to the Resistance: the ruins continue to exist, the meadow is mowed, the woodland and scrub are cleared, etc. Various notice boards all around the site tell of its history. Here the landscape is part of the testimony; its sacredness may induce meditation. But surveys show that the location is more connected to the memory of World War II and national identity. The local population does not express a real attachment; they might prefer to forget. This example allows us to focus on relationships between identity and memory.

- Is a golf club a modern landscape? This landscape is extremely well appreciated by the local population because it was created on an abandoned area. Now the forest is cleaned, the grass is green and perfectly cut, some statuesque trees have been preserved in the golf course. This is an example of a totally artificial mountain landscape, an example demonstrating that identification and attachment not only refer to heritage and tradition but also to recent practices and sceneries.

The workshop also addressed issues of forest landscapes and peri-urban landscapes in mountains.

All these examples try to converge on the main idea, i.e. the fact that the construction of collective identity is a permanent process; that expressions of identity change as populations and territories change; that identification is based on memory or lack thereof, and on transformation and adjustment. It is generally more relevant to study processes and "materials" used by the population to build and express different forms of identity, rather than to try and fix a "local identity" as a well-defined object.

\subsubsection{Toponymy and Geoheritage in the Alps - cultural approaches in geoheritage research Workshop 1/4}

\author{
Moderators: \\ Isolde Hausner (Austrian Academy of Sciences,
Vienna, Austria)
}

\section{Emmanuel Reynard (Institut de Géographie IGUL, Université de Lausanne, Switzerland)}

Geological and geomorphological processes and dynamics drastically influence alpine landscapes, and shape the main valleys in the Alps. Geoconservation and geoheritage research, however, is poorly developed in this region. Landscape studies are mostly concerned with aesthetic and biological aspects(landscape as habitat) and do not really examine the geological and geomorphological characters of alpine landscapes.

This workshop aimed at considering the topography of alpine landscapes from two perspectives, focusing on the importance of geology and geomorphology (geoheritage) for a complete analysis of the alpine landscapes, and on the contribution of cultural studies and linguistics (toponymy) to the analysis of alpine topography and geomorphology.

The introductory paper by Emmanuel Reynard (University of Lausanne) provided an overview of geoheritage research (assessment, mapping, geoconservation, geoparks, geotourism) currently being developed in Alpine countries. Isolde Hausner (Austrian Academy of Sciences) illustrated how cultural studies can contribute to geoheritage research by providing information on the relationship between a given society and its natural environment. The discussion following these papers had a wider scope.

\section{Geoheritage conservation in the Alps}

Several biotical alpine elements in the Alps (i.e., ibex or ede/weiss) have been protected for several decades. Although the geological structure (i.e., folds) and geomorphological features (i.e., glaciers, alluvial valleys or karstic areas) form the skeleton of alpine landscapes, their geoheritage is poorly known and protected in the various alpine countries. Especially in the ski areas at high altitudes, several landforms and „mineral landscapes” have been damaged, and even destroyed, by ski tracks and artificial snow-making infrastructures. One explanation of the weak protection of the abiotical heritage is the poor knowledge of Earth sciences among stakeholders and the general public. Another reason is an inaccurate perception of the value of geoheritage: the common view is that geology and landforms are quite stable and solid; the dynamic nature of geological and geomorphological features is not well perceived. Therefore, geoheritage 
fragility is poorly taken into account during environmental impact assessment procedures.

Geoheritage of interest not only to geoscientists. Some sites integrate other interests in the ecological, cultural, and even economic domains. In heritage actions and studies, the abiotical heritage should therefore be integrated with ecological and cultural aspects of landscape in order to obtain a global view. One way of creating links between geosciences and cultural studies is the study of toponymy.

\section{Mountain and alpine pasture toponyms in East Tyrol}

The second paper presented the main results of the project ALPKULTUR - cultural-historical documentation of toponyms in the alpine space: Mountain and alpine pasture toponyms in East Tyrol. The project focused on toponyms and their cultural-historical value. In the workshop affiliations to geoheritage were pointed out. The following highlights relating to examples from the corpus were discussed.

References to geomorphological and topographical features mainly occur in the names of mountains: One motive of naming is a reference to the rock or its composition, as for instance Kristallkopf, Kristallspitzl or Kristallwand. These names are very rare and every single case requires verification that the name is actually geologically motivated (rather than being a metaphor for ice or similar phenomena). A more common form of naming is the reference to salt in names like Salzkopf, Salzkogel, Salz- klamm. The mineral was important for livestock farming. Names like Schlatenkees (the name derives from slavic *slatina "sour water, carbonized water", and is applied to a location above the so called Salzboden) show that people have been aware of the value of these places for a very long time. A reference to ore is contained in the name Rudnik, derived from slavic * rudbnik b which means „ore mountain”.

A frequent naming motive that hints at special kinds of stone is colour (fig 3). Red, for example, in Osttirol is commonly used for rocks whose colour is derived from inclusions of iron discharged by weathering and oxidisation. As the name Cimaross, derived from Romanic * cima rossa "red peak", shows, this naming motive also is very old. The names Blauspitze, Blaues Hüatle and Blaue Knöpfe, however, are situated in a zone of green schist, where the typical blue screes below the summits motivate the name.

Rural metaphors are commonly used to describe mountain shapes. In certain cases they also depend on the stone. The dialect word Schober, for example, designates a cone-shaped haystack. Mountains bearing these metaphorical names (e.g. Hochschober, Kleinschober, Schoberköpfl) typically are situated in areas with primitive rocks rather than limestone.

Some names also refer to the weathering phenomena in the rock and its results (moraines, screes). The Falmoritalpe, for example, derives from Romanic vall "valley" + Protoromanic *marra "debris" + the Romanic diminutive suffix -ittu. The meaning of Falmorit would therefore be „valley strewn with small-sized debris" (i.e. screes).

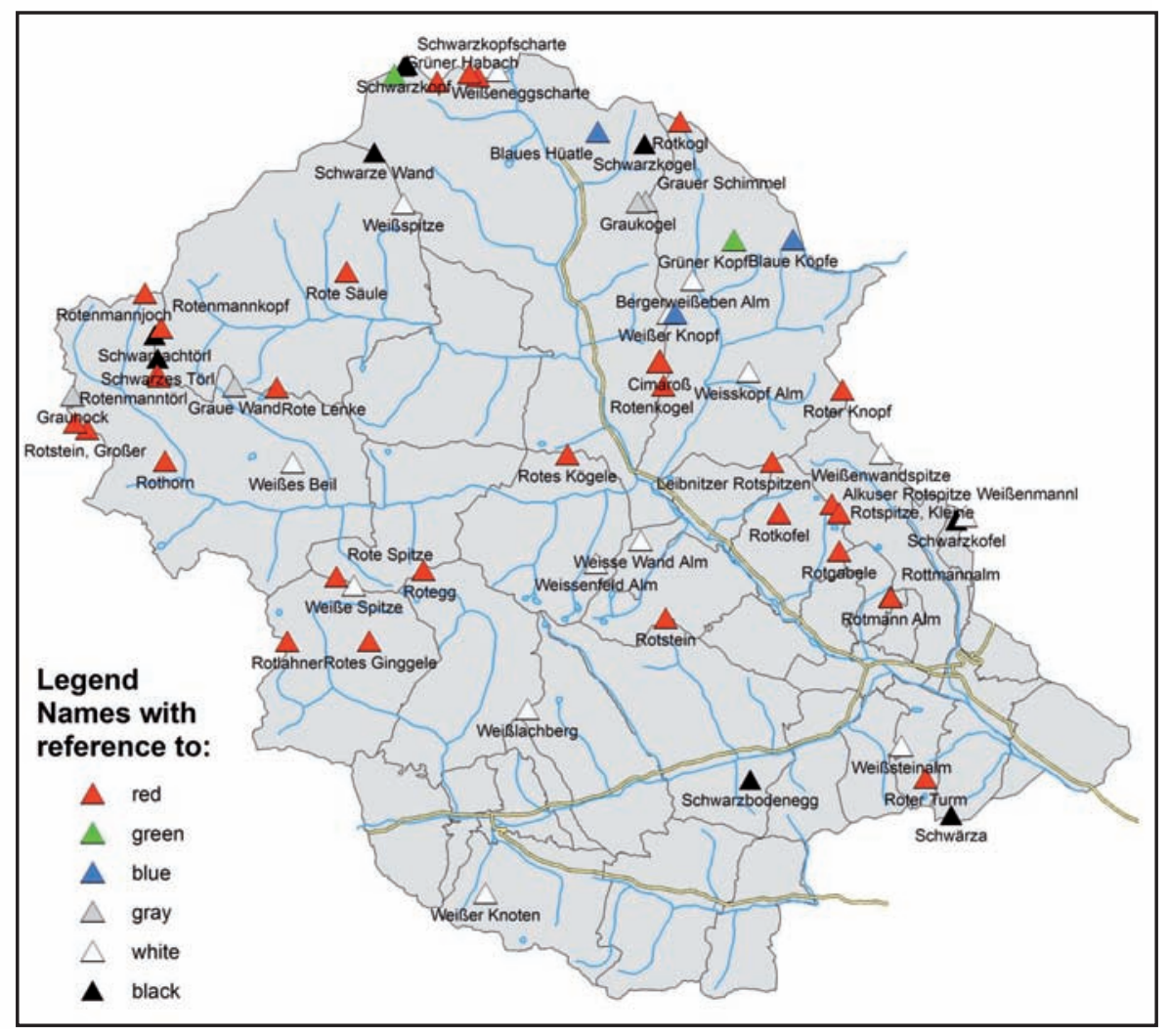

Fig. 3: East-Tyrolean names with reference to a certain colour 


\section{Conclusions and perspectives}

In evidence there is a close relationship between the geomorphological realities of a certain area and its toponyms. Interdisciplinary research, especially with geology, is the only way to obtain further results in this interesting field of onomastics. A further result of the workshop was that the onomastic research could be extended to the relatively new topic of soil conditions. This would affect toponyms referring to weathering phenomena etc., as well as to vegetation, and might provide a missing link between geomorphology and biology.

An ideal approach to elaborate this interdisciplinary method could be a joint project of these two disciplines in a certain area, for example a national park. 


\section{Plenary Session 2: Transformation processes}

\subsection{Summary}

\author{
Moderators: \\ Mojca Golobič (Urban Planning Institute of the \\ Republic of Slovenia, Ljubljana, Slovenia)
}

Jean-Jacques Brun (CEMAGREF, Grenoble, France)

The Alps are undergoing an acceleration of social, economic and climate processes which transform landscapes. Although change is a natural phenomenon of the landscape, the rate at which it occurs makes it difficult to monitor, evaluate and react appropriately. Plenary Session 2, "Transformation processes", focused on current and future changes in mountain landscapes. Its aim was to highlight the transforming driving forces and processes, and to identify the most notable changes in traditional alpine landscapes from the ecological, cultural and aesthetic aspects. The speakers were asked to address the following questions:

- What are the most important driving forces of land use and landscape change in mountain regions and in the Alps?

- In what way will current and future transformation processes change mountain landscapes? Do some of these changes need particular attention because they threaten people and the environment? What are potential threats and benefits to people and selected species?

- How far are policy measures (e.g. agricultural, transport or energy) adequate to guide or mitigate effects of these transformation processes on landscapes?

The presentations covered a wide range of aspects of landscape change and driving forces. While the first two presentations ( $U$. Tappeiner and F. Kienast) focussed on changes in natural environment and land cover caused by various natural, socio-economic and cultural drivers, the third (M. Bertrand) showed an approach balancing ecological and socioeconomic perspectives. The fourth presentation (D. Vancutsem) opened a different set of questions, appealing to our emotional relation to landscapes, and questioning our attitudes based on a design oriented approach of active and intentional landscape changes.

- Ulrike Tappeiner (Institute of Ecology, University of Innsbruck, Austria \& European Academy, Bolzano/Bozen, Italy):

Land-use change in the European Alps: effects of historical and future scenarios of landscape development on ecosystem services

In the European Alps, 41.4 per cent of all farms cea- sed operations and an average of about 20 per cent of the agricultural land was abandoned over the past twenty years. Based on remote sensing and historical maps, a detailed analysis of the landscape development over the past 150 years has been carried out in different agrarian structure regions in the Alps. Results show that the winners of this trend are built-up and forested areas, while the main losers are traditionally used areas (e.g. lightly used meadows in the subalpine and alpine belt). The magnitude of this trend differs greatly from one region to the next, as well as along altitudinal gradients. Furthermore, in a case study in the Austrian Alps landscape-scale changes of carbon pools and biodiversity - important ecosystem services - in relation to historical and current land use were analysed, as well as explorative scenarios of future land use. Due to replacement of up to 70 per cent of former alpine meadows by dwarf shrubs and forests, carbon pool has increased by $426 \mathrm{t} / \mathrm{km}^{2}$ and a further increase of 230 per cent can be expected in the next thirty years. With regard to development, species diversity and ecosystem diversity do not always correlate: between 1865 and 1970, phytodiversity decreased by 6.6 per cent, while ecosystem diversity increased by 12 per cent. Since 1970, both species and ecosystem diversity have decreased.

- Felix Kienast \& Janine Bolliger (Swiss Federal Research Institute WSL, Birmensdorf, Switzerland): Observed and simulated transformation of Alpine landscapes: driving forces and potential impact on landscape functions

As a result of free market forces, marginal regions (e.g. mountains) throughout Europe are at risk of experiencing increasing land abandonment and spontaneous reafforestation. In mountain areas in particular, the likely consequence of this marginalisation is an increasingly segregated land-use pattern. At higher elevations, various stages of spontaneous reafforestation are expected, replacing the formerly open-land habitats by closed forests, whereas at lower elevations, open land may be prone to increasing intensification. Based on historical evidence, we present analyses of past land-use change and show how they have affected plant and animal species. Furthermore, we show new results on how people perceive and remember changing land use. These findings as well as extensive literature reviews represent the knowledge base for various predictive models aiming at simulating various goods and services of landscapes (i.e. biodiversity, carbon storage, landscape attractiveness) 
under changing conditions. These goods and services are discussed in the context of landscape functions, a concept being pushed forward by several articles in the international literature.

- Nathalie Bertrand \& Sylvie Vanpeene (CEMAGREF Grenoble, France):

Landscape under urban pressure: agreement or divergence between socio-economical and ecological approaches

Changes in regional landscapes due to urban pressure raise questions regarding land use, economic, social and environmental issues related to urban sprawl, daily commute increases, and land consumption.

These changes and dysfunctions jeopardise sustainable development in such areas, especially in the Alps with their diverse biotopes in a geographically constrained space.

Sustainability calls for three pillars: economic, sociological, environmental. However, what does „landscape under urban pressure" mean? What kind of analysis can take into account the three pillars of sustainability? How can we go beyond disciplinary approaches and offer an integrated analysis?

This paper is based on two years of work undertaken by socio-economists and ecologists on the effects of peri-urbanisation on landscape and the environment in an alpine area. The first of them regards space and how space is taken into account in the environmental, economic or social processes, respectively. Three themes are developed: landscape point of view, problems of spatial and temporal scales, indicators.

The three pillars of sustainability require the definition of a common field with regard to temporal and space scales as well as indicator type. To go beyond requires a hierarchisation of these questions, taking a more ecological, economic and / or social approach, and dropping the notion of a common interface to address specific disciplinary questions.

\section{- Didier Vancutsem (ISOCARP \& Vancutsem Stadtplaner} Landchaftsarchitekten, München, Germany): Shaping our future urban landscapes - experiences from Bavaria

Radical changes in the urban landscape due to demographic change and various trends in settlement structure are a topical phenomenon in Germany. Forecasts predict a population decline in Eastern Germany and growth in Southern Germany, especially in Bavaria, with increasing urban pressure on the foothills of the Alps.

Current soil consumption in Bavaria is about 20 hectares per day. Our landscapes are laboratories of urban transformation and urban sprawl. Regions are facing various challenges: planners are yet to see evidence of shrinking.

Our landscapes are mirrors of our society. In view of trends of suburbanization, dispersion, sustainable re-urbanization, and return to core-cities, the region's role must be reconsidered: new strategies for urban regions are being developed. Regional landscape will shape regional identity.

What types of landscapes will there be in the future? Our generation has to decide.

\section{Conclusions and outlook}

Especially the first two contributions presented a significant step forward in landscape-change modelling techniques. Both included construction of cause-effect chains, explanation and evaluation of present change as well as modelling future landscape. Methods have acquired increasing scientific value and are based on better data, resulting in reliable forecasts. Both presentations also evaluated landscape change in terms of its consequence for landscape services (visual quality, biodiversity and Cpool capacity). Although we tend to think of landscape change as something prevailingly negative, the presentations showed some interesting results: expected landscape change does not necessarily mean loss of biodiversity but could be beneficial in terms of increasing C-pool capacity, while negative visual effects would become neutral in time due to human adaptive capacity.

This brings us to a challenging perspective of how to use these methods to answer the important questions of whether changes will bring us closer to desired landscape or not; and of course, what landscape services will be required in the future. It inevitably raises management issues, i.e. how (and if) processes of change could be managed. Mapping of the main trends shows that many of them correlate to administrative borders. This indicates that policies do affect certain change processes. But detailed analysis of pilot areas often reveals a much more complex picture of drivers and changes. In fact, ecological analysis is mainly spatially based (habitat mapping) but space is not considered as a major dimension of economic and social processes. We must therefore be aware of impacts of urban pressures on the integrity of remarkable ecosystems (recreational activities) and on the functionality of ecological corridors (ordinary nature consumption). New indicators depicting socio-economical and socioecological trends at a local scale have to be devised to illustrate these transformation processes and their limits.

While the first three contributions were science-oriented and structured, the last presentation discussed landscape change more from a design perspective, meaning that experts are the actors of change rather than passive observers and analysts. This slight antagonism was also reflected in the discussion, which raised the question of whether this view is suitable only for man-made / urban 
landscapes or could be appropriate for predominantly natural and agricultural landscapes. This dilemma is related to the key question of distinguishing between urban and rural landscapes and changing concepts: ways of life in Alpine cities and in marginal areas are no longer so different; physical processes are following in their wake. Land abandonment for example, which we usually attribute to remote areas, also occurs in urbanized areas, although land use intensification still prevails. Therefore, answers in the last presentation emerged not so much from traditional scientific methods as from choosing and interpreting examples that respond to challenges by a new, more complex understanding of landscape typology, which goes beyond an urban-rural distinction and traditional categorisation by land use (agricultural, energy production, industrial, natural landscapes). These answers also consider multifunctional landscapes whose production of goods and services is embedded in a dynamic view, i.e. communication landscapes, transit landscapes, recreational landscapes, contemplation landscapes, valuable intermediary places, changing landscapes, etc.

\subsection{Key input contributions to Plenary Session 2: extended summaries}

\subsubsection{Land-use change in the European Alps: effects of historical and future scenarios of landscape development on ecosystem services}

Ulrike Tappeiner (Institute of Ecology, University of Innsbruck, Austria \& European Academy of Bolzano/Bozen, Italy)

\section{Keywords}

Landscape-scale changes, biodiversity, agrarian structure region

In the European Alps 41.4 per cent of farms ceased operations within the last 20 years (1980-2000). In addition, almost 70 per cent of farms still in operation today are run only as a secondary source of income (Tappeiner \& Bayfield 2003). With regard to the land use issue, this means that an average of about 20 per cent of the agricuItural land of the Alps has been abandoned, and in some areas as much as 70 per cent (Tappeiner et al. 2003). These developments vary greatly in the different regions of the Alps. Due to climatic, demographic and socio-cultural differences, the Alps are not a single, cohesive unit in a natural, social and/or economic sense. There are certain essential contrasts between the traditional Germanic and Romanic Alpine agricultural methods of the northern Alps (grassland farming with cattle husbandry) and Southern Alps (mixed grassland-arable-farming, permanent crops and sheep husbandry). In addition, the agricultural sector in the Alpine Countries is also affected by the differences between federal and more centralized forms of government, the varying instruments of subsidy for mountainous areas, and the issue of EU membership to the Common Agricultural Policy (CAP).

Change of agricultural land use in the Alps in the past 150 years

Based on a set of 76 indicators, Tappeiner et al. 2003 showed that eight characteristic agrarian structure regions have developed in the Alps. Each region represents a specific type of agricultural settings in terms of socio economic factors, in terms of population trends and in terms of physical characteristics such as climate and altitude. In past decades these differences still led to varying developments in agriculture (fig. 4). In four of these agrarian structure regions we analysed in detail the landscape development in the last 150 years based on orthophotos (1980-2002), aerial images (1950-80), and historical maps (1869-87) (fig. 5). 


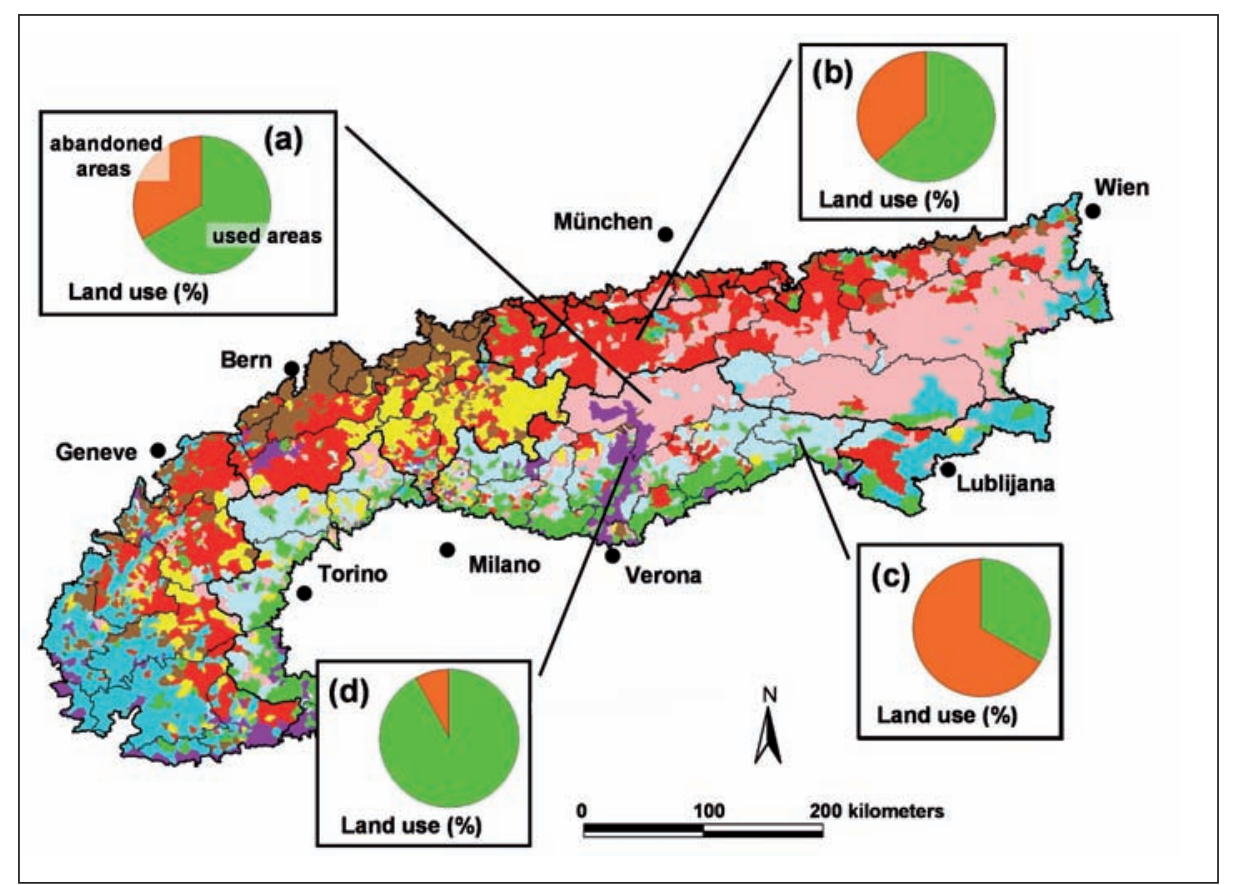

Fig. 4: Classification of the Alps by eight agrarian structure regions as well as land abandonment from 1865 (100 per cent) to 2000 in the South Tyrolean grassland region "Südtiroler Berggebiet" (a), the ,alpine standard region' "Innsbruck Land" (b), the agricuItural retraction region "Carnia" (c), and in the South Tyrolean wine and fruit cultivation region "Unterland / Überetsch" (d) (after Tappeiner et al. 2003).

The general trend in landscape development moves toward the decrease of agriculturally used areas. Winners of this trend are the settlement areas on the one hand and the forest on the other hand, while the main losers constitute the traditionally used area of cultivation (larch meadows and the lightly used meadows in the subalpine and alpine belt). The magnitude of this trend differs greatly between regions (fig. 4) as well as along an altitudinal gradient (Becker et al 2007). With the exception of the agricultural retraction region Carnia, no area was abandoned in the agricultural used valley bottom, the agrarian most favourable region. The more difficult the conditions for agricultural use of the locations are, the more obvious the tendency of farmers to abandon their land. In steeper mountainsides of the valleys, agricultural areas were increasingly taken out of cultivation. The main areas abandoned were on the mountain pastures (-39 per cent to -80 per cent).

Effects of likely future scenarios of landscape development on the phytomass- and C-pools and biodiversity in the Stubai Valley

In one of the investigated regions, the alpine standard region (Innsbruck Land), we developed and tested a landscape model in order to analyse landscape-scale changes of carbon pools and biodiversity in relation to historical and current land use, as well as explorative scenarios of future land use. This was achieved by integrating socioeconomic drivers and spatially explicit information, scaling up C-pools and diversity from the ecosystem to the landscape scale (fig. 5).

Results: Over the past 150 years, a massive reduction of agricultural land use has taken place, particularly in areas considered unfavourable, where traditional agriculture has been reduced to about 30 per cent. Dwarf shrubs and forests have replaced up to 70 per cent of the former alpine meadows and pastures. Even the favourable areas have undergone significant changes. Where 50 years ago arable land spread across the hill slopes, we now find highly used grassland or settlements instead. These landuse changes have a massive effect on the above-ground and below-ground phytomass-pools and the C-pool: from 1865 to 2003 the total phytomass increased by 21.7 per cent, equivalent to $253^{\prime} 886 \mathrm{t}$ in the whole valley $\left(249 \mathrm{~km}^{2}\right)$ (fig. 5). The growth of phytomass combines a proportional increase of C-pool. Depending on the phytosociological communities, the C-storage lies between 42 per cent and 47 per cent of the total phytomass. For the period from 1865 to 2003, this means an increase of total C-pool of 22.9 per cent (106'171 t). However, our studies showed highly differential developments along the elevational gradient. While in the valley bottoms only small changes in the pools can be seen, the subalpine belt (1700-1900 $\mathrm{m}$ a.s.I.) experienced massive increases due to natural reforestation.

In all future scenarios the aforementioned trend is assumed to continue. The transition matrices imply the development of the past 15 years and forecast a continuous reduction of land use, particularly in the subalpine belt. The stakeholders expect the settlements to grow considerably over the next 30 years, but do not expect any major changes in land use. According to the developed agroeconomic model, even more dramatic changes can be expected. As a simulation result we obtained that the most unfavourable areas will be abandoned if milk support is reduced by the EU. Assuming the subsidies will be further cut down, even favourable areas in the valley bottom will be abandoned. This will induce a dramatic reforestation. 
Hence, a further increase in the $C$ pool of 18.7 per cent (95'663 t C) over the next 50 years can be expected.

As another important ecosystem service we calculated the changes in biodiversity at landscape level. It is well known that shifts in vegetation, related to changing management strategies, are often accompanied by changes in biodiversity (e.g. Tasser and Tappeiner 2002, Tasser et al. in press). Studies of changes in the diversity of ecosystems have rarely been performed. Our analyses of the Stubai Valley

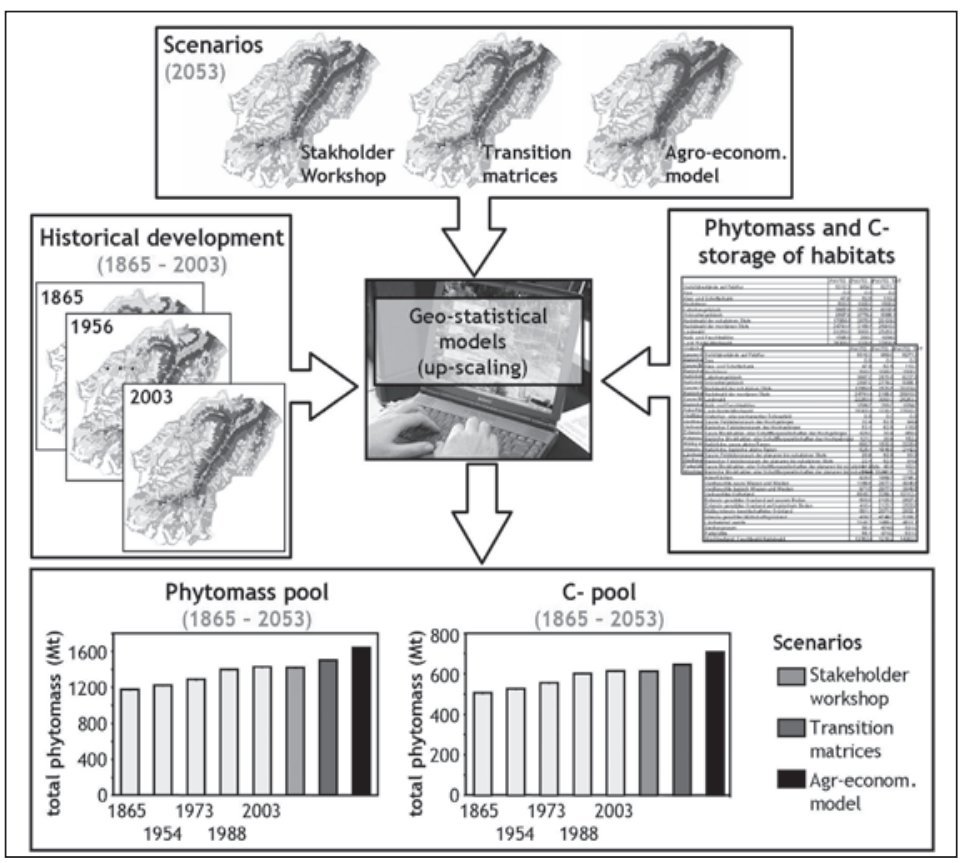

show, that species diversity and ecosystem diversity do not always have to correlate regarding their development. Between 1865 and 1970 the phytodiversity (mean species number of vascular plants) decreased by 6.6 per cent, while the ecosystem diversity (patch richness) increased by 12 per cent. From this point on the species as well as the ecosystem diversity decreased. Future scenarios point out a further slight decrease in both species and ecosystem diversity (Tappeiner et al. 2007).
Fig. 5: Research approach to analyse landscape-scale changes of carbon pools in relation to historical and current land use, as well as explorative scenarios of future land use on the example of the Stubai Valley in Austria (region Innsbruck Land). The approach combines: (i) historical and current land cover, (ii) scenarios of land use as inferred from stakeholder consultations, from a spatially explicit land-use change model (transition matrices), from an agro-economic model, and (iii) an estimation of above- and belowground C-stocks in the phytomass via a geo-statistical model (from Tappeiner and Tasser 2004).

\section{References:}

Becker, A., Körner Ch., Björnsen Gurung A., Brun J, Guisan A., Haeberli W., Tappeiner U. and GLOCHAMORE participants 2007: Altitudinal Gradient Studies and Highland-lowland Linkages in Mountain Biosphere Reserves. Mountain Research and Development, forthcoming

Tappeiner U. and Bayfield N. 2002: Management of mountainous areas. In Land Cover and Land Use - Land Use Management, edited by W. Verheye, in Encyclopedia of Life Support Systems (EOLSS). Developed under the Auspices of the UNESCO, Eolss Publishers, Oxford, UK, [http://www.eolss.net].

Tappeiner U., Tappeiner G., Hilbert A. and Mattanovich E. 2003: The EU Agricultural Policy and the Environment. Evaluation of the Alpine Region. Blackwell Science, Berlin, Germany.

Tappeiner U, Tasser E, Leitinger G, Tappeiner G 2007: Landnutzung in den Alpen: historische Entwicklung und zukünftige Szenarien. In: Psenner R, Lackner R (eds) Die Alpen im Jahr 2020. Alpine Space - Man \& Environment Vol.1, pp.23-39. Innsbruck, University Press.

Tasser, E. and Tappeiner, U. 2002: Impact of land use changes on mountain vegetation. Applied Vegetation Science 5, 173-184.

Tasser E., Tappeiner U., Cernusca A. (in press):Ecological effects of land-use changes in the European Alps. In: Huber, U. / Becker, A. / Bugmann, H. (ed.): Global Change and Mountain Regions - A State of Knowledge Overview. Springer. 


\subsubsection{Observed and simulated transformation of Alpine landscapes: driving forces and potential impact on landscape functions}

\section{Felix Kienast \& Janine Bolliger (Swiss Federal Research Institute WSL Birmensdorf, Switzerland)}

\section{Keywords}

Transformation, modeling, landscape functions, land use, perception

Long-term economic changes as well as shifts in agricultural policies and management have been leading to largescale land-use changes throughout Europe. As a result marginal regions (e.g. mountains) are at risk to experience increasing land abandonment and spontaneous reafforestation. This trend could be accelerated by ongoing global warming. In mountain areas in particular, the likely consequence of this marginalization is an increasingly segregated land-use pattern. At higher elevations various stages of spontaneous reafforestation are expected, replacing formerly open-land habitats by closed forests, whereas at lower elevations open land may be prone to increasing intensification. Marginalisation and on-going intensification might cause loss of cultural and social identity and will certainly have decisive impacts on fauna and flora.

The paper elaborated on the above mentioned transformation processes at three organizational levels, i.e. regional (Surselva), national (Switzerland) and continental (Europe). Based on historical evidence we presented analyses of past land-use change and showed how plant and animal species react(ed) to these changes. Furthermore we showed new results on how people perceive and remember changing land use. The findings as well as extensive literature reviews represent the knowledge base for various predictive models aiming at simulating various goods and services of landscapes (i.e. biodiversity, carbon storage, landscape attractiveness).

These goods and services were discussed in the context of landscape functions, a concept pushed forward by several articles in the international literature. Landscape functions measure to what degree landscapes fulfill societal and ecological needs. Recently it has been suggested to embed the landscape function approach in the ecosystem millennium assessment (www.maweb.org). According to this framework policy both the social/cultural and the natural/cultivated capital of a society are affected, and they both have decisive impacts on people's well-being. Within this framework, landscape functions act as a link between land use (change) and an ecosystem's goods and services, which are assumed to be direct drivers of human well-being

Finally, the presentation concentrated on the potential impacts of future land-use change on three landscape functions, i.e. (a) the potential of a landscape to host species; (b) the potential to store carbon (soil, above- and below ground); and (c) the potential to be attractive for the population.

Land-use predictions are derived from three scenarios based on synergetically assessed drivers originating in different disciplines (socio-economy, ecology). The three scenarios are: (1) a business-as-usual scenario that relies on trends of land-use change observed during the last 20 years; (2) a biodiversity support scenario that assumes optimal management strategies and subsidies for biodiversity and conservation; and (3) a liberalisation scenario where agriculture and conservation receive no public support.

\subsubsection{Landscape under urban pressure: agreement or divergence between socio-economical and ecological approaches}

\section{Nathalie Bertrand \& Sylvie Vanpeene (CEMAGREF,} Grenoble, France)

\section{Keywords}

Urban pressure, sustainable development, ecosystem and spatial sustainable development, land use function, multidisciplinarity

Changes in regional landscapes due to urban pressure raise questions regarding land use as well as economic, social and environmental issues related to urban sprawl, increasing daily commutes, and land consumption. On the one hand, land use becomes more complex as competition between agriculture, urbanization, natural areas and forests intensifies, and relates to space multifunctionality. On the other hand, functional and structural urban integration of peripheral rural areas implies negative externalities such as social segregation, or degradation of natura environments subjected to human pressure (as tourist or residential frequentations).

These changes and dysfunctions question the sustainability of development in such areas. This point is all the more critical in the Alps since it is a geographically constrained space that is rich in unique biotopes and subject to highly disparate human pressure, for example the French Alpine Sillon with intense conurbation, or the Carpatians' very low population density. Sustainability calls for three pillars: economical, sociological, environmental. However, what does a "landscape under urban pressure" mean? How to develop an analysis that takes into account the three pillars of sustainability? How to go beyond disciplinary approaches and offer an area of integrated analysis? 
This paper is based on two years of work undertaken by socio-economists and ecologists on the effects of peri-urbanisation on landscape and the environment in an alpine area. By crossing two disciplines - ecology and (socio-)economy - it highlights dimensions that the analysis covers with such processes. The first of them regards space and how space is taken into account respectively in the environmental, economic or social processes. Ecological analysis is mainly spatially based. But space has been a problem for a long time in economic analysis, where space has not traditionally been considered a dimension of economic (and social) processes. Thus, it is around the confrontation of these differences that it seems interesting here to underline some dimensions of major processes that are current concerns in the alpine arc and landscape changes, by confronting the differences of the disciplinary approaches. This paper has this aim, and includes three steps.

The first step focuses on disciplinary questions. To socioeconomists, questions about "landscape" and its change predominantly concern natural areas and land used by human beings, including settlement areas. Questions related to urban pressure focus on spatial segregation, processes of population and activity polarisation. In this sense, landscape is closely related to the concept of regional development. To ecologists, the environmental dimension covers two types of concerns. One is related to unique ecosystems while the other is related to "ordinary" nature and its organization patterns. Remarkable ecosystems are frequently included in protected zones or management plans. This means that they may escape from urban pressure even if they are affected by recreational activities. On the other hand, urban pressure takes its full significance in the evolution of space organization of "ordinary nature". This can influence ecosystems or remarkable species when urbanization destroys or damages corridors that used to ensure the functionality of a whole landscape by connecting ordinary and remarkable "milieux".

Regarding landscapes, the two disciplines also ask different questions. But they do converge on land use and changes in land use, even if specific concerns about management or economic development belong to each discipline. Thus, a study carried out in the French Alps highlighted a common socio-economic and environmental analysis by identifying indicators of land use: landscape fragmentation, evolution of linear corridors for the environment; demographic trends and increase in building permits for the economy. Other research in the European context found the concept of land use functions (Sensor IP, 2006).

The second part of the presentation dealt with scales of analysis (temporal or spatial). Economics (or sociology) call upon various scales, answering mainly to administrative perimeters (area Nuts 2, Nuts 3, common Nuts 5 in the French case...). It concerns statistical data available (or not) at a pan-European dimension; more local analysis makes it possible to highlight evolutions at finer scales and calls for qualitative information collection revealing the importance of institutional dimensions. Environmental data can be overlayedwith these zonings, such as land use cartographies (Corine Landcover), inventories of protection zonings, or cartography of the NATURA2000 network. However, this level of data is very global and not suitable to areas of very complex landscape mosaic, as in the case of mountain areas. For many ecological questions, it is necessary to go down to a finer level of information by habitat mapping. These data are not generalized. To combine the two disciplines requires working in a common area of analysis that could be supplemented by finer approaches carried out by each discipline.

The temporal scale of the two disciplines can be relatively similar and requires less disciplinary adaptation than the spatial scale. Indeed, over the 50 past years and in 10-year sample steps, the two disciplines can combine their data, for example of successive censuses (e.g., population and agriculture) and land cover photos interpreted from aerial photography.

Lastly, the question of indicators was addressed. The nature and sensitivity of indicators able to reflect a process is questioned in the same manner for the two disciplines. It is the same for indicator availability at a European scale. As an example, analysis of the impact of a peri-urban land use pressure in a Regional Natural Park (Parc Naturel Regional, PNR) was given. The analysis of its sustainability did not lead to the creation of a mixed indicator but rather to some joint indicators. For example:

- analysis of municipal population growth rate related to travel time to the city (this analysis being able to be refined by social and economic category and age of new residents);

- percentage of change between two dates in land use, which can be related to population growth rate.

At plot level, data overlay between land zoning (urbanised classified surfaces) and aerial photo interpretation of land use makes it possible to quantify and locate areas actually consumed by residential use, and available land reserves. This also makes it possible to identify the type of land use on which urbanization actually occurred. To identify the rate and localization of land reserves that are still available can help mediation between municipalities and PNRs, and help build a vision of future land use if all currently planned buildings were actually constructed.

The three pillars of sustainability require defining a common field on the level of temporal and space scales 
and on the type of indicators. To go beyond requires addressing the questions on a hierarchical basis, and asking more ecological or more economic and/or social questions, dropping the notion of a common interface in favour of specific disciplinary questions.

\subsubsection{Shaping our future urban landscapes - experiences from Bavaria}

\section{Didier Vancutsem (ISOCARP \& Vancutsem Stadtplaner} Landchaftsarchitekten, München, Germany)

In July 2005, the community of Fraunberg, in the Munich region, made headlines: in a village that wants to keep its identity, the council abolished traditional activity zones in the land use development plan.

"So kann das nicht weiter gehen" („This cannot go on“), Mayor Wiesmaier declared two years ago, as his municipality of 3'400 inhabitants was again faced with the problem of peripheral urban extension. The council was sure of its strategy as it decided to abolish all activity zones in the periphery. In their place, an exchange platform of buildings and plots was established. It became possible for enterprises to use disused farmland; in comparison with industrial zones, investment costs were reduced. The urban structure of the community was preserved, and most workplaces are still in the village centre.

\section{Sustainable Landscape}

Despite our cities' urban transformations, problematic economic growth and strict intervention of nature protection services, soil consumption is still very high. Today, the Bavarian State has a daily consumption of 20 hectares.

The federal government goal to reduce current soil consumption of 93 hectares to 30 hectares is utopian. Unless current instruments are implemented forcefully, and new ones are introduced, this goal will not be reached even if economic growth should be slow.

The most recent demographic indicators for Germany - taking births, life expectancy and immigration into account - show a shrinking population. The German population will drop from 82 million (in 2000) to 68 million (in 2050). More important than this reduction, however, is the population's average age. The number of people over 60 will increase from 17.5 million (in 2000) to 28 million (in 2050). This deficit could be compensated by a net immigration of 3.4 million, which, however, is not a realistic assumption.

Our consumption of resources should allow sustainable development. But land consumption is currently too high.
Conclusion: high land consumption cannot be tolerated. Solutions must be found, in urban transformation and planning methods.

Our landscapes: laboratories of urban transformation and urban sprawl.

Our cities and regions are facing various paradoxical challenges:

- low income, higher social costs;

- unused infrastructures, high maintenance costs;

- more economic competition, social cohesion at risk;

- disappearance of the European city, erosion of our society.

How could our cities and regions react creatively to these developments?

Today, 75 per cent of the European population lives in urbanised areas. In 2020, more than 80 per cent of the population will be urban and the phenomenon of urban sprawl will be omnipresent all over Europe.

In the past, some cities opted for compact growth - the city of Munich is one example. The Munich development strategy applied since 2000 has produced some impressive results.

\section{Urban landscape typology}

Our landscapes mirror our society - what types of landscapes will we have in the near future?

Our cultural landscape is undergoing a rapid and complex transformation process. It is subject to increasingly intense, global pressure; yet it is still considered as a commodity. Locations' loss of identity is common, points of identification are fast disappearing.

Will our future landscapes be used for energy production, monoculture, multi-functionality, transformation, or for history and nature conservation? Our generation has to decide. 


\subsection{Workshops Plenary Session 2: summaries}

\subsubsection{Urbanisation: changes of the built environment \\ Workshop 2/1}

\section{Moderator:}

Manfred Perlik (Gebirgsforschung: Mensch und Umwelt - Forschungsstelle der Österreichischen Akademie, Innsbruck, Austria \& ETH Zürich, Switzerland)

This conference was intended to show impacts of the current urbanisation process on alpine landscapes, and to discuss these changes in terms of land use, conformation of the built environment, and regional development. It is an especially significant topic for the following two reasons:

- cities and agglomerations are increasing, both within and outside the alpine region. Hence, the number of rural areas used by urban populations for leisure and recreational purposes is also increasing. These areas are slowly being transformed into urbanised landscapes, although this often only shows on closer inspection.

- in spatial development circles, a debate on land use for housing and transport is raging under the label of land consumption. New architectural and design disciplines have entered the fray - disciplines that primarily consider the aesthetics of landscape and anthropogenic impacts. ${ }^{1}$ They have a visual perception of landscape change and use images to try and exert some influence.

It has therefore been the intention of this Workshop to contrast aspects of the material basis and socio-cultural construction of landscapes, their interrelations and underlying driving forces. Discussion was based on three input presentations of case studies on alpine landscapes, focusing on

- economic interest of external and local actors, in particular investors;

- new socio-cultural housing, leisure and life-style needs;

- marketing, design and architecture as spatially relevant actors.

Marie Wozniak (French ministry of environment, Paris / Grenoble, France), discussed new demands on the built environment in her input contribution.

From 1946 to 1977 , skiing resorts of the stations in-

1 Schuler, M.,Dessemontet, P. et al. 2006: Atlas des räumlichen Wandels der Schweiz. Bern. S. 8 tégrées type were constructed according to French regional policy goals for the economic development of the snow-rich northern Alps; opportunities for extra-regional investors; and urbanistic planning principles of a French hue. The resorts were much criticised, especially their central planning, lack of consideration of regional interests, and monostructural character. In response to a shift in demand, a slow transformation into "villages" has been taking place since the 1980s, geared to destination management for the international market. International tourism companies, such as Intrawest (Motto: "The World's Greatest Playgrounds"), have been involved in marketing these resorts, which is why alpine traditions using selected features of local culture are being re-invented. Messages focus on tradition, authenticité, convivialité.

In terms of the built environment, this meant that some chalets were relocated and/or designed an international pseudo-rural style that may meet consumer needs but has nothing to do with what a Savoyard chalet would traditionally have been like. This re-invented "alpine tradition" is uniform, supplanting authentic local heritage. The result is paradoxical: alpine resorts are increasingly changing their aspect to resemble a clearly defined village; but the "village's" local roots have been severed completely. Tourists may arrive in search of local heritage, but their expectations refer to an imaginary world. The terms Alpine resorts (for economically successful tourist destinations) and Alpine wasteland (for unused and reusable landscapes and landscapes to be built up) have been thrown into the architectural debate. ${ }^{2}$

In Marie Wozniak's opinion, this raises not only the question of whether a separate development of these two regional types is desirable since tourists definitely desire some kind of "Alpinity", however that may be defined, but also of whether it is desirable to ignore the local knowledge of underprivileged areas, and how links could be established between resorts and their "wasteland"/ hinterland.

Tiziana Quaglia (Regione Veneto, Venezia, Italy) and Viviana Ferrario (Università luav di Venezia, Italy) presented experiences from the AlpCity INTERREG IIIB project concerning renovating and reusing traditional rural and productive alpine buildings, focusing on historic architecture in small towns and villages. The Veneto regional government explored the re-use of farmyard buildings, so-called "tabià", in Belluno province. Thousands of these buildings exist, both in village centres and in scattered settlement areas. They are a strong landscape feature and a cultural heritage element that the regional government wants to preserve. In village centres re-use is usually quite easy, but scattered settlement areas are more problematic, espe-

2 Diener, R. et al. 2005: Die Schweiz - ein städtebauliches Portrait. Basel. 
cially if agricultural use is abandoned. Often it is only the buildings that change hands while the actual land remains the property of the erstwhile owners who, however, stop looking after it. Buildings are re-purposed for housing and leisure; the cultural and historic connection and information of buildings and their territories is lost. In other words, preservation efforts lead to destruction; rural landscapes are essentially transformed into leisure landscapes. It is a process that has to be acknowledged.

Viviana Ferrario expressed the opinion that in the Italian Alps the solution lies on the "lower", local level rather than with higher authorities. However, this aspect could not be explored further during the discussion.

Sibylle Omlin (Hochschule für Gestaltung und Kunst, Fachhochschule Nordwestschweiz, Basel, Switzerland) focused on the social and symbolic elements of urbanisation processes.

Urbanism is not only a field of urbanisation theories, urban planning and densely built-up space. The term is also connoted with symbols (semiotics) and rhetoric, thereby representing aesthetic qualities. However, urbanism is concerned not only with landscape aestheticisation but also with social qualities, such as life-style and ways of life. On this background, the urbanisation of the Alps must be considered as a change of landscapes due to a mixture of rural and urban elements, and a re-construction of social life-worlds (in the sense of Henri Lefebvre's production of space).

Sibylle Omlin demonstrated this using the alpine towns of St. Moritz and Davos, where returnees after years of apprenticeship and training produce designer goods for an urban clientele (e.g., the Freitag bags made in Davos). Mountain regions adopt urban branding strategies for their products, occasionally in the form of double branding, i.e. the overlay of two brands from different fields in order to attracte more than twice the attention. Marketing experts also tap into local and rural traditions. For example, "Chesa Futura" in St. Moritz, an apartment building, was marketed using the double brands of (Norman) Foster + Partners (the architects) and St. Moritz, heavily drawing on Reto-Romansh roots. Current large projects are also being planned along these lines. Sawiris is an Egyptian investor who wants to build a resort (hotel, golf course) at Andermatt in Uri, for example. It is being positioned as a brand intended to eclipse Davos and St. Moritz.

\section{Discussion}

The ensuing discussion addressed two questions:

1. Why should we not deliberately design museal landscapes? The first input presentation made a plea for a deliberate development of mountain areas as museums. It was inspired by the city of Venice, whose inhabitants and tradespeople are fully aware that they live in and off a museum. This contribution chiefly referred to negative outcomes of re-using so-called "tabià" in Italy's Veneto region, and to the branding strategies mentioned in the section above. At the same time, the input presentation addressed the notion that we might be able to distinguish between „artificially constructed landscapes" and "landscape with a territorial identity", which should make it possible to renounce artificial landscapes.

Various participants objected, firstly, because it is a wellknown fact that the very inhabitants of mountain areas themselves have repeatedly expressed their objection to being forced to live in a "museum"; secondly, because this position would contradict the opinion that landscapes are products of values and valuations related to specific material and cultural contexts. The presenters themselves had expressed this opinion in their input presentations. Accordingly, it was argued that any (perception of) landscape is a construct by society and individuals alike, and that, therefore, the term "artificial" missed the point entirely.

2. Will the transformation processes that have been described provide for stable regional development in mountain areas? This question referred to the material function of mountain regions as providers of resources and as territories within which the local population try to counteract the encroaching loss of signification. One of the participants in the discussion demanded that no irreversible changes in the alpine space must be made. This opinion met with some strong objections from a cultural perspective and considering observable cultural dynamics, noting that stability was neither achievable nor desirable. Time constraints made it impossible to explore this issue in greater depth, however.

\section{Conclusions}

Landscapes are socio-economic and cultural constructs. Their perception and use is the result of traditional and the starting-point of new territorial relationships entered into by regional actors and incoming user interests subject to bio-physical environmental conditions. This corresponds to the double function of landscape identified in the Synthesis Report of the National Resarch Programme 48 of the Swiss National Fund.

In Europe, traditional, materially constituted significance of landscape (agricultural cultural landscape; water reservoir; industrial landscape) has been losing value. In the event of structural change in peripheral areas, traditional territorial relationships are not easily supplanted by equivalent new ones. This is particularly true for new uses, which are less stable and can be more easily and more 
quickly relocated than centureis-old, traditional production systems.

From a socio-cultural perspective, the crucial question arises whether it is realistic to expect this kind of stability, no matter how transient. From a sustainability perspective - social costs, energy consumption, irreversible land-use changes, etc. - however, any change of use that proves to be instable and short-lived must be criticised.

Some twenty participants attended this workshop. Evidently, it is a polarising issue. The predominant participant profile meant that the focus was on socio-cultural construct aspects of landscape. The ensuing discussion showed that it is difficult to link the two aspects of „materially constituted perception of landscape" and an "image-based cultural construct" , and that - depending on the participants' respective scientific disciplines - views tend to veer exclusively in the one or the other direction.

\subsubsection{Agriculture, Alpine landscapes and biodiversity (NRP 48 synthesis 2)} Workshop 2/2

\section{Moderator:}

\section{Jürg Stöcklin (Botanisches Institut, Universität Basel, Switzerland)}

\section{Starting point and aim of the workshop}

The alpine landscape is particularly fine-structured, rich in habitats and may be considered as a refuge of biodiversity on the European continent. Alpine landscapes and biodiversity have been shaped by centuries of human land use. Socio-economically motivated changes in recent decades significantly affect landscape quality, habitats and biodiversity.

The aim of this workshop was to present results of research focus II of the research programme NRP 48, "Land Use and Biodiversity in the Alps", of the Swiss National Foundation SN, and to explore, a) how changes affect agriculture, forestry and policy in Switzerland as regards landscape quality and biodiversity, and b) the pros and cons of significant expansion of forest areas in Alpine regions all over Europe.

Markus Fischer (Institute of Plant Sciences, University of Berne, Switzerland) gave a summary of the recently published (May 2007) syntheses of research in Switzerland on the roles of agriculture and forestry for landscapes and biodiversity in the Swiss Alps. He showed that from the mid-20 $0^{\text {th }}$ century on, positive impact of human land use on species and landscape diversity increasingly reversed into a negative aspect. The main causal factors were mechanisation and intensification of landscapes, and uncontrolled spread of human settlements. On the other hand, steep or ill-accessible areas were increasingly excluded from agricultural use. In Switzerland forest areas have expanded by up to 100 per cent in the past 150 years. From a biodiversity perspective this is negative, since reafforestation primarily affects dry meadows and species-rich pastures. Markus Fischer showed that Swiss agricultural policy with its system of direct payments to farmers is particularly suited to reversing negative effects on landscapes and biodiversity. As a consequence and based on insights gained by the projects of the NFP 48 and from further sources, recommendations are made to modify the present system of direct payments to the agricultural sector insofar as public, non-marketable services (ecological payments and landscape protection) are to receive consistent compensation. To a large extent, current direct payments are not directly linked to such services. As food for discussion Markus Fischer proposed five theses:

1) landscape quality and biodiversity in alpine regions are no longer guaranteed by-products of land use;

2) high biodiversity in the Alps is decreasing rapidly due to intensification, land-use change, abandonment; negative trends are augmented by global change;

3) the current sitution deviates from constitutional and legal obligations in Switzerland, and runs counter to population and tourist preferences;

4) landscape quality and biodiversity can be maintained and restored by a combination of suitable measures;

5) this requires joint efforts and breaking some taboos.

Georg Grabherr (Department of Conservation Biology, Vegetation- and Landscape Ecology, University of Vienna, Austria) summarized the consequences of forest expansion in the Alps. Abandonment of land use would lead to a recovery of forests in large parts of the Alps. He claimed that the rich vascular biodiversity of the Alps with ca. 2'500 out of a total of ca. 12'000 European vascular plants could be particularly affected by forest expansion. 70 out of 291 alpine habitats depend on human land use. As an example, the alpine flagship of rural diversity, i.e. the mountain hay meadow is now particularly threatened by land-use changes. On the other hand, remote "wilderness" areas may be valuable habitats for population expansion of large carnivores, such as lynx, wolves and brown bears. As a conclusion, Georg Grabherr proposed the following five theses for discussion:

1) although they maintain pleasant sceneries, recent agricultural practices do not necessarily guarantee the maintenance of alpine rural biodiversity;

2) maintenance of land-use dependent biodiversity requires professional landscape and biodiversity management based on deep knowledge; optimal practices would be integrated into production cycles that are economically effective but - at the same time 
- support biodiversity;

3) biodiversity must have a value apart from its economic value;

4) maintaining alpine wilderness is as important as maintaining rural landscapes, and land-use dependent biodiversity; wherever possible wildernesses should be restored, especially in remote areas.

Discussion was lively and covered various issues of landuse practices and biodiversity protection in the Alps as well as differences in agricultural policy among European countries. Participants agreed that it is important to maintain rural landscape in order to preserve existing biodiversity. However, regional differences should be taken into account more than is currently the case in Switzerland and other countries. Some participants agreed that forest expansion is negative from a biodiversity perspective, but others mentioned opportunities for wilderness areas. It was questioned whether biodiversity is an attractive issue for farmers, and a participant wondered if in the future there will be enough state subsidies to maintain agricuItural use in high mountain areas. The critical comment that we should not aim to convert alpine landscapes into an open-air museum was contradicted by the argument that a consequence of a general retreat of agricultural land use from the Alps would be that alpine ecosystem services could no longer be maintained. This might cause much greater costs to society than maintaining land use. Particularly for tourism, it is crucial that open landscapes be maintained. In wilderness areas hiking paths will soon have vanished altogether.

\section{Outlook}

The maintenance of alpine landscapes, habitats and biodiversity is an important issue for all alpine countries. Despite large differences in policy and farming conditions, positive experiences and the success of appropriate policies in different regions are highly valuable to support efforts in preserving the rich alpine landscape and biodiversity.

\section{Reference:}

Stöcklin J., Bosshard A., Klaus G., Rudmann-Maurer K:, Fischer M. 2007: Landnutzung und biologische Vielfalt in den Alpen: Fakten, Perspektiven, Empfehlungen. Synthesebericht NFP 48. Zürich.

\subsubsection{Changing climate - changing landscape \\ Workshop 2/3}

\section{Moderator: \\ Thomas Probst (Alpenforschungsinstitut AFI, Garmisch-Partenkirchen, Germany)}

Especially as a consequence of recent floods and extreme summer temperatures, climate change has become a major issue in political, scientific and public debate in the Alpine Space. At present, the focus of interest is no longer limited to temperature rise and precipitation change, but has shifted to ecological and economic impacts. The workshop particularly dealt with impacts of climate change on landscape and land use in the Alps, addressing the following questions:

1) in what way has climate change affected landscape? What changes are expected in the next decades?

2) what are current reaction / adaptation strategies of policy, the private sector and other stakeholders? Are these strategies adequate to cope with future challenges?

3) what efforts have to be made to maintain and further develop landscape in the Alpine Space as a basis for living, working and recreation?

\section{Introduction}

Various recent and current studies show an increase in annual mean temperature since 1860. On the global level, this increase is about $+0.8^{\circ} \mathrm{C}$, in Alpine Space up to $+1.6^{\circ} \mathrm{C}$ (Lebensministerium 2006). The warming trend has grown more intense over the past three decades. 1994, 2000, 2002, 2003 were the warmest years on record in the Alps. With regard to precipitation, there is no distinct long-term trend over the past 500 years. Nevertheless, a slight decline in mean regional precipitation can be observed in the Alps since the 1970s (OECD 2007). Until 2100, the Intergovernmental Panel on Climate Change (IPCC) predicts a "likely" range of further global warming from $+1.1^{\circ} \mathrm{C}$ to $+6.4^{\circ} \mathrm{C}$, depending on socio-economic development.

The Alpine Space will be massively hit by global change. Data processing in the context of the INTERREG III B project ClimChAlp for Austria shows an increase in annual mean temperature until 2055 of between $+1.0^{\circ} \mathrm{C}$ and $+2.5^{\circ} \mathrm{C}$, until 2085 between $+2.5^{\circ} \mathrm{C}$ and $>+5.0^{\circ} \mathrm{C}$ (ECHAM 5/Remo model, A1B scenario). Summer precipitation will decrease significantly, while it will increase in winter. Thus, climate change will have massive consequences on the Alpine Space in terms of ecosystems, water management, natural hazards, agriculture, forestry, tourism, and settlement and infrastructure development. 
Sergeja Praper (Urban Planning Institute of the Republic of Slovenia, Ljubljana, Slovenia) presented an input contribution on climate change impacts on settlements. As she stated, it is expected that the majority of significant longterm impacts of climate change on settlements will occur in 30,50 , or 80 years from now, and that future impacts will not be different in type from what we know today (e.g. floods, droughts, storms, landslides, rock falls), but that we will observe differences as regards their severity and recurrence periods. The Alpine space comprises very heterogenous spatial units, which even today experience natural hazards to differing degrees. Settlement types also vary a great deal, from scattered mountain villages to large cities. It is thus impossible to speak of a generalized pattern of climate change impacts on settlements. Therefore, two aspects have to be considered. Firstly, the consequences of different climate-related factors (which include increased mean temperatures and higher extremes and heat waves, droughts and water scarcity, extreme events and natural hazards), secondly, driver-dependency relations between key variables of climate change in the urban system. The main "drivers" include, for example, higher temperatures, changing precipitation patterns, wind and urban densification. Dependency variables, on the other hand, have shown to be health, biodiversity, vegetation and building integrity. As a conclusion, it seems necessary to link mitigation and adaptation efforts with current activities towards sustainable development in settlement areas.

Ulrike Pröbstl (University of Natural Resources and Applied Life Sciences Boku, Vienna, Austria) addressed the subject of climate change impacts on winter tourism and consequences for landscape development in her input contribution.

In the past 20 years, many destinations in the Alps focussed their tourism business mainly on the winter season. For these destinations, climate change has negative effects on snow security and snow cover. To investigate the possible consequences for mountainous areas, two web-based surveys - one on down-hill skiing and one on cross-country-skiing - were conducted. Each study involved some 500 respondents. The main motivation for both groups is physical activity and experience of snow in winter. Using a two-step choice experiment, the majority of ski-enthusiasts were found to prefer a higher-altitude destination with better prospects for snow cover in the future. However, by increasing the attractiveness of destinations with extra services such as spa-facilities and childcare, a significant proportion of respondents (up to 40 per cent) would remain in lower-lying destinations. Thus, concerning trends in winter sport tourism, it has to be taken into account that artificial snow can ensure skiable conditions, but is less preferred than areas with natural snow at higher altitudes, and that creative (leisure) services can contribute to a shift from winter to summer holidays. Finally, the consequences for agriculture and forestry have to be considered, as small-scale farming is often closely linked to tourism and an expansion of forests in mountainous areas is to be expected.

Wilfried Haeberli (Institute of Physical Geography, University of Zürich, Switzerland) focused on climate-driven landscape and geosystem changes in high mountain-regions in his input contribution, where he presented an integrated case study in the eastern Swiss Alps.

An integrated spatio-temporal ( „4D“) geo-information system (GISALP) was developed as a tool for communication, analysis, participatory planning and management in the highest parts of the Alpine landscape. Regional data and spatial models relating to key variables concerning climate-driven landscape evolution were compiled for analysing the current situation and for modelling potential future development scenarios. Special emphasis was placed on glaciers and permafrost as well as expanding periglacial surfaces, soil evolution and pioneer vegetation where the strongest change is known to occur in the mid to long term. A system analysis was carried out in order to define the most important drivers, indicators, buffers and ambivalent elements concerning relevant processes and phenomena. Climate change and forward-looking local policy are dominant long-term drivers. As expected, the highest belts of high mountains, especially perennial ice (glaciers, permafrost), are subject to the most dramatic changes in scenarios of potential future atmospheric temperature rise. Closely connected to the corresponding evolution, natural hazards and landscape attractiveness are most likely to be subject to striking changes, as well. One consequence is the decline in landscape attractiveness where glaciers once were visible, i.e. also in the main valleys.

\section{Conclusions from the discussion and outlook}

The following discussion shows that most participants consider climate change one of or even the mostessential future challenges for the Alpine space. Generally speaking, most climate change impacts on landscape and land use are regarded as negative. Especially the increasing natural hazard potential is seen as a serious threat for people, settlements, infrastructure and economy in the Alps. In the worst case, certain valleys will no longer be adequate places to live in. As far as impacts of climate change on land use are concerned, both positive and negative aspects are mentioned. In winter tourism, a twofold trend can be assumed: while skiing infrastructure could be given up in several regions at low altitudes, concentration and intensification could take place at high-altitude winter resorts. In low altitude areas, artificial snow production 
could contribute to maintaining winter tourism, but it will not be the only solution; diversifying services seems to be the required option. On the other hand, summer tourism could generally benefit from climate change: if summer seasons get too hot in southern Europe and overseas destinations, the Alpine space could be preferred due to its more moderate climate. As far as agriculture is concerned, longer vegetation periods and more favourable growing conditions could be an advantage.

In the last part of the discussion, a strong need for action at different levels became obvious. The current policies were felt to be far from adequate, and do not seem to be suitable to cope with expected climate change impacts, increasing natural hazards in particular. Therefore, the most urgent challenges were seen in counteracting adverse impacts by intensifying mitigation and adaptation measures while preventing an even larger extent of climate change. In terms of prevention, not only the public and private sectors and science were seen to have to make strong efforts; each individual person also bears certain responsibilities. Thus, one basic requirement was felt to be to raise awareness for potential impacts of climate change and overall social responsibility to take adequate measures. In this context, it was deemed necessary to pursue discussion on climate and landscape change in the Alps. This workshop was a first step; further ones should follow in order to deepen the debate. In addition, a network of experts in this field could bring the issue forward.

\section{References:}

Lebensministerium 2006: Klimawandel im Alpenraum. Wien. OECD 2007: Climate Change in the European Alps. Paris.

\subsubsection{Land-use changes in the Carpathians and in the Alps Workshop 2/4}

\section{Moderators:}

\section{Jacek Kozak (Institute of Geography and Spatial Management, Jagiellonian University, Krakow, Poland)}

Franci Petek (Geographical Institute Anton Melik, Slovenian Academy of Sciences and Art, Ljubljana, Slovenia)

The aim of the workshop was to compare land-use and land-cover changes in the northern Carpathians and in the Alps. Understanding the determinants of change requires considering multiple scales, historic backgrounds and development scenarios of the regions under consideration. Inter-regional comparisons allow to identify problems shared as well as similarities and differences. In particular, one of the questions discussed during the workshop was whether the current state of the Alps can be considered one of many possible futures of the Carpathians. If yes, then setting Carpathian land changes in the Alpine context may be of practical importance for land-use policies and decision making.

During the workshop, three case studies related to land changes on high mountain pastures were presented, from the Slovenian Alps, the French Alps and the Carpathians, respectively:

- Overview of Alpine pasture development in the Slovenian Alps and development of pastures on common land of Velika planina, the Slovenian Alps, by Franci Petek, Matej Gabrovec, Mimi Urbanc (Anton Meliki Geographical Institute ZRC SAZU, Ljubljana, Slovenia).

- Evolution of common pastures: two examples in Savoy (Northern French Alps), by Amaia Legaz, Dominique Baud, Christophe Gauchon (Université de Savoie, France).

- Land use changes on high mountain pastures in the Chornohora Range, the Carpathians, by Izabela Sitko, Mateusz Troll, Jacek Kozak (Institute of Geography and Spatial Management, Jagiellonian University, Krakow, Poland).

The Carpathians and the Slovenian Alps share a similar history over the past centuries (part of the Austro-Hungarian Empire, communist regimes after World War II). Now these two regions face rapid political and socio-economic changes due to ongoing transformation to market-oriented economies and accession to the European Union. The transformation has triggered a widespread land change. Several examples, such as conversion of mountain pastures into recreational areas, or land abandonment and forest expansion were shown in the case studies from Slovenia and Ukraine. The problem of land change in post-socialist countries, its impacts on cultural landscapes, biodiversity and ecosystem services were the topic of the concluding presentation:

- Post-socialist land change and impacts on ecosystems and habitats in the Carpathians by Patrick Hostert \& Tobias Kuemmerle (Institute of Geography, HumboldtUniversity of Berlin, Germany), Per Angelstam (Faculty of Forest Sciences, Swedish University of Agricultural Sciences, Umeå, Sweden), Marina Elbakidze (Institute of Geography, Ivan Franko National University of Lviv, Ukraina)

In the open discussion following the four presentations, workshop participants exchanged information and experiences derived from research or visits, both in the Carpathians and in the Alps. Several comments referred to data availability and reliability in the Carpathian area, with a 
particular concern on the Ukrainian part. This issue was further discussed during Workshop 3/4 of Forum Alpinum: Cooperation in European Mountains - the example of the Alpine and Carpathian Conventions.

\subsubsection{Soil system services in mountain environments \\ Workshop 2/5}

\section{Moderators: \\ Christine Alewell (Institut für \\ Umweltgeowissenschaften, Universität Basel, Switzerland)}

Eva Spehn (Botanisches Institut, Universität Basel, Switzerland \& Global Mountain Biodiversity Assessment GMBA)

\section{Introduction}

Changes in climate and land use practices affect alpine biodiversity and the stability of alpine soils. The integrity of alpine ecosystems is crucial to sustain important ecosystem services such as drinking water production, flood prevention and slope stability. Thus, the stability of alpine soils has a high ecological and economic value for today's society. The workshop explored the likely effects of global change on soil stability in the Alps and its consequences for the lowlands.

Erich Tasser (European Academy, Bozen/Bolzano, Italy) discussed in his input presentation the effects of landuse changes on vegetation rooting and soil stability. Erika Hiltbrunner (Botanisches Institut, Universität Basel, Switzerland \& Global Mountain Biodiversity Assessment GMBA) presented a contribution addressing global change impacts on alpine soils.

Further, contributions by the following workshop participants are included in this report: Katrin Meusburger (University of Basel, Switzerland) Ludwig Braun (Commission for Glaciology of the Bavarian Academy of Sciences, Munich, Germany), Roland Psenner (Institute of Ecology, University of Innsbruck, Austria), Jean-Jaques Brun, CeMAGREF, St. Martin d'Hères, France).

\section{Outcome of the workshop}

The stability of alpine soils is influenced by multiple factors (e.g. global warming, nitrogen deposition, land use change), interacting and reinforcing each other.

\section{Land use change effects on soil stability:}

The present situation in the Alps leads partly to an abandonment of high alpine lands and partly to an intensification of easily accessible areas. Loss of agricultural land in the Swiss Alps between 1979/85 and 1992/97 amounted to approx. 18'000 ha, with most of the land being changed to bushes, forests and woods (Areastatistik Schweiz, BFS). Simultaneously, animal numbers increased, tripling livestock density on the remaining land from 1950 until today. For example, livestock in the Urseren Valley (Meusburger \& Alewell in prep) shows an increase of 1'000 to nearly 8'000 sheep, and 800 to 1'500 cattle since the 1960s. This increase in livestock has important consequences on soil stability and thus, on the water and nutrient cycles. Changes in vegetation composition and rooting leads to a change of erosion risk. A comparison of aerial photographs from 1959 and 2004 showed a dramatic increase of eroded area by $92 \%$ over 45 years. This was caused mainly by changes in land use practice rather than the mere increase in animal numbers, e.g. no herded summering but uncontrolled grazing in grasslands with low soil stability.

\section{What determines erodibility of alpine soils?}

In the Passeier Valley (South Tyrol) and Stubai Valley (Tyrol), important factors which influence erodibility in alpine soils were exposition (East, South-East), slope inclination, soil depth, land use type (abandoned land), rooting depth and root density (Tasser et al 2003). Biodiversity of alpine land decreased with intensification as well as with abandonment, but was highest in traditionally managed meadows. The latter also had the higher root densities (up to 120 $\mathrm{km} / \mathrm{m}^{2}$ ) than intensively used meadows and abandoned land with dwarf shrubs $\left(20-40 \mathrm{~km} / \mathrm{m}^{2}\right)$.

In the study of Hiltbrunner on the Furka Pass (central Swiss Alps), erosion rates (runoff and sediment loss) where correlated to vegetation cover but not to diversity of alpine grasslands. Dense plant cover is key against erosion in steep slopes, whereas species number/plant diversity is not directly linked to runoff or sediment loss due to high variability (Hiltbrunner).

The presence of different plant functional types (e.g. dwarf shrubs) has a major impact on surface water runoff. As dwarf shrubs significantly increased soil erosion and decreased slope stability at the Austrian site, Tasser recommended that abandoned areas on steeper slopes should be reafforested as rapidly as possible to avoid the succession stage dominated by dwarf shrubs. Dwarf shrubs were also found to decrease surface runoff (Hiltbrunner). However, evaluation of aerial photographs of the Urseren Valley (Switzerland) showed that landslide susceptibility was reduced with higher dwarf shrub cover (Meusburger, Univ. of Basel). These different results of the two sites led to a discussion of the influence of dwarf shrub effects on stability/erosion of soils and therefore of their role during succession after abandonment of managed grasslands. We conclude that the effect of dwarf shrubs depends on the specific invading dwarf shrub species (e.g. Rhododendron ferrugineum seems to have a positive effect on 
soil stability), and on the soil type. Land slides and surface erosion are caused by two different processes: overland flow causes surface erosion, whereas the retention of overland flow (e.g. by soil compaction due to heavy grazing) increases subsurface flow, which triggers landslides and thus, increases landslide risk. Brun reported a case of induced soil erosion by forest encroachment on abandoned slopes on schist soil in the French Alps. Forested parts were exposed to soil erosion, as "trees were too heavy" and induced soil slips. Foresters had to cut trees out (forest thinning) to reduce weight.

\section{Climate change effects on alpine vegetation, hydrology and soils}

Warming (in the range of $+1 \mathrm{~K}$ ) leads to predominantly negative plant responses (biomass). Snow bed species were most negatively affected. None of the plant species was stimulated under warmer conditions. Soluble "nitrogen deposition" exerts significant plant responses at rather low deposition rates ( $25 \mathrm{~kg} \mathrm{~N}$ ha y). Herb species were negatively affected by experimental trampling. Most responses increased with time. Trampling often intensified the negative warming impact. Fine root density increased under warming, but only in combination with $\mathrm{N}$-addition (Hiltbrunner).

In the discussion, Braun showed that water yield from catchments with glaciers is enhanced during dry and hot summers due to excessive ice melt. However, this compensating effect will be lost once the glaciers are gone. With further global warming, the solid fraction of precipitation will diminish at all elevation levels. However, maximum snow depths are expected to increase at high elevations (above $2500 \mathrm{~m}$ ) due to higher precipitation in winter (Gıowa-Danube study, www.glowa-danube. de). This will lead to more runoff in winter and spring, but less in summer. Processes during snow melt will gain importance in the future, as higher melt intensitites are predicted. This will alter the timing and velocity/intensity of nutrient release from snowpack, changing the concentration and seasonality of nutrients (Psenner). Nitrogen flux models predicted $10-15 \mathrm{~kg} \mathrm{ha}^{-1} \mathrm{y}^{-1}$, but measurements at $2500 \mathrm{~m}$ asl showed only 3-5 kg ha-1 $\mathrm{y}^{-1}$ in the Central Alps (Hiltbrunner). 1-3 kg N ha-1 $\mathrm{y}^{-1}$ is assumed to be added by mineralization. As indicated in some areas in the Central Alps, forest soils started to release significant amounts of nitrate (Psenner).

\section{Climate warming and carbon in alpine soils}

C-mineralization showed highest temperature sensitivity under low incubation temperature, therefore climatic warming will lead to higher $\mathrm{C}$-mineralization rate in alpine soils (Wüthrich and Hiltbrunner). Since carbon pools will change over time, the feed-forward mechanism of increased carbon mineralization at increased temperatures probably will not persist, but lead to a new equilibrium over time. The time to reach a new equilibrium depends on a variety of factors, such as the total carbon pool, the labile fraction, soil humidity, and permafrost.

\section{Outlook}

Tasser's data reflect the "nail and screw" concept of the Global Mountain Biodiversity Assessment (GMBA) of DIVERSITAS (fig. 6) indicating that a greater variety of roots and rooting patterns with higher plant diversity increases soil stability on steep slopes. Tasser's data not only showed a significant increase of root density when more grass species were present in the vegetation, but also an increase in soil stability. Roots in alpine grasslands are like a mat of felt with high mechanical stability reducing gravitational forces acting on the soil layer (Hiltbrunner). Let's call them "the underground web" (Psenner).

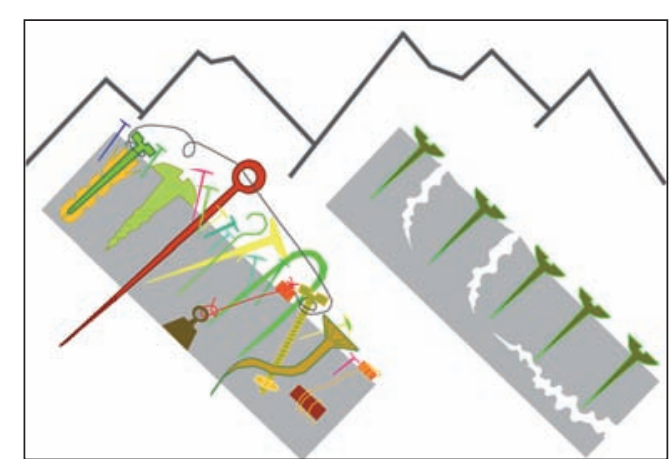

Fig. 6: Roots and rhizomes, nature's diverse screws and nails for mountain soils. Mountain ecosystem services depend on slope stability, which in turn depends on a diverse and intact vegetation cover with associated animal and microbial life (Körner 2002).

\section{References:}

Tasser E., Mader M., Tappeiner U. 2003: Effects of land use in alpine grasslands on the probability of landslides. Basic and Applied Ecology 4: 271-280.

Körner C. 2002: Mountain Biodiversity: its causes and function: an overview. In: Körner C and Spehn E. (eds): Mountain Biodiversity: a global assessment. The Parthenon Publishing Group, London, New York 


\section{Plenary Session 3: Cooperation and decision-making in landscape management}

\subsection{Summary}

\section{Moderators:}

Sandra Luque (CEMAGREF, St. Martin d'Hères, France)

Norbert Weixlbaumer (Institut für Geographie und Regionalforschung, Universität Wien, Austria)

The central goal of this session was to analyse the state of the art on research that would help directly to promote the understanding among rural regions of how relationships function in ecosystems and to render relevant processes in landscape management visible. The session stressed the link between ecological science and decisionmaking in theory and practice. A fundamentally different model of knowledge transfer is required, i.e. a network rather than a linear model, so that scientists may learn from practice how to insert local knowledge into their generic tools.

The session addressed the following topics:

- theoretical frameworks regarding aims in decision-making and realisation of goals in rural development;

- tools to improve communication paths between biodiversity and ecosystem services and stakeholders;

- development of methods to increase cooperation and communication between conservation scientists, decision-makers and citizens;

- increased research on the understanding of public attitudes and views on biodiversity and biodiversity management to develop and present arguments for a comprehensive approach for socially and environmentally effective ecological outcomes.

With reference to these topics, the first two presentations (by G. Wiesinger and M. Coy) concentrated on theoretical frameworks and methods focusing a socio-economic approach. The third one (by M. Zebisch \& M. Hirschmugl) discussed the usefulness of technological tools to promote cooperation and decision-making in landscape management.

- Georg Wiesinger (Bundesanstalt für Bergbauernfragen, Vienna, Austria):

The importance of social capital in rural development, networking and decision-making in rural areas Rural decline is frequently explained in economic terms by unfavourable conditions and by missing resources or support. Hence this link is not entirely clear and does not apply in all regions. Recent discussions of this issue have emphasized the importance of social ties and shared norms for societal well-being and economic efficiency. The concept of social capital has been widely used in the study of social inequality and hierarchical social structures. Several authors attempted to capture the non-economic aspects of society that promote economic growth, among other positive effects; thus, social capital may affect a community's performance and competitiveness, as well as its social cohesion.

This presentation addressed the question of whether the concept of social capital could indeed lead to a better understanding of these patterns. The role of social capital was demonstrated by means of a model connecting it with rural development, multifunctionality, local governance, environmental perception and national policies.

Since this presentation clearly pointed out the importance of social capital in rural development dynamics, it was suggested both by the author and the plenary that social capital should be better recognized by policy-makers as a key factor in rural development processes - a factor that hampers when weak, but helps when strong and well-rooted, the implementation of rural development policies and, specifically, those policy measures aimed at counteracting marginalization processes and, to some extent, land abandonment. Thus, creation of social capital should be a deliberate goal of any rural development policy, even though the downside of social capital and its „territorial imperative" (e.g. excluding incomers and obstructing innovation) must also be critically considered. The debate showed that awareness is required that social capital is just one of a number of "soft" factors of rural development, and that without functioning hardware (e.g. infrastructure, local services), the story of social capital will not be a successful one.

- Martin Coy (Institut für Geographie, Universität Innsbruck, Austria):

The perception of landscape management - the example of the Großes Walsertal Biosphere Reserve Although success stories were not on the agenda of Session 3, this presentation dealt with one. Five years after the proclamation of the Großes Walsertal Biosphere Reserve (Vorarlberg, Austria), an analysis was carried out to ascertain acceptance and early regional economic effects in the context of the so-called Sevilla 
strategy. Biosphere Reserves are expected to contribute substantially to the sustainable and well-adapted socio-cultural, ecological and economic development of both region and population. In this context, it is of great relevance to consider local potentials and restrictions, to fully involve regional stakeholders, and to consider regional production chains and economic cycles. Multiplier effects and the success of innovative project ideas rely fundamentally on the ability of motivating or integrating respective target groups on a broad basis. Further conducive factors are ongoing enhanced acceptance by creating awareness and proving the (economic) feasibility of project ideas.

Results of the analysis five years post-initiation showed that successful landscape management, as well as innovative regional development strategies depend on the positive perception of spatial planning instruments such as biosphere reserves. Sustainable innovative strategies are more easily realised in large protected areas where the gap between inside and outside perspective is not too great. The study showed that expectations of local residents and their assessment of concrete implementation measures concerning the Biosphere Reserve policy should not diverge. The author pointed out that, in accordance with the integrative paradigm of nature conservation, it is essential to accompany evaluation and acceptance-enhancement of Biosphere Reserve as a mental construct both on the inside and from outside. Discussion and positive results of this study have shown that perception of landscape management can be a useful instrument for evaluating landscape development projects. An important point raised by the plenary was the need to implement a truly participative process in order to achieve truly bottom-up management. Taking into consideration the needs of the local population and local agents was found to be a key step towards genuinely sustainable conservation management.

- Marc Zebisch (Institute for Applied Remote Sensing, European Academy Bozen/Bolzano, Italy) \& Manuela Hirschmugl (Institute of Digital Imaging Processing, Joanneum Research, Graz, Austria):

How can remote sensing support landscape planning and landscape management in mountain regions? A joint presentation by Marc Zebisch and Manuela Hirschmugl focused on Remote sensing and its application for monitoring at the landscape level to use a different approach and explore state of the art techniques that may help to promote our understanding of relationships in ecosystems and to visualise relevant processes in landscape management as outlined in the objectives of this conference.

Remote sensing has a long tradition in landscape planning and landscape management. Particularly the use of aerial photography for land-cover and landscape-element mapping is a widespread approach and an excellent supplement of field work. In actual fact, mountain regions are very dynamic landscapes whose elements change rapidly due to natural hazards such as landslides, avalanches or storm events. Even if they are often remote areas, human activities influence and determine mountain ecosystems. While anthropogenic landscape dynamics have traditionally and primarily been driven by settlements, infrastructure and land-use activities, climate change and its impacts are becoming increasingly important. Retreating glaciers, vegetation changes and a rising snow line are just some of the fields that could be addressed by remotesensing applications.

The presentation focused on how satellite-based sensors offer new opportunities for remote-sensing applications in various spatial and temporal scales. High-resolution sensors provide imagery with a ground resolution of less than $1 \mathrm{~m}$; radar sensors allow weather and daylight-independent surveys; lidar explorations yield digital elevation data with the precision of decimetres. Moreover, a series of new methodologies and software tools for image processing and interpretation enhance and enlarge remote-sensing applications.

The presentation provided a good overview of potential applications of remote sensing in mountain regions in the context of landscape planning and landscape management. A series of case studies from the Alpine Space were used to illustrate the applications.

The discussion chiefly focused on the use of the right tools for the right purposes. In that sense, it was stressed that aerial photographs are still an important tool for temporal studies and mapping in certain cases. Not only remote sensing but also the use of Geographic Information Systems (GIS), were highlighted as important approaches to work in processes related to decision making. In particular remote sensing capabilities in tandem with GIS were seen to be good tools for rapid assessment methods that allow to take rapid management decisions if required. 


\subsection{Key input contributions to Plenary Session 3: extended summaries}

\subsubsection{The importance of social capital in rural development, networking and decision-making in rural areas}

\section{Georg Wiesinger (Bundesanstalt für \\ Bergbauernfragen, Vienna, Austriaa)}

\section{Keywords}

Social capital, rural development, networks

Rural decline is frequently explained in economic terms by unfavourable conditions and by missing resources or support. But this link is not entirely clear and does not apply in all regions: some particularly remote rural regions with a very sparse population, a lack of policy support, poor economic performance and unfavourable climatic conditions prove more viable than some regions with more plentiful economic resources and more support. Recent discussion on social capital has emphasized the importance of social ties and shared norms for societal well-being and economic efficiency, and the concept has been widely used in the study of social inequality and hierarchical social structures. In particular, Robert Putnam (1993 and 2000) linked the idea of social capital with the importance of civic associations and voluntary organisations, emphasising the positive aspects of social control. More recently, Árnason et al. (2004) applied the concept of social capital in the context of rural development. Using this concept, they attempted to capture non-economic aspects of society that promote economic growth, among other positive effects; thus social capital may affect a community's performance and competitiveness, as well as its social cohesion.

The presentation discussed the question whether the concept of social capital could indeed lead to a better understanding of these patterns. The role of social capital was demonstrated by means of a model connecting it with rural development, multifunctionality, local governance, environmental perception and national policies. Since social capital is immanent in, and created by the people living in a given area, the ways in which people perceive the socio-economic, cultural and environmental situation in their area seem of crucial importance. People's perception was shown to differ according to age, gender, profession, education and life experience. Thus people brought up or permanently living in a region, and incomers may have extremely divergent attitudes towards their shared social and natural environment. Although part-time dwellers, summer cottage owners, short-time visitors and tourists do not tend to contribute to social ca- pital, they do influence the attitudes of local people. We can also observe the impact of the economic, social and environmental situation in a rural region on social capital. Rural decline may cause a weakening of social capital while wealth and prosperity might facilitate the further enhancement of social capital.

In current neo-liberal discourse it is often argued that social capital could act as a remedy to strengthen civic society and local cohesion, substituting for services formerly organized by government while public infrastructures and institutions are being cut. However, these tendencies might destroy social capital by placing too heavy demands on people's solidarity and on social safety nets. On the other hand, strong social capital can strengthen local governance and its negotiating capacity in decision-making.

The findings of several case studies within the Eurolan project (Strengthening the Multifunctional Use of Land: Coping with marginalisation) suggest that social capital should be more recognized by policy makers as a key issue in the rural development process, hampering (when weak) or supporting (when strong and well-rooted) the implementation of rural development policies. The creation of social capital should be a conscious aim of any rural development policy. However, the downside of social capital and its "territorial imperative" has to be critically considered, too. Much as local communities involve their citizens and assist people in need, their close ties also account for the dynamics of excluding those who are unable or unwilling to comply with the strict norms of a particular traditional community. Young people with different cultural lifestyles, people whose political opinions deviate from the norm and those who do not belong to local associations or religious congregations may experience social exclusion. Strong social capital can also produce hostility towards incomers and thus prevent innovation in local communities.

Summing up the debate, one should be aware that social capital is just one among many "software package" for rural development. We also require functioning "hardware" in terms of local employment, infrastructure and services. Any further reductions in those facilities might mean that the "software" can no longer be successfully installed. 


\subsubsection{The perception of landscape management - the example of the Großes Walsertal Biosphere Reserve}

\author{
Martin Coy (Institut für Geographie, Universität \\ Innsbruck, Austria)
}

\section{Keywords}

Biosphere Reserve, Regional Sustainability, Regional Economic Effects, Perception, Austria, Vorarlberg

According to the so-called Sevilla strategy Biosphere Reserves have to fulfil a development function in order to guarantee regional sustainability. In this sense, the design of future development strategies for a Biosphere Reserve, which may be understood as a typical case of landscape management, has to be based on regional economic and perceptional analyses. Following the principle of sustainability, development projects within the framework of the management strategies of a Biosphere Reserve are expected to contribute substantially to a lasting and adapted socio-cultural, ecological and, above all, economic development of both region and population. In this context, it is highly important to take local/regional potentials and restrictions into account, to fully involve regional stakeholders, and to consider production chains and economic cycles which are specific for the region. Multiplier effects and the success of innovative project ideas rely fundamentally on the ability to motivate or integrate respective target groups. Further conducive factors are increased awareness to enhance acceptance, and producing proof that project ideas, in particular economy-related ones, are feasible.

Moreover, successful landscape management and innovative regional development strategies depend on the perception of spatial planning instruments like Biosphere Reserves as mental constructs. Sustainable innovative approaches can be realised in large protected areas provided the divide between inside and outside perspectives is not too great. On the other hand, local residents' expectations and their assessment of specific implementation measures concerning the Biosphere Reserve policy should not diverge. In accordance with the integrative paradigm of nature conservation, it is essential to accompany evaluations and to improve inside and outside acceptance of the Biosphere Reserve.

November 2005 was the fifth anniversary of the Biosphere Reserve Großes Walsertal in Vorarlberg (Austria), and therefore a convenient time for an appreciation and a first regional economic effect analysis. This paper gave an overview of the objectives and the main results of a research project which was conducted in 2005 / 2006 by working groups of the Institute of Geography of the University of Vienna (Norbert Weixlbaumer) and the Institute of Geography of the University of Innsbruck (Martin
Coy) in close cooperation with the management of the Biosphere Reserve Großes Walsertal, financed by the Austrian Academy of Sciences in the context of the Man and Biosphere Programme.

As part of a general assessment of landscape management strategies, the study mainly focused on the concrete development projects of the Biosphere Reserve Großes Walsertal with respect to their strategy, implementation and regional stakeholder-acceptance, and regarding their contribution to a regional sustainable development. The image of the park, the qualities of the social construct of a Biosphere Reserve as perceived by the population were examined.

Four levels of analysis were of particular importance for the specific research design:

- embedding the projects initiated or supported by the Biosphere Reserve, in the general regional economic development trends of the study area;

- an „inside view” of stakeholders participating in these projects (e.g. regarding motivation for participation, assessment of implementation, evaluation of success, future perspectives);

- an „outside view” of non-participating stakeholders and of target groups addressed by the projects;

- inside and the outside perspectives of the Biosphere Reserve Großes Walsertal in general, with the main focus on establishing a perception profile of the local population.

Against this general background, the analysis of regional economic effects of the Biosphere Reserve should provide answers to the following questions:

- what economic potentials are there in the region Großes Walsertal and how are these potentials incorporated in the strategies of the Biosphere Reserve?

- how well do the projects initiated by the Biosphere Reserve Großes Walsertal and other regional stakeholders stimulate a sustainable economy in the region, and how are they integrated in superior initiatives and politics of regional development?

- in what ways do both interest and acceptance rates of the regional population / craftsmen / the political decision-makers change with respect to the projects promoting sustainable economic activities within the framework of the Biosphere Reserve?

Our perceptual analysis also focussed on the following questions:

- against what background has the Biosphere Reserve developed so far (landscape potential; population and socio-demographic developments; policies for regional development and construction of corporate identity; the Biosphere Reserve as a protected area in 
the international context - e.g., as role model for rural regions)?

- what is the outside perspective of the Biosphere Reserve Großes Walsertal? Does this view conform to the paradoxical perception internationally typical for protected areas (outside one's own settlement area they are rated essential, while they are rated non-essential in one's own surroundings)?

What kind of inside perspective exists in the region after the first five years of the Biosphere Reserve? What do the local population's mental maps look like and what recommendations can be deduced for the future development of the Biosphere Reserve in combination with the results at different research levels?

\subsubsection{How can remote sensing support landscape planning and landscape management in mountain regions?}

Manuela Hirschmugl (Institute of Digital Imaging Processing, Joanneum Research, Graz, Austria)

Marc Zebisch (Institute for Applied Remote Sensing, European Academy Bozen/Bolzano, Italy)

\section{Keywords}

remote sensing, landscape planning, monitoring, scale

Remote sensing has a long tradition in landscape planning and landscape management. Particularly the use of aerial photography for mapping land cover and landscape elements is a widespread approach and an excellent supplement of field work. Today, recent satellite-based sensors offer new opportunities for remote sensing applications in various spatial and temporal scales.

One benefit that satellite data can offer is the opportunity for semi-automatic image interpretation. Satellite data not only provide visual images of landscapes but contain quantitative physical information about the reflectance of landscape objects. Only this digital and quantitative information enables the interpretation and classification of satellite data with semi-automatic, computer-assisted processes that are reproducible, time and cost effective, and allow the integration of additional data as well as expert knowledge.

The very short update intervals of satellite data constitute a second advantage. Depending on resolution and type of the sensor, data are available typically every $1-30$ days. In combination with semi-automatic interpretation methods, this allows monitoring dynamic landscape processes, a point which is becoming increasingly important in landscape planning. Impacts of climate change, i.e., retreating glaciers, vegetations changes and rising snow lines, are just some of the examples for such monitoring tasks.

A third advantage is the opportunity to work across scales. Today's satellites can provide high-resolution data on objects smaller than 1 meter, across an area of some onehundred square kilometres; they can also supply mediumresolution data ( $250 \mathrm{~m}$ resolution) that cover areas such as the whole alpine range. The combination of such data allows cross-scale applications and the development of nested methods, an approach of increasing interest, particularly in the context of global change research. Studies on biodiversity, for instance, are now being conducted from local to global scales.

Apart from optical sensors, other types of sensor also offer new opportunities. Radar sensors, for instance, are not weather and daylight-dependent, and allow the identification of very slight changes in terrain, such as mass movements or subsidence, which is important in particular to monitor glaciers, land-slides and areas with instable terrain. LIDAR data, a technology based on airborne laser scanners, provide very high resolution digital terrain as well as advanced vegetation models.

Furthermore, a series of new methodologies and software tools for image processing and interpretation enhance and enlarge remote sensing applications.

The following applications illustrate the range of remote sensing possibilities in the context of landscape planning. They concern projects in forestry, natural disaster management, habitat mapping and visualisation. The forestry projects provide important information, for example for protection forest planning. The first application concerns the classification of forest parameters such as crown closure, tree species and age classes - important information for planning measures in protection forests. The classification was performed on SPOT satellite data and carried out for the whole province of Salzburg and for parts of Carinthia in Austria. A second application in the field of forestry is the assessment of storm damaged areas, also based on SPOT data. The third application is a project dealing with avalanche modelling. The role of remote sensing was to classify individual trees and their volume as an important input for the avalanche model SAmos. The results of such a model are important for protection forest planning, but also for risk zonation planning.

The project Assist that deals with disaster management is also situated in the context of natural hazards. This project includes the concept of rapid information flow from aerial image data-acquisition, the derivation of landslide susceptibility maps for prevention and preparedness, as well as a disaster management system employing web- 
based service nodes and mobile devices.

Remote sensing tools can assist habitat mapping. Pointwise terrestrial information is linked to land-use classification and other remote sensing data, such as terrain information, i.e., slope, aspect or surface roughness. This project shows one main advantage of remote sensing particularly well, i.e., the regionalisation of information.

Finally, a project was presented which deals with land use changes in mountain environments and their visualization. Based on old topographic maps, classification based on historic aerial imagery and recent satellite data, the change of forest cover in the Möll valley in Carinthia was visualized with $3 \mathrm{D}$ tools. The animation showed changes over time and gave an excellent impression of how land cover affects the way a region looks.

\section{Conclusion:}

Satellite remote sensing is a valuable tool to broaden approaches of traditional landscape planning with its focus on local to regional applications and long update intervals, and helps to bridge gaps between long-term planning processes and continuous monitoring requirements, and between local applications and trans-regional, European and even global planning and monitoring activities

This kind of expansion of ideas of landscape planning seems particularly important in the light of European planning and monitoring activities, such as the water framework directive, the NATURA2000 network, or even global efforts like the Convention on Biological Diversity. In that way remote sensing may help to promote the understanding of interdependencies of local requirements and global change in the sense of the well-known saying "think global, act local".

\subsection{Workshops Plenary Session 3: summaries}

\subsubsection{Shaping future landscapes: negotiation processes and best practices (NRP 48 synthesis 3) Workshop 3/1}

\author{
Moderator: \\ Johannes Heeb (seecon international, Wolhusen, \\ Switzerland)
}

Alpine development is increasingly characterized by larger numbers of potential negotiating parties; by growing information needs regarding administrative, economic and political contexts and developments; by an increasing complexity of the economic and political contexts and developments, and by growing coordination needs. In this context, the following challenges or needs for future landscape processes can be identified: a) regional negotiation capabilities, b) networking activities, c) information flow and processing, d) improvement of organisational knowledge (Pfefferkorn et. al., 2006). This workshop reflected on this situation and discussed best practice examples in landscape development negotiation processes by highlighting several cases in Switzerland and Austria. Experiences with new participative methods in Swiss NRP
48 projects

In his input presentation, Felix Walter (ECOPLAN, Berne, Switzerland) discussed whether participative processes resolve the conflict of interests concerning alpine landscapes. His presentation was based on synthesis report III of the Swiss NRP 48, where several participative methods were applied and analysed. Apart from classic methods such as voting, consultation procedures etc., a great number of more recently developed participative methods were tested, i.e. conferences on future development, stakeholder-workshops and open-space conferences. Overall, respective NRP 48 projects have confirmed the significance and value of participation processes and have also demonstrated transferability to other situations.

The project "SOCIETY" showed that a participative approach - as in the case of the conference on future development - can lead to a convergence of the different stakeholders' positions. Various projects concerning natural parks also showed that the choice of organisational forms and participative methods to be applied has a distinct influence on project outcomes.

Participation is not a guarantee for sustainable solutions. However, participative methods often contribute to more efficient conflict resolution with longer-lasting results. In many cases, participants' suggestions prove to be more 
comprehensive. Suggestions are also received better and debates become more factual. Participative methods sometimes have a preventative effect in the sense that they can anticipate conflicts. In landscaping, participative methods are the necessary prerequisite for different population groups to contribute their ideas.

Given the increasing complexity of problems concerning the alpine region - e.g. migration, structural change, climate change, increasing dependence on resources from outside the area etc. - utilisation conflicts in alpine landscapes are likely to intensify. Therefore, (new) participative methods in landscape development in alpine regions will most likely continue to gain greater relevance.

\section{Austrian NATURA2000 management plans - implementation aided by mediation}

Wolfgang Pfefferkorn (Rosinak\&Partner ZT GmbH, Vienna, Austria \& CIPRA International, Schaan, Liechtenstein) presented the case of the NATURA2000 area of Verwall (Montafon valley in Vorarlberg / Austria), which had been subject to conflicts among landowners, users and public authorities.

With the instrument of Natura2000, the EU wanted to create, protect and develop a network of particularly valuable habitats in Europe. In doing so, not only aspects of nature conservation, but all the current uses as well as regional and local particularities were to be taken into account. Implementing the NATURA2000 guideline had already caused commotion in Austria as well as in other member states of the EU. Since then, representatives of agriculture, forestry, hunting and tourism as well as private-sector companies have protested against the restriction of utilisation options.

The nomination of the Verwall NATURA2000 area and particularly its designation as a nature protection area led to insecurities and strong opposition among landowners. Communication between local authorities and the people affected became increasingly difficult. Finally, the provincial government of Vorarlberg agreed to the environmental lawyer's suggestion to arrange a mediation procedure, carried out by the consulting firm, Rosinak\&Partner. The aim was for landowners, users, various interest groups and local authorities to formulate agreements on the future use of the area.

A negotiating team of 33 was appointed, representing the interest groups involved; if necessary, further experts were consulted. After negotiating terms of procedure and providing participants with the necessary information on the EU NATURA2000 guidelines, related laws and regulations, several negotiating rounds took place. First, existing conflicts had to be analysed; next, the most important application areas were addressed in detail. Finally, agreements were drawn up, discussed and negotiated.
Within eighteen months, the mediation process resulted in a written agreement on the monitoring of the area, including the definition of future uses. This became effective in form of a NATURA2000 decree in October 2003. Moreover, an advisory committee was appointed for further cooperation and tasked to deal with an additional protocol containing all positions and suggestions on which no agreement had been reached.

The procedure has shown that various factors combined towards a successful participation process:

- timely start;

- involvement of everyone concerned;

- clear rules of procedure encouraged participants confidence in the process;

- clarity about aims and limitations of participation;

- identical information for everyone;

- clarity about roles in the procedure;

- intensive preparation and post-processing of every round of negotiations;

- adequate time frame for the entire process; in this case, eighteen months;

- mediators' expertise and cultural competence (language!);

- mediators in charge of open and respectful communication style among everyone involved;

- adequate flexibility in terms of content and organisation of the procedure;

- binding character of results: a decree, in this case.

It was found that further integration of people concerned in the implementation process was required, which is why an advisory committee was appointed.

When it comes to allocations, a win-win situation may be illusory. What is more important is to ensure that public and private costs and benefits are allocated fairly.

\subsubsection{Virtual worlds - real decisions: modelling the Alps (NRP 48 Synthesis 5) Workshop 3/2}

\author{
Moderator: \\ Eckart Lange (Department of Landscape, University \\ of Sheffield, UK) \\ Introduction \\ A model is an abstraction of the real world. We use \\ models quite frequently, not just in a scientific context but \\ also in our everyday lives. They include traditional maps. \\ In recent times, it has also become possible to access \\ 3D-visualisations of the real world (Lange 2001) on the
}


Internet, for example via Google Earth. In a decision-making context, models are not only used to represent an existing situation, they are also used to predict and assess the effects of potential changes (Bishop \& Lange 2005). In his framework for landscape planning, Steinitz (1990) distinguishes between representational models (e.g. maps, visualisations), process models (e.g. climate change models), evaluation models (e.g. evaluation of landscape qualities), change models (e.g. scenarios), impact models (e.g. evaluation of impacts of proposed changes) and decision models (e.g. how to reach a decision).

The modelling process itself can involve modelling both visible and invisible features and processes. Modelling outputs can be communicated in abstract (e.g. tables) or realistic format (e.g. 3D visualisation).

Landscape modelling and visualisation as instruments for planning and decision-making (Swiss National Research Programme Landscape and Habitats of the Alps, NRP 48)

In order to show the potentials and limitations of modelling applications in planning and decision-making in the synthesis phase of the NRP 48, all contributions in the field of landscape modelling were reviewed and assessed in terms of their potential for application to decision-making in planning processes (Walz et al. 2007). Modelling contributed to a wide range of aspects of landscape research, e.g., driving forces, patterns and processes as well as impacts of landscape change, and also when it came to linking models and techniques (fig. 7).

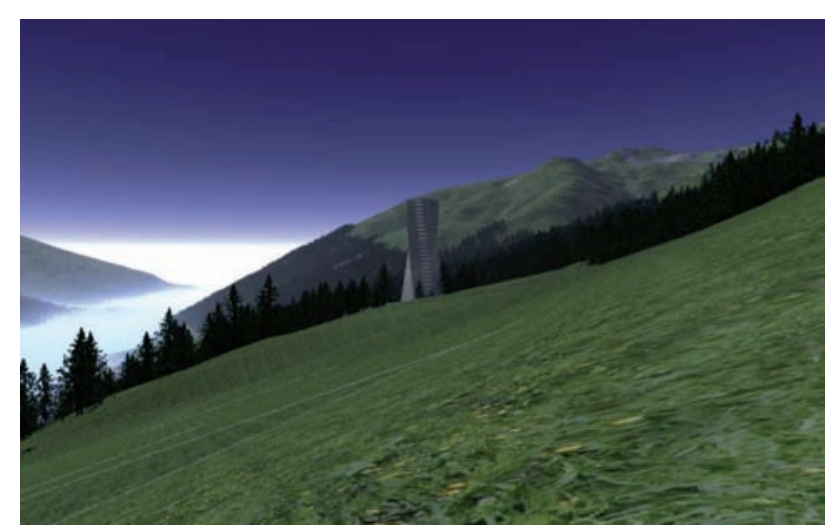

Fig. 7: Frame from an animated virtual walk towards the proposed Schatzalp building (Walz et al. 2007)

The actual synthesis phase extended existing approaches by implementing a modelling procedure including the formulation of "use cases" by transferring the application of an existing agent-based model (Cavens et al. 2005, Gloor et al. 2003) to a new "use case" in Davos. Furthermore, through stakeholder involvement, expectations and thoughts on modelling applications in planning and decision-making were identified.
Micro-simulation of alpine landscape transition due to local agent behaviour and climate change - experiences to support qualitative foresight scenarios from the Montafon Region, Austria (proVIsIon research programme)

Modelling land-use change often refers either to areas in which change turns out to be related to human activities, or related to environmental changes without human interference.

The approach applied on the Montafon region tried to cope with these issues through simulating landscape transition by an agent-based model. Agents (households, farmers, entrepreneurs) change land use actively through construction activities or passively through extensification of agriculture in steep or remote terrain. The GISMo model (fig. 8) further adds some mapping and GIS-functionality to the authors' Repast-ABM environment (http://repast. sourceforge.net) developed earlier (Loibl \& Peters-Anders 2003, Loibl et al. 2007). The actor-agents are here hidden below the model surface but occur as activity results - the agents on the model's landscape are visible as additional buildings due to home-building and tourism activities, and as additional forest patches due to decline of cattle breeding. The transition of land use is thus triggered by land-use change probability surfaces out of a set of topographic and topologic criteria. Climate change in general directly contributes to landscape changes by increasing the frequency of natural disasters, shifting the timberline and changing economic conditions for (winter) tourism, which relies on certain climate conditions.

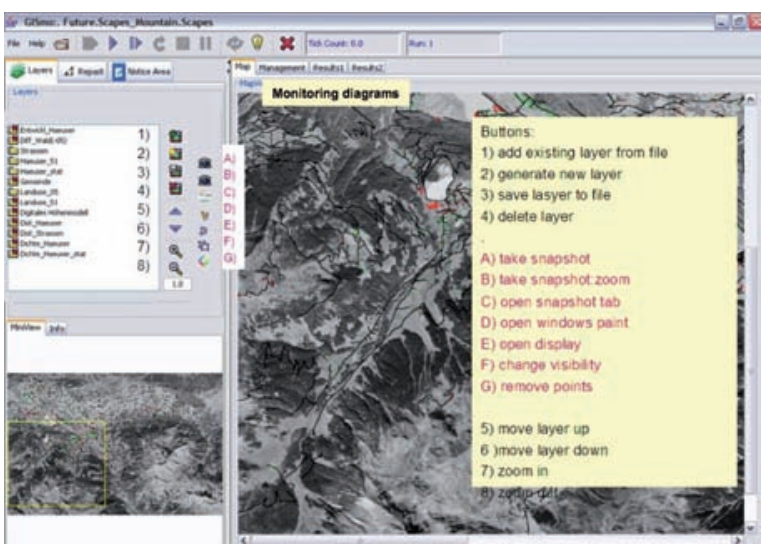

Fig. 8: User interface for the Gismo model showing the Montafon model site (Loibl, proVIsIoN)

\section{Points for discussion}

The two examples from Davos by Ariane Walz (Institut für Schnee- und Lawinenforschung SLFMsL, Davos, Switzerland): Landscape modelling and visualisation as instruments for planning and decision-making) and the Montafon region by Wolfgang Loibl (Umweltplanung, ARC Seibersdorf research GmbH, Seibersdorf, Austria): Micro-simulation of alpine landscape transition due to local agents' behaviour and climate change - experiences 
to support qualitative foresight scenarios from the Montafon Region, Austria) to which landscape modelling was applied generate a number of questions such as

- what are the specific modelling tools needed in planning practice and for decision-making?;

- what is the role of modelling and visualization in decision-making?;

- should modelling be linked stakeholder involvement?;

- what level of accuracy is required in an often timeconstrained decision-making process?

\section{Conclusions}

Experimental approaches via landscape modelling can help to increase our knowledge base in the field of spatial and landscape planning and can assist in decision-making. Simulation models can be represented as virtual worlds where experiments can be conducted and the effect of alternative scenarios demonstrated.

Modelling fulfils functions such as knowledge generation, communication and information, evaluation and also helps in understanding systems to improve decision making.

In a participatory planning context, it is of particular importance that the modelling output can be understood by the end-user. It must also be rememberd, however, that models are often characterised by a (high) degree of uncertainty due to underlying base data or the actual modelling process itself. However, data availability and accessibility has been improving and the functionality and interfaces of models are becoming more sophisticated. The question should also be raised why models and resulting data are typically not made available to the public even though many research projects are financed by publicly-funded research agencies.

\section{Outlook}

Models will become increasingly important in assisting complex decision-making processes in landscape and environmental planning. However, models are often designed for a specific purpose. That is why it is often quite a complex task to transfer models to different regions and / or scales and to integrate them with other models that were most likely created for a different purpose, region and scale. Improved data availability and modelling functionality, wider accessibility as well as easier-to-use interfaces will help to overcome these obstacles.

\section{References}

Bishop, I. \& E. Lange 2005 (eds.): Visualization in Landscape and Environmental Planning. Technology and applications. Taylor \& Francis, London, New York.

Cavens, D., C. Gloor, E. Lange, K. Nagel \& W. A. Schmid 2005
Using Autonomous Agent Simulation as an Integrative Approach to Landscape Modelling. In: E. Lange \& D. Miller (eds.) Our shared landscape. Integrating ecological, socio-economic and aesthetic aspects in landscape planning and management. NSL, Zürich, 26-27.

Gloor, C., D. Cavens, E. Lange, K. Nagel \& W. Schmid 2003: A Pedestrian Simulation for very Large Scale Applications. In: A. Koch \& P. Mandl (eds.): Multi-Agenten-Systeme in der Geographie. Klagenfurter Geographische Schriften, 23, 167-188.

Lange, E. 2001: The limits of realism: perceptions of virtual landscapes. Landscape and Urban Planning 54, 163-182.

Loibl, W. \& J. Peters-Anders 2003: Transition von suburbanen und ländlichen Landschaften und deren Simulation mittels Agenten. A. Koch \& P. Mandl (Eds.): Multi-Agenten-Systeme in der Geographie. Klagenfurter Geographische Schriften, 23, 89-122.

Loibl, W., T. Tötzer, M. Köstl \& K. Steinnocher K. 2007: Simulation of polycentric urban growth dynamics through agents - Model concept, application, results and validation. In: E. Koomen, J. Stillwell, A. Bakema \& H. Scholten, (eds.), Modelling Land-Use Change - Progress and applications. Springer, Dortrecht, 219235.

Steinitz, C. 1990: A Framework for Theory Applicable to the Education of Landscape Architects (and other Environmental Design Professionals). Landscape Journal, vol.9, No. 2, 136-143.

Walz, A., C. Gloor, B. Allgöwer, P. Bebi, A. Fischlin, E. Lange \& K. Nagel 2007 (in press): Virtuelle Welten - Reale Entscheide? NFP48 Synthese V. VDF, Zürich.

\subsubsection{Strategic Environmental Assessment and Alpine landscape development Workshop 3/3}

\section{Moderators: \\ Benedetta Castiglioni \& Massimo De Marchi (Dipartimento di Geografia, Università di Padova, Italy)}

EU Directive 2001/42/CE introduced the SEA (Strategic Environmental Assessment) in EU legislation. Prior to adoption, plans and programmes should be accompanied by an Environmental Report and submitted for consultation; results of consultation and observations have to be considered in final decisions. SEAs also define monitoring and evaluation provisions to be put in place during programme implementation.

Countries and regions in the EU have been adopting SEA directives, defining guidelines to evaluate sectorial or territorial plans and programmes. In this context, many questions arise concerning the relationship between SEAs and landscape:

- Is the SEA a suitable evaluation process for alpine landscape issues?

- How can SEA performance be improved by inserting landscape critical analysis and evaluation in SEA processes?

- Considering the role of territorial agents (insiders 
and outsiders) in alpine landscape decision making, is the SEA a suitable tool to take this dimension into account?

Benedetta Castiglioni provided in her input presentation („SEA and regional planning: the place of landscape change in the alpine region") some reference points concerning both SEA and landscape (firstly from the European Landscape Convention), in order to point out the context in which to consider their relationship.

In particular, landscape-change evaluation plays a very important role in a strategic assessment aiming at sustainability. The presentation drew attention to how different approaches to landscape evaluation arise from different theoretical and methodological approaches to landscape (in synthesis: landscape as a sectorial or a holistic concept; landscape in its strictly visual aspect or as an empirical manifestation of territory; exceptional place or ordinary landscape; conservation and protection or change management; "élite" or "democratic" landscape; landscape as a commodity or as a resource for living). The presentation underscored that landscape critical analysis and evaluation could usefully be inserted in SEA processes because it is a useful tool to ensure coherence among various aspects (i.e. in the Environmental Report); it strengthens the possibility of including and making visible different agents' points of view; it encourages imaginative scenarios; and, finally, it can help placing territorial and environmental analysis and participatory processes into useful relationships.

The second input presentation was held by Viviana Ferrario (Università luav di Venezia, Italy) on „Post-rural landscapes in the Alps in contexts of abandonment, mountain agriculture and leisure - Evaluation: perceptions and decision-making". She presented a case study in the alpine region concerning an ongoing process of landscape change and its evaluation.

Researchers are well aware of the fact that the rural Alps are at the intersection of two global processes, i.e., the decline of mountains as life spaces and the decline of agriculture as an economic activity. The decline of the traditional alpine agro-pastoral economic system has visible consequences, i.e. in the guise of slope abandonment, reafforestation, urbanisation of the valley floor, industrialisation of agriculture.

In the Veneto mountains (and in many other parts of the Alps), this process expresses itself particularly in the aspects of abandonment and transformation of rural sloped areas and of historic rural buildings considered "no longer useful to rural activity". Planners usually approach the issue of abandoned rural buildings in the context of heritage conservation of the traditional rural landscape. However, such buildings are not only relicts of a dead world. Their increasing re-use as weekend homes - and mostly the transformation of their rural context into leisure landscapes - seems to suggest the existence of a new way to relate to rural mountain territories. This may be reflected by major landscape changes, often creating local conflicts (between the different agents involved - local inhabitants, owners, tourists, local administration, etc. - but also with the environment and heritage conservation agencies), and a demand for specific policies for these "new" territories. The creation of such policies requires a refined assessment effort in which landscape changes must be considered not only as regards their physical components, but also as regards the transformation of public perceptions, ideas and the different "aspirations of the public" concerning landscape, in the new sense given by the European Landscape Convention. A case study in the Veneto mountains (Comelico Valley) was presented in this workshop to simulate a possible use of the landscape notion in the assessment process.

Fig. 9: Scale of Obliged Priority

\begin{tabular}{|c|c|c|c|c|c|c|c|c|c|c|c|c|c|c|c|}
\hline $\begin{array}{l}\text { Landscape evaluation } \\
\text { criteria }\end{array}$ & $\begin{array}{r}\text { group } \\
1\end{array}$ & $\begin{array}{r}\text { gr. } \\
2\end{array}$ & $\begin{array}{r}\text { gr. } \\
3\end{array}$ & $\begin{array}{r}\text { gr. } \\
4\end{array}$ & $\begin{array}{r}\text { gr. } \\
5\end{array}$ & $\begin{array}{r}\text { gr. } \\
6\end{array}$ & $\begin{array}{r}\text { gr. } \\
7\end{array}$ & $\begin{array}{r}\text { gr. } \\
8\end{array}$ & $\begin{array}{r}\text { gr. } \\
9\end{array}$ & $\begin{array}{l}\text { gr. } \\
10\end{array}$ & $\begin{array}{l}\text { gr. } \\
11\end{array}$ & $\begin{array}{l}\text { gr. } \\
12\end{array}$ & $\begin{array}{l}\text { gr. } \\
13\end{array}$ & $\begin{array}{l}\text { gr. } \\
14\end{array}$ & $\begin{array}{r}\text { Shared } \\
\text { list }\end{array}$ \\
\hline Local identity & 14 & 4 & 1 & 3 & 6 & 1 & 1 & 4 & 5 & 7 & 2 & 1 & 2 & 2 & 1 \\
\hline Biodiversity & 1 & 5 & 12 & 2 & 15 & 9 & 3 & 2 & 1 & 1 & 4 & 4 & 4 & 5 & 2 \\
\hline Cultural heritage conservation & 4 & 3 & 3 & 9 & 5 & 5 & 2 & 3 & 6 & 6 & 14 & 7 & 5 & 6 & 3 \\
\hline Hydro-geological stability & 6 & 6 & 11 & 1 & 1 & 10 & 8 & 1 & 9 & 2 & 3 & 6 & 9 & 11 & 4 \\
\hline Participation of stakeholders & 3 & 10 & 10 & 5 & 13 & 3 & 9 & 6 & 10 & 10 & 5 & 2 & 11 & 1 & 5 \\
\hline Social impact & 5 & 11 & 5 & 7 & 4 & 7 & 11 & 9 & 3 & 8 & 15 & 8 & 10 & 3 & 6 \\
\hline Aesthetics & 7 & 1 & 4 & 11 & 16 & 2 & 4 & 11 & 8 & 13 & 13 & 13 & 1 & 4 & 7 \\
\hline Information of stakeholders & 2 & 9 & 9 & 4 & 14 & 10 & 10 & 5 & 4 & 9 & 6 & 3 & 13 & 12 & 8 \\
\hline Demographic stability & 12 & 12 & 2 & 6 & 11 & 6 & 13 & 8 & 7 & 11 & 1 & 5 & 10 & 7 & 9 \\
\hline Panorama & 9 & 2 & 6 & 12 & 9 & 4 & 7 & 13 & 11 & 3 & 16 & 16 & 3 & 10 & 10 \\
\hline Noise & 11 & 7 & 7 & 13 & 2 & 8 & 6 & 16 & 15 & 4 & 10 & 14 & 8 & 15 & 11 \\
\hline Tourist attractiveness & 8 & 15 & 15 & 10 & 12 & 13 & 12 & 7 & 9 & 14 & 8 & 12 & 6 & 8 & 12 \\
\hline Smell & 15 & 8 & 8 & 14 & 3 & 12 & 5 & 15 & 16 & 5 & 11 & 15 & 7 & 16 & 13 \\
\hline New jobs & 13 & 16 & 14 & 8 & 7 & 14 & 14 & 10 & 12 & 12 & 12 & 11 & 16 & 9 & 14 \\
\hline Income increase & 10 & 13 & 16 & 16 & 8 & 16 & 16 & 14 & 13 & 15 & 7 & 10 & 15 & 13 & 15 \\
\hline Land rent increase & 16 & 14 & 13 & 15 & 10 & 15 & 15 & 12 & 14 & 16 & 9 & 9 & 14 & 14 & 16 \\
\hline
\end{tabular}


After the two input presentations, participants were involved in the creation of a SoOP (Scale of Obliged Priority) concerning landscape evaluation criteria. They first proposed a "theoretical", graded list of priorities arising from the discussion of small groups and summarised in a "shared" list. In the table (fig. 9) the different columns present the opinion of the small groups and the "shared" list (assigning 1 to the most, 16 to the least important criteria).

In the ensuing discussion the list was applied and compared with the "hypothetical" lists (priorities hypothetically given by different local territorial agents) standing beneath the different landscape-change choices presented by $\mathrm{V}$. Ferrario for the case study.

The workshop discussion focused on the general question of landscape evaluation rather than on technical aspects of the SEA; different positions arose concerning landscape evaluation criteria, probably linked also to different landscape contexts in the alpine region each participant referred to.

In this sense, it would probably be very useful to have a wider discussion on these topics, not to force a standardization of criteria, but to achieve a higher and shared awareness of the complexity of landscape issues, both in their theoretical and applied aspects.

\subsubsection{Cooperation in European mountains - the example of the Alpine and Carpathian Conventions Workshop 3/4}

\section{Moderator:}

\section{Harald Egerer (Interim Secretariat of the Carpathian Convention, United Nations Environment Programme, Vienna, Austria)}

\section{Leading questions}

What are the main substantive (research) areas in need of / with potential for cooperation, within the Carpathians and between the Carpathians and other mountain ranges? How can research partnerships between mountain regions be encouraged? What are possibilities for public-private partnerships and possible funding sources?

These questions were discussed by a panel with contributions by Regula Imhof (Permanent Secretariat of the Alpine Convention, Innsbruck, Austria), Gianfranco Tamburelli (Institute for International Legal Studies IsGI, National Research Council CNR, Rome, Italy), Marc Zebisch (European Academy Eurac, Bozen/Bolzano, Italy) and Jacek Kozak (Jagellonian University, Krakow, Poland).

\section{Conclusions}

The Workshop was organized at the ForumAlpinum 2007, which is the leading symposium on research in the Alps organized by IscAR (International Scientific Committee on Research in the Alps). The Workshop was mainly attended by some of the leading European institutions for remote sensing, satellite imagery and 3D modelling in the Alps, who express a major interest in becoming active in the Carpathian mountain range.

A first consideration was that there is a lack of Pan-Carpathian, and of panalpine mountain research as well. As there is a growing interest in research in the Carpathians, there is considerable potential for research cooperation between the Alps and the Carpathians. In the case of the Carpathians, it seems currently easier to strengthen research cooperation between mountain ranges than within one mountain range.

Political processes (including e.g. Alpine and Carpathian Conventions, Conventions under development) should aspire to define main needs of research and coordinate research efforts. For this, a "research agenda" needs to be defined by the Conventions. Convention secretariats cannot keep large databases but could act as „spiders in the web" and maintain minimum harmonised datasets. Research agendas for mountain ranges should be mutually interlinked and never loose sight of the pan-European agenda (INSPIRE etc.). Research networks need to be enhanced, e.g. a research network for the Carpathians is required and cooperation with the Forum Alpinum for this purpose should be sought.

\section{Recommendations}

- create a "research mailing list" for the Carpathians, organize a meeting in Vienna, link it to upcoming ESF and Cost research workshops;

- build up a Carpathian Network of Scientists by organising an open science meeting on research in the Carpathians („ForumCarpaticum“);

- $\quad$ prepare a Carpathian Research Agenda;

- develop the idea of a Carpathian or Alpine-Carpathian Research summit (e.g. in conjunction with COP2);

- create a voluntary informal partnership aiming at enhancing the Carpathian research agenda and its interrelations with the Alps, with other mountains in Europe, and with the rest of the world;

- create a complete „baseline" of the Carpathians before transition (e.g. 2005) based on remote sensing / satellite imagery / 3D modelling of, in particular, land cover information of the Carpathian mountain range;

- used this baseline to analyse mid and long-term changes of land cover in the Carpathian Mountains, a major indicator for almost all sectors concerning a "territorial" Convention. 


\section{Plenary Session 4: Landscape's role in a changing society}

\subsection{Summary}

\section{Moderator:}

\section{Hans Karl Wytrzens (Institut für nachhaltige Wirtschaftsentwicklung, Universität für Bodenkultur ВокU, Vienna, Austria)}

The concluding Plenary Session focused on interactions between landscape development and societal change. From a socio-economic perspective, this focus was an essential complement. While, in the course of the forum, numerous contributions addressed on valuation and analytical tools to monitor landscape development in mountain areas, specific societal objectives as such were not explored. A more rounded and more easily comprehensible impression of how to qualify landscape changes can only emerge if societal values and needs related to landscape become part our considerations. The Plenary Session therefore specifically examined interrelations between the demand for landscape and land(scape)-use. In doing so, a shift in temporal perspective occurred, from more retrospective analyses towards a primarily forwardlooking view. Accordingly, presentations used various approaches to explore landscape as an object of societal demands, as a negotiable resource and, finally, as a multifunctional space.

Using results from research projects such as the EU-funded SENSOR Project for the development of sustainability impact assessment tools for environmental, social and economic effects of multifunctional land use in European regions, and using results of integral research programmes such as the Swiss National Research Programme 48 "Landscapes and Habitats in the Alps", presenters traced, analysed and projected current trends in landscape development. Their ultimate goal was to find answers to the perhaps somewhat dramatic key question of the significance of mountain landscapes in future societies.

In this context and in a process of free association, various subordinate questions imposed themselves:

- Does our society actually perceive landsape primarily as that proverbial ,stage' on which the great play of the world is enacted?

- Is and will landscape remain a record of all human activities that was not originally or deliberately shaped or perceived, and that has its own very strong dynamics?

- Is landscape increasingly being transformed into a designable resource?

- Will the mountains in the heartland of Europe be re- duced to forming a mere backdrop for fun and leisure activities?

- Will the Alps be reduced to becoming a refuge for the ageing upper class?

- Is landscape slowly turning into a luxury commodity for the overfed, affluent masses, subject to constantly changing fads, fashions and designer spleens?

The diversity of answers provided by the social and economic sciences demonstrate the complexity inherent in the very term "landscape", a complexity that also emerges from the questions raised above.

- Bernard Debarbieux (Département de Géographie, Université de Genève, Switzerland):

Social demand for landscapes

This presentation proposed an analysis of the contemporary status of landscape in European societies whose collective and institutional territorialities are undergoing major transformations.

The analysis drew on Hannah Arendt's essay, The Human Condition (1958), which, admittedly, does not deal with landscape. However, it relies on a clear distinction between three kinds of human activities

- labour, work and action - which can be used to understand conceptions and the social relevance of landscape in various contexts. The analysis argued that landscape, whose main significance for centuries has been landscape-as-labour and landscape-as-work, is increasingly conceived as action, especially when introduced in collective debate and formal participation. To Arendt action was the source of definition of the subject's political identity and, at the same time, the modality through which men and women in society defined what they had in common and what they placed at the core of public space.

Debarbieux's findings, i.e. that pluralistic societies generate ever more sweeping, heterogeneous and occasionally contradictory demands on landscapes, extend to various levels: they are as true for work and working-out in landscapes in response to physiological needs, as for the production of landscape as a cultural, more or less stable artefact, and even for landscape as a result of human interaction in public space. 
- Bernard Lehmann (Institut für Agrarwirtschaft IAW, ETH Zürich, Switzerland):

Landscapes: from by-product to resource - selected conclusions from the Swiss NRP 48 „Landscapes and Habitats of the Alps"

Similarly, Lehmann discerned two contrasting sides to the phenomenon of landscape, whose position seems to be shifting from scarcely registered by-product to separately appreciated resource whose valuation prompts new questions, in particular that of who shall own what rights in this complex landscape-generating system. In the course of the discussion, the fundamental question was raised of whether the concept of landscape as merely a construct of the human mind might not overlook the fact that landscape development occasionally escapes human influence, with nature's own dynamics imposing itself.

- Norbert Kräuchi (Swiss Federal Institute for Forest, Snow and Landscape Research WSL, Birmensdorf, Switzerland) \& Katharina Helming (Leibniz-Centre for Agricultural Landscape Research ZaLF, Münchenberg, Germany):

Assessing land-use impacts on landscape goods and services - the specific case of mountain landscapes The principle of multifunctionality simultaneously considers a variety of social, economic and environmental goods and services related to land use. It is thus a key to sustainable development of land and rural areas. Land-use planning and policy-making seek to support the economic competitiveness and sustainable development of rural areas. Efficient Impact Assessments require policy makers to be given tools for assessing anticipated policy impacts on a wide range of sustainability issues across European regions. The EU-funded Integrated Project SENSOR develops ex-ante Sustainability Impact Assessment Tools (SIAT) to support decision-making on policies related to multifunctional land use in European regions. This paper provides an overview on the analytical approach in SENSOR and documents preliminary results focusing specifically on mountain landscapes. Special attention will be paid to identified shifting key issues in mountain regions and the need for better coordination and dissemination of experiences between regions and countries.

Kräuchi and Helming addressed impacts on sustainability that society should expect from various land-use options. They presented the main features of a model that permits running through various impact parameters to assess their landscape-changing effects. The model provides information for decisions on future landscape development, information that is required more and more urgently because of a notable shift in the fundamental relationship between humans and landscape, insofar as a casual co-product is trans- forming into an autonomously perceived object of political action.

The forum has shown that a wide range of scientific findings on mountain landscape development is already available. Nevertheless, changes in societal demands on landscapes are expected to continue, which means that ongoing, targeted research will be required also. 


\subsection{Key input contributions to Plenary Session 4: extended summaries}

\subsubsection{Social demand for landscapes}

\section{Bernard Debarbieux (Département de Géographie, Université de Genève, Switzerland)}

\section{Keywords}

Landscape, work, social representations, political meaning

If political approaches take the lion's share in the analysis of territory and territoriality, they are proportionately less numerous when it comes to landscape. Moreover, most political analyses of landscape, often inscribed within a historiographical project and cultural studies, have focused on the staging of monarchical and aristocratic power and on landscapes emblematic of national imageries and texts devoted to the contemporary political dimension of landscape in modern or hyper-modern societies are less numerous. This paper proposes an analysis of the contemporary status of landscape in European societies which are experiencing major transformations of their collective and institutional territorialities.

The analysis strongly draws upon an essay by Hannah Arendt, The Human Condition, written in 1958. While it does not deal with landscape, and only marginally with territoriality, it does evoke, here and there, national territories among the products of modernity. It also proposes a reflection on the vita activa and the different forms of activities which characterise the human condition; with regard to these activities, it is possible to question the status of landscape. One of the advantages of this exercise lies in the fact that it allows to emphasise the diverse meanings of the notion of landscape and to highlight the contemporary - notably political - stakes of its practices.

In The Human Condition, Arendt, sceptical of any abstract statement concerning human nature, strives to define the human condition as it is conditioned by our existence on earth and our material environment: "The earth is the very quintessence of the human condition" (2). Her project aims more specifically to investigate "those general human capacities which grow out of the human condition" (6); in other words, men's [and women's] embeddedness within the terrestrial world, within a world of objects and interactions. If this project could be described as philosophical anthropology, it also emerges as a political philosophy of action. Indeed, Arendt proposes to distinguish three categories of human activity:

- labour, a response to the basic physiological needs of man - especially food. Labour satisfies those needs in an ever-ephemeral way and necessarily needs to be continuously renewed in order to ensure the survi- val of the individual and of the species; Arendt links labour to the animal laborans' activity;

- work, product of homo faber, which corresponds to enduring artificial objects transmitted from individual to individual, from generation to generation, and whose sum constitutes a range of cultural artefacts;

- and, finally, action, which "goes on directly among men" (7) and relates them to each other through acts and words: "Speech and action reveal this unique distinctness [of man]. Through them, men distinguish themselves instead of being merely distinct; they are the modes in which human beings appear to each other, not indeed as physical objects, but qua men. This appearance, as distinguished from mere bodily existence, rests on initiative, but it is an initiative from which no human being can refrain and still be human" (176). Thereby, Arendt considers action simultaneously the source of the definition of the subject's political identity and the modality through which men in society define what they have in common and what they place at the heart of the public space.

Arendt anchors her analysis of modernity in this ternary conception of human activity. According to her, modernity marks the triumph of homo faber and of the animal laborans over the political identity of the subject, which was essential in classic antiquity. She sees this triumph as the outcome of many factors, in particular the priority given in our modern civilization to economic production, and to the constitution of nation-states and national societies.

Though apparently remote, at first sight, from the question of landscape, Arendt's proposition presents analytical advantages which permit to apprehend landscape under the different status it was endowed with in Western modernity. I begun by presenting landscape in its status of landscape-as-labour and landscape-as-work; their complementarity and simultaneity are at the heart of the modern conception of landscape. I then pursued the question of the complex status of landscapes in contemporary societies and identified a landscape-as-action which, though not complying entirely with Arendt's historiographical perspective, appears to have emerged, under some peculiar circumstances, in recent decades.

Taking into account the academic context of this conference, all case studies presented were alpine or related to mountain landscapes. 


\subsubsection{Landscapes: from by-product to resource - selected conclusions from the Swiss NRP 48 „Landscapes and Habitats of the Alps"}

\section{Bernard Lehmann (Institut für Agrarwirtschaft, IAW, ETH Zürich, Switzerland)}

\section{Keywords}

Land use and adding value, change, perception, policies, virtual representation

NRP 48 was launched in 2000 with five main topics to be developed simultaneously in order to

- show and understand processes of change affecting landscapes and habitats; and identify main reasons and drivers [change];

- show and understand how landscapes and habitats are perceived; and identify reasons for differences in perception among various segments of the population [perception, appreciation];

- show and understand what institutional frameworks can identify needs for action and design collective goals of landscape development; and how appropriate policies can be implemented in a participatory, consensual process [policies, incentives];

- show and understand what potentials of adding value have existed, and continue to exist, considering the increased relevance of landscape [land use and adding value];
- show existing possibilities of predicting variations in landscape development based on computer simulations that take various parameters into account (landscape use, incentives, climate change, etc.) [virtual representation].

It was a further objective of NRP 48 to achieve a systemic view of landscapes, their relevant actors and sub-systems (fig. 10):

- human use of natural resources available in specific areas (use, protection);

- primary use of natural resources resulting in cultural landscapes as a by-product which, over the past decades, has itself become a resource of further forms of land use;

- settlement areas very strongly impact on and (mis-)use both natural and cultural landscapes;

- tourist use of landscape (natural and cultural landscapes) represents an important economic factor in the alpine area; the tourist sector particularly needs to address sustainability issues and principles (complementary and substitutional relationships between added value and estimated quality of landscape);

- "public use” of landscape as use value, option value or existence value. The more society is affected and the greater the value attributed by society, the stronger public desire grows to control changes and implement appropriate policies;

- a further result from the above is a particular challenge facing those involved in the process of ad-

Fig. 10: systemic view of landscapes, their relevant actors and sub-systems

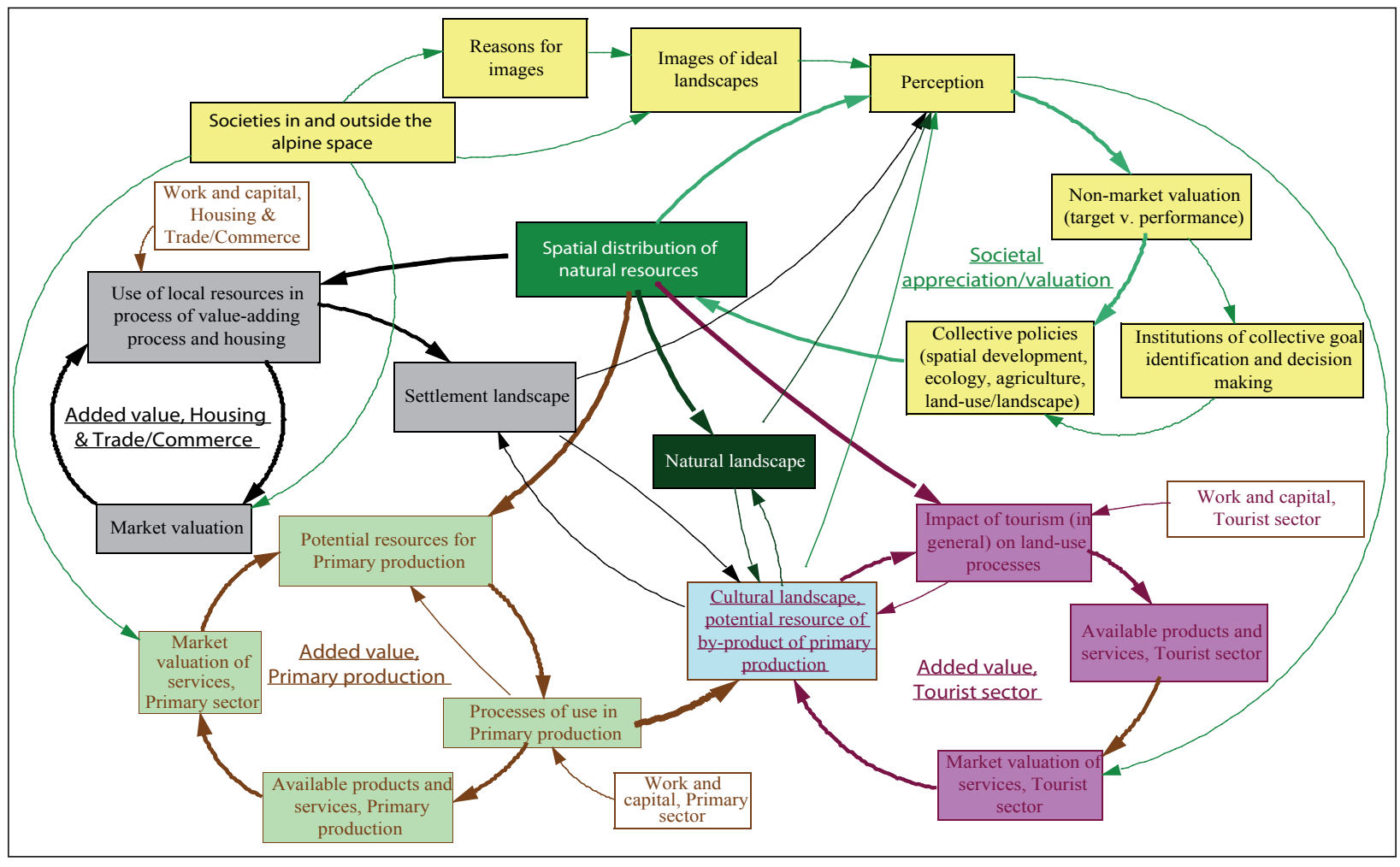


ding economic value, which is to achieve a balance between the production of private / public goods and the provision of private / public services.

The results of these studies have been published in various scientific journals. Moreover, in 2006/2007, the NRP published five thematic synthesis reports:

1) „Alpenlandschaften - Von der Vorstellung zur Handlung" (Alpine landscapes - from image to action)

2) "Landnutzung und biologische Vielfalt in den Alpen" (Land use and biodiversity in the Alps)

3) "Landschaften gemeinsam gestalten - Möglichkeiten und Grenzen der Partizipation" (Shaping landscapes together - potentials and boundaries of participation)

4) "Den Wert der Alpenlandschaften nutzen" (Using the value of alpine landscapes)

5) „Virtuelle Welten, reale Entscheide - Die Alpen in der Modellwelt" (Virtual worlds, real decisions - modelling the Alps)

In autumn of 2007, the Steering Committee will publish a final document entitled "Landschaften und Lebensräume der Alpen zwischen Wertschöpfung und Wertschätzung - Reflexionen zum Abschluss des nationalen Forschungsprogramms 48" (Landscapes and Habitats of the Alps: appreciating and valuating/adding value - reflections on the completion of NRP 48).

\subsubsection{Assessing land-use impacts on landscape goods and services - the specific case of mountain landscapes}

Norbert Kräuchi (Swiss Federal Institute for Forest, Snow and Landscape Research WSL, Birmenssdorf, Switzerland)

Katharina Helming (Leibniz-Centre for Agricultural Landscape Research ZaLF, Münchenberg, Germany)

\section{Keywords}

Land use impact assessment, landscape goods and services, sustainable development, multifunctional land use, mountain landscapes, global change

Land use is one of the key pressures translating economic, political and other driving forces into environmental and social impacts on landscapes. The motivation of planners and policy makers to interact with land use is devoted to the principle of sustainable development, which in turn is considered to be intrinsically linked to the concept of multifunctionality (Wiggering et al., 2003). The basic principle of multifunctional land use is to consider social, economic, and environmental effects of any land use action simultaneously and interactively, to include those of commodity production and those of negative and / or positive externalities. These effects are linked to "functions" or "goods and services" in the landscape context, which cover aspects of production, regulation, habitat and information (Costanza et al., 1997, De Groot et al. 2002). The multifunctionality of any land use action then lies in the degree to which it affects each of these functions as well as their interactions. Based on the knowledge on these functional relationships stakeholders and the civil society will have to negotiate targets and achieve trade-offs for land use decision making in order to best fit their specific priority list of demands for landscape goods and services. According to this definition, multifunctional land use is not an absolute term describing the outcomes of any land use in a specific bio-geo-physical setting, but is rather a description of the relation between functional performance of land use on the one hand, and of societal demands for these functions on the other hand (Barkmann et al., 2004; Potschin and Haynes-Young, 2005).

For competent decision making, stakeholders require knowledge on possible sustainability impacts of any land use option. This type of ex-ante knowledge can be generated by scenario-based land-use change models that generate data relevant to ecological, economical and socio-cultural landscape functions (Zander et al., 2007). By using indicators that translate land-use model parameter measures into simple and meaningful data on the likely outcomes on environmental, social and economic sustainability issues, stakeholders may obtain information on the likely results of particular decisions.

This paper reports on the conceptual design and preliminary research results of the EU Integrated Project SENSOR (www.sensor-ip.eu), which develops ex-ante Sustainability Impact Assessment Tools (SIAT) to support decision making on policy options related to multifunctional land use in European regions (Helming et al., 2006). SIAT is based on 3 key assessment approaches:

1) Europe-wide, model and indicator-based impact analysis of land use driving force scenarios and optional policy interventions for projection years 2015 and 2025;

2) region-specific problem, risk and threshold assessment making use of spatial reference systems and participatory processes; and

3) case-study-based sensitive area studies using detailed information on sustainability issues. SIAT operates on a regional scale for the countries of the European Union and is based on existing, pan-European data.

SENSOR considers policy-driven land-use activities with a spatial dimension. These include agriculture, forestry, tourism, nature conservation, transport, and energy 
infrastructure. The list of regional sustainability issues addressed, include spatially explicit environmental functions (abiotic and biotic resources including soil, water, air, biodiversity), societal functions (social welfare, migration, cultural heritage, recreation, aesthetics) and economic functions (employment, growth).

European mountain regions are one of the sensitive areas, studied within SENSOR. They are of vital importance to the continent's population in many ways, and have been described as, the undervalued ecological backbone of Europe' (EEA, 1999). 9 relevant changing key issues have been identified for Europe's mountain regions (fig. 11):

- outmigration and overageing;

- tourism and recreation;

- traffic networks governed by needs outside mountains;

- jeopardised sustainability of land use;

- climate change impacts;

- mountains as a natural and cultural heritage;

- mountains as watertowers of the lowland;

- mountain soils sensitive to degradation;

- living with risks - natural hazards in mountains. ge in precipitation patterns (Frei et al. 2006). If this trend continues, a strong shift in environmental conditions is to be expected, which will significantly affect the sustainability of ecological services through changes in organism performances and ecosystem functioning, with important socio-economic implications (Stern, 2007).

Different sectoral policies concerning, e.g., agriculture, forestry, tourism and water management, as well as other political institutions, will affect future land use and socioeconomic impacts that result from ecological changes. Thus, an evaluation of policy trends will be required and new policy options will have to be identified that may mitigate negative social, economic and ecological effects of changes described, and to promote more sustainable land-use patterns. These policy options may well require a reallocation of competencies among political actors, the use of new and innovative policy instruments, as well as an integration of different sectoral policies.

In terms of national and European policy implications, many mountain areas have opportunities for development as a result of new information and communication technologies. There is also potential for development

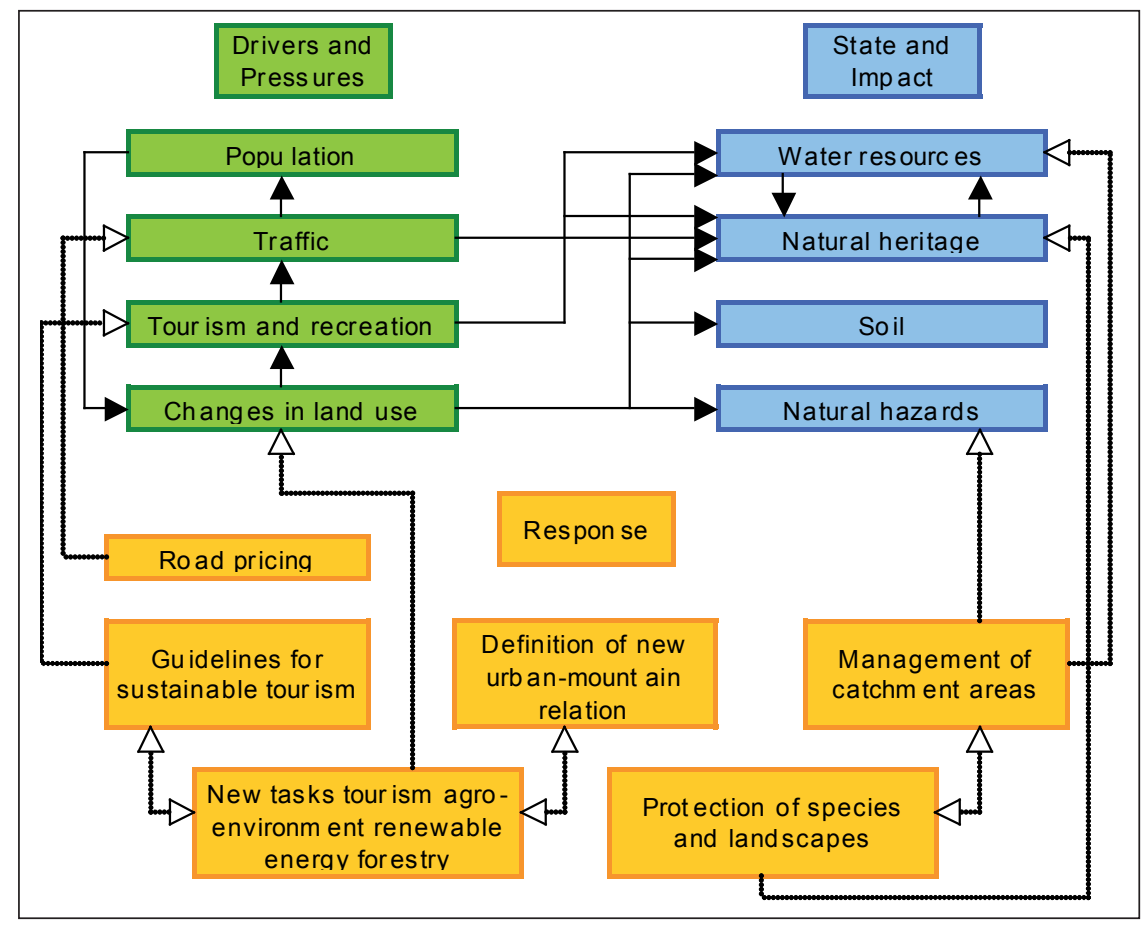

Fig. 11: DPRSI scheme "interactions of key issues in mountain areas" (EEA, 1999)

Specific national and European Commission policies focused on Europe's mountain areas have primarily tended to consider agricultural production, which remains an essential element of mountain economies and cultural identity (Nordregio, 2004). The vertical topographic dimension as the basic and characteristic element of mountains introduces specific features relating to global change issues. Mountain regions such as the Alps have experienced a higher than global average temperature shift and a chan- as centres of recreation for urban dwellers, although this must be managed in a sustainable way that ensures nature protection. Given the great diversity in national approaches to mountain issues, there is much to gain from better coordination and dissemination of experiences between regions and countries. Networking between various players (institutions, communities, enterprises) is therefore important in cross-border co-operation at different levels - within as well as between countries. International 
cooperation is essential not only for the mountain areas themselves, but also for the lowland areas they separate (Hallenbarter et al., 2006).

The concept of multifunctional land use is key to understanding the complex interactions of commodity production with the rural economy, with rural communities and rural environments. Political systes, policies and governance structures play a crucial role in mitigating the impact of such changes and enhancing sustainable management practices which are economically and ecologically efficient, and socially and institutionally feasible.

\section{References:}

Barkmann, J., K. Helming, K. Müller, H. Wiggering 2004: Multifunctional landscapes: towards an analytical framework for sustainability assessment of agriculture and forestry in Europe. Final Scientific Report. EU FP5 Project EVK-CT-2002-80023.

Cairol, D., E. Coudel, D. Barthélémy, P. Caron, E. Cudlinova, P. Zander, H. Renting, J. Sumelius, and K.H. Knickel 2005: Multifunctionality of agriculture and rural areas: from trade negotiations to contributing to sustainable development. New challenges for research. Summary of main results from the MuLtAGRI project. 23 pp. www.multagri.net

Costanza, R., C. Folke 1997: Valuing ecosystem services with efficiency, fairness and sustainability as goals. In: G. Daly (ed.): Nature's services: societal dependence on natural ecosystems, Island Press, Washington, DC.

De Groot, R. S., M. Wilson, and R. Boumans 2002: A typology for the description, classification and valuation of Ecosystem Functions, Goods and Services (p. 393-408). Ecological Economics 41: 367-567.

Dilly, O., C. Rogaß, C. Dörrie, B.U. Schneider, G. Siebielec, T. Stuczynski, R. Korzeniowska-Puculek, P. Koza, P. Kowalik, R. Lopatka, R. Pudelko,D. Hallenbarter, N. Kräuchi, Z. Imrichová, F. Putzhuber, H. Hasenauer, T.A. Oja, A. Kull, Ü. Mander, S. Moncada, M. Camilleri, S. Formosa, R. Gale, R.F. Hüttl (in prep.): Key sustainability issues and the spatial classification of sensitive regions in Europe. In: Helming, K., Tabbush, P., Perez-Soba, M. (eds.): Sustainability Impact Assessment of Multifunctional land use.

European Environment Agency (EEA) 1999: Environment in the European Union at the turn of the century. Environmental assessment report No 2, Office for Official Publications of the European Communities, Luxembourg.

Frei C., R. Scholl, S. Fukutome, R. Schmidli,P.L. Vidale 2006: Future change of precipitation extremes in Europe: Intercomparison of scenarios from regional climate models. Journal of Geophysical Research-Atmospheres 111: D06105.

Hallenbarter, D., N. Kräuchi, Z. Imrichová, F. Putzhuber 2006: European Mountains in a changing Environment. SENSOR Deliverable 6.1.

Helming, K., L. Firbank, D. Wascher, M. Perez-Soba, S. Sieber, H. Bach, O. Dilly, P. Tabbush, K. Tscherning 2006: Sensor first annual report, public part. In: Helming, K. and H. Wiggering (eds.) SensoR Reporting Series 2006/1. ZaLF, Germany.

Nordregio 2004: Mountain areas in Europe, Analysis of mountain areas in EU Member States, acceding and other European countries, Nordregio Final Report 2004:1, Stockholm, 271 pp.

Potschin, M. and R. Haynes-Young 2005: Multifunktionale Landschaften - Zum Verständnis der nachhaltigen Landschaftsentwicklung. Regio Basiliensis - Basler Zeitschrift für Geographie 46/1: 21-32 (in German).
Stern, N. 2007: The economics of climate change. The Stern review. Cambridge University Press, Cambridge, 692 pp.

Wiggering, H., K. Mueller, A. Werner and K. Helming 2003: The concept of multifunctionality in sustainable land development. In: Helming, K. and H. Wiggering (eds) 2003: Sustainable Development of Multifunctional Landscapes. Springer-Verlag Berlin Heidelberg New York. 286 pp. ISBN 3-540-00008-9. 3-18.

Zander, P., A. Knierim, J. Groot, W. Rossing 2007: Multifunctionality of agriculture: tools and methods for impact assessment and valuation. Agriculture, Ecosystems and Environment. In press. 


\section{Project \& Programme Fairs}

In the first part of the Project \& Programme Fairs, the following input contributions were presented (no abstracts):

- Thomas Schaaf (MAB-Programme, Unesco, Paris, France):

A world-wide network for global change research in UnEsCo-Mountain Biosphere Reserves Information: http://www.unesco.org/mab/

- Harald Bugmann (Environmental Sciences, ETH Zürich, Switzerland):

Activities of the Mountain Research Initiative MRI Information: http://mri.scnatweb.ch/

- Eva Spehn \& Christian Körner (Gмва \& Institute of Botany, University of Basel, Switzerland):

The Global Mountain Biodiversity Assessment GmBA by DIVERSITAS

Information: http://gmba.unibas.ch

- Georg Grabherr (Faculty of Life Sciences, University of Vienna, Austria):

The GLORIA-Initiative (Global observation research initiative in alpine environments)

Information: http://www.gloria.ac.at/

- Silvia Jost (Federal Office for Spatial Development ARE, Ittigen, Switzerland):

European Territorial Cooperation: Outlook on the Alpine Space Programme 2007-2013

Information: http://www.alpinespace.org/

\subsection{Project networking in European Mountains (FP 6, INTERREG III and COST) Project \& Programme Fair 1}

Organiser:

Axel Borsdorf (Institut für Geographie, LeopoldFranzens-Universität Innsbruck, Austria)

It was the objective of the Project and Programme Fairs to provide insights into the application of, the participation in and even the management of internationally funded projects. These insights are based on my own experience in leading $\mathrm{a}^{\text {th }}$ Framework Programme project (COMET) and an INTERREG IIlb Alpine Space project (DIAMONT), on my participation as an Austrian delegate to the Management Committee of two Cost Actions (C 10, A 26), and as an expert or partner institution in several EU-projects (SUPER, Viadventure) and as a member of the Steering Committee of other projects.

The input presentation focussed on the Cost programmes (Actions and Strategic Workshops), the INTERREG A and
B strand, the Framework Programmes of the European Commission and several other programmes, such as Marie Curie and Espon, to which researchers in the Alpine realm might want to apply.

Cost (European Cooperation in the Field of Scientific and Technical Research) was restructured in 2006 to encompass nine domains, of which at least six encourage applications by Alpine researchers. The presentation included the internal structure of COST as well as practical hints for application and participation.

Based on the example of the quite successful Cost Action C 10, the internal structure and the possible results of such actions were demonstrated. Delegates from 14 countries, organized in four working groups (Methods, Structures, Dynamics, Governance), visited the peripheries of European city regions and discussed their findings at length. Eleven case studies produced new knowledge based on inductive and explorative logic. The results were structured in a comparative matrix, instructive sketches and maps, and published in four volumes. An international audience attended the final conference in the Grande Arche of La Défense, Paris.

The INTERREG programme is part of the EfRE initiative of the European Union. It is structured in three strands: Strand $\mathrm{A}$ is dedicated to cross-border cooperation between two European countries. Strand B is made for transnational cooperation involving national, regional and local authorities. It aims to promote better integration within the Union through the formation of large groups of European regions. With programme period IIIb, a proper Alpine space programme was created, in which 51 projects were founded. Strand $C$ is dedicated to interregional cooperation and aims to improve the effectiveness of regional development policies and instruments through large-scale information exchange and sharing of experience (networks). As a rule, only administrative units can participate in strand $C$.

INTERREG IV period begins in 2007. INTERREG IVa projects are quite open, and it is not too difficult to obtain funding for projects. About two thirds of the total funds go to Strand A.

For research projects located in the Alpine arc and including more than two countries, Strand B is rather more challenging. The presentation was based on the example of InTERREG IIIb Alpine Space project DiAmont (Data Infrastructure for the Alps. Mountain Orientated Network Technology), coordinated by the Institute of Geography, University of Innsbruck, to demonstrate proposal, internal structure, research questions, methods and first results 
of such a project. It should be mentioned that within the IVb Strand, the CADSES and the Western Mediterranean programme are suitable for mountain research as well.

The InTERREg IVb Alpine Space programme is focussed on the thematic priorities of "Competitiveness and attractiveness of Alpine space", "Accessibility and connectivity", and "Environment, resources and risk management". Another InTERREg project area is Espon (European Spatial Planning Observation Network). Its objective is to improve the knowledge of spatial development trends at EU level that affect the development of the Union, to encourage the harmonious development of the entire Community, as laid down in Article 158 of the EC Treaty, and to clarify the concept of territorial cohesion referred to in Article 16 of the Treaty. In particular, Espon seeks to study the spatial dimension of economic and social cohesion policy and other EU policies in view of ensuring better co-ordination of decisions which have an impact on spatial planning. The 5 Espon 2013 programme priorities are:

1) Applied research on territorial development, competitiveness and cohesion: Evidence of territorial trends, perspectives and policy impacts;

2) Targeted analyses based on user demand: a European perspective to development of different types of territories;

3) Scientific platform and tools: Territorial indicators and data, analytical tools and scientific support;

4) Capitalisation, ownership and participation: Capacity building, dialogue and networking;

5) Technical assistance, analytical support and communication.

The presentation also included a short introduction to the INTERACT programme.

Finally, the $7^{\text {th }}$ Framework Programme of the European Commission was presented. It is the European Union's main instrument for funding research in Europe between 2007 and 2013, and supports research in selected priority areas. It represents a 41 per cent budget increase from FP6 at 2004 prices.

The programme's internal structure and its thematic areas were presented. Within the four sections of the 7FP, "Cooperation" and „People" may be of special interest for Alp-wide research and cooperation. The Marie-Curie programme is now integrated in the "People" section, including network building in the Marie Curie Research and Training Network programme.

As an example of an FP project, Cомет (Competitive Metropolises) was presented in order to demonstrate the proposal, financing, structure, methods and results of an FP project.

The discussion focused on quite practical questions regar- ding all programmes presented in the input presentation. It became very clear that there is great interest among Alpine researchers to participate in international programmes and projects.

\subsection{Global change research in European mountains: Implementation of the Glochamore Research Strategy and Research Agenda in the multi-annual working programme of the Alpine Convention among the scientific community} Project \& Programme Fair 2

Organisers:

Astrid Björnsen Gurung (The Mountain Research Initiative MRI, Zürich, Switzerland)

Heinz Veit \& Thomas Scheurer (International Scientific Committee on Research in the Alps IsCAR, Berne, Switzerland)

\section{Summary}

Research coordination can enhance the efficiency of the participating research partners and add value to their findings. Larger frameworks (e.g., the Glochamore Research Strategy) or treaties (e.g., the Alpine Convention) may steer research projects and programs in the desired direction. Research coordination may enhance the efficiency of participating research partners and add value to their findings. The workshop identified actions suitable to introduce research frameworks to target audiences in science, administration and NGOs.

\section{Introduction and questions raised}

GlochAMORE (Global Change in Mountain Regions) has been a specific support action of the EU's FP6 aiming at the development of an integrated research strategy to gain a better understanding of the causes and consequences of global change. The participation of 28 UnESCO Mountain Biosphere Reserves (MBRs) and the integration of activities and knowledge from both natural and social sciences was most critical to the development of the strategy. The Glochamore Research Strategy (see http:// mri.scnat.web) is the project's compiled and negotiated product. Both the Mountain Research Initiative (MRI) and UNESCO MAB are committed to working towards the implementation of the strategy, taking into account local specificities of individual Mountain Biosphere Reserves and other mountain areas.

The Multi-Annual Work Programme (MAP) of the Alpine Convention 2005-2010 contains a wide range of targeted political and administrative actions to implement the goals 
of the Alpine Convention. The MAP has been analysed from a scientific point of view and "transformed" into 22 research topics to encourage scientists to provide strategic and action-oriented knowledge. Each topic refers to the actions of the MAP, thereby addressing potential stakeholders in politicy-makers and the public administration. In early 2007, the Research Agenda was still being developed.

The panel and open discussion of this Project Fair aimed at exploring the factors determining whether or not, and how, research recommendations such as the two presented above, are taken into account and implemented in the field. Experiences in research implementation were analysed under three aspects:

1) Communication. What are effective and ineffective communication tools to inform the research community about research recommendations?;

2) Incentives. What factors enhance or hamper the adoption of research priority themes by individual scientists?;

3) Impact assessment. What instruments / indicators are suitable to monitor the success of such research implementation?

\section{Results}

\section{1) Communication}

A major challenge in communicating research recommendations to the targeted audience lies in their extent and complexity. Both amount and complexity need to be reduced and tailored to the targeted audience (e.g., scientists, Biosphere Reserve managers, administrations, media, institutions). Professional translation of scientific messages into a language comprehensible to laymen and politicians could profoundly influence the uptake. Hardcopy publications are viewed as a necessary supplement to electronic information accessible via the internet. Although the target audience, i.e. the scientific community working on mountain topics, is very large, relevant information needs to be personalized and highlighted in the specific context (vs. mass mailing of general messages).

Crucial to the promotion of research recommendations is the involvement of stakeholders in the development of such, i.e. through consultation and participation, before the recommendations are elaborated. Involving stakeholders in the process at an early stage, however, requires adapted planning of research projects or programmes. Stakeholder involvement requires resources (time and money) are rarely available at an early project stage.

Face-to-face meetings in the form of national and international meetings, thematic working groups, summer schools, or exchange visits for practical field experience - all aiming at research implementation - are most important to the promotion of research frameworks for
Global Change research in mountains. Existing science - stakeholder networks and supportive legal and political frameworks can accelerate the uptake of research recommendations.

\section{2) Incentives for implementation}

Due to the long-term nature of Global Change research in mountains, local and regional funding is most important for sustaining research. Consequently, lobbying funding schemes such as the EU's Framework Programmes to consider research priorities such as those outlined in the GlOCHAMORE Research Strategy is one step towards implementing mountain research. In the same vein, research recommendations need to be conveyed together with potential funding opportunities.

Apart from funding, implementation is encouraged if the information package contains the technical or scientific advice necessary for the next step (e.g., methodology handbook or field guide). Similarly, stimulating thematic and regional interest groups (e.g., the "Meteorological Network" or the "Snow Monitoring Initiative" as a part of the Global Change Research Network in European Mountains, GCRN_EM; the building of a Alp-wide network on tourism research to take up topics from the MAP) could be an effective and efficient means towards implementation. However, this requires active and devoted members of the scientific network.

The implementation of specific research recommendations is more likely if recommendations are congruent not only with government policies, but also with topics highly relevant to a specific stakeholder group (e.g., "water" and "climate change" for the Alpine Convention), and can make use of existent research interests, infrastructure and contacts with concerned communities.

\section{3) Impact assessment}

The degree to which research recommendations are successfully implemented can be quantified by numbers of:

a) project collaborations between universities and MBRs or NGOs on recommended topics;

b) MBRs or bodies of the Alpine Convention implementing recommended research;

c) EU projects and proposals (FP7, Cost, INTERREG, etc.) using the GLOCHAMORE Research Strategy or the MAP Research Agenda as an orientation; and

d) research publications referring to GLOCHAMORE or the MAP of the Alpine Convention.

Active regional Global Change research networks and projects such as initiated by the MRI (see http://mri.scnatweb.ch/content/category/3/47/68/) are indicators that the recommendations on paper are implemented in the real world. Annual review meetings and/or a post-project evaluation after 10 years, e.g., for GLOCHAMORE, could serve 
as both an incentive and assessment tools for monitoring implementation of Global Change research in European Mountains.

\subsection{Ecological networks within and into the Alps: from concepts to actions} Project \& Programme Fair 3

\section{Organiser:}

\section{Lisa Bose (Swiss Biodiversity Forum, Berne, Switzerland)}

\section{Introduction: The Ecological Continuum Project}

The four Alpine organisations AlPARC, CIPRA, ISCAR and WWF are working together to contribute to the preservation and sustainable use of biodiversity in the Alps. The aim of the Ecological Continuum Project is to concentrate conservation efforts in order to implement an ecological continuum by connecting regions with high biodiversity values. The ecological continuum will allow the "dynamisation" of nature protection by allowing species to migrate and at the same time develop their habitats. The project will be divided into a pre-project phase of about one year, and a subsequent main project with a duration of at least three years. Within the pre-project the methods of two already existing connectivity concepts (functional approach of the WWF/AlPARC/AlPARC/ISCAR consortium and AlPARC's structural approach) will be assessed and, if necessary, harmonised. An application for funding a preproject is currently under way.

\section{Objectives}

The objective of the Project Fair was to discuss key elements for establishing ecological networks within and into the Alps, to gather existing experiences concerning the most promising measures to improve ecological connectivity, and to find important stakeholders when implementing ecological networks.

\section{Results}

The main focus of the discussion was on the migration of large carnivores in the Alps. An important issue for establishing ecological networks is the high public awareness of problems concerning the migration of large carnivores, e.g. wolves. Studies carried out by CemAGreF, Grenoble, showed that farmers will do almost anything to prevent attempts to earmark areas where the wolves can migrate. Hunters were also identified as important stakeholders. With regard to the migration of brown bears, beekeepers have to be involved, as brown bears can cause considerable damage.

At the Project Fair the concept of networks in fragmented landscapes was critically discussed. It was pointed out that as their habitats are protected, the populations of large carnivores will likely increase, which in itself will automatically lead to the migration of sub-populations. The quality of their habitats is therefore the main determinant for the well-being of a species. Austria, for example, is surrounded by areas where there are good habitats for the lynx and the wolf. Now these populations have begun to migrate to Austria.

Moreover, the question of enough existing space for establishing corridors was raised. In areas with dense human settlements and activities, it could be almost impossible to establish wildlife corridors, as the distance between settlements might be less than $1 \mathrm{~km}$. Studies have shown that the Brown Bear chooses areas for migration that are furthest from settlements.

For plants there would be no real need for connected habitats. In the Alps, high species diversity of plants (e.g. by endemic species) is the result of isolation. Studies showed that genetic diversity hotspots differ from species hotspots.

There is also the question of how to manage a system in which every species can be found everywhere. Ecological networks might suspend the often desired effects of isolation.

\section{Outlook}

The concept of the Ecological Continuum Project will be developed within the context of and in accordance with the Alpine Convention. The IX Alpine Conference (November 2006) decided on the establishment of an „ecological network" platform, with representatives from all contracting parties as well as concerned observers and NGOs. The platform started its work in March 2007. The Ecological Continuum project of the consortium will contribute directly to the activities of the platform of the Alpine Convention. 


\subsection{The Alpine Space Programme: A successful approach to transnational cooperation in the Alpine Space} Project \& Programme Fair 4

Organisers:

\section{Silvia Jost (Swiss Federal Office for Spatial Development ARE, Ittigen, Switzerland)}

\section{Magali Kirchgesser (Joint Technical Scretariat INTERREG IIIB Alpine Space Programme, Rosenheim, Germany)}

The enlarged European Union has challenging territorial disparities, which the Cohesion Policy is aiming to reduce. Since 1989 INTERreg has been one of the funding instruments supporting territorial cooperation among the 268 European regions. This Community Initiative has been financed under the European Regional Development Fund (ERDF) offering financial support for crossborder, transnational and interregional cooperation projects.

During the period 2000-2006, the first transnational EU cooperation programme was launched for the Alps, involving the partner states Austria, France, Germany, Italy, Slovenia, Liechtenstein and Switzerland. The INTERREG IIIB Alpine Space Programme funded forward-looking cooperation projects searching for transnational solutions within the three main working fields of "Spatial planning and competitiveness", "Promotion of sustainable transport systems" and "Management of natural and cultural heritage and the prevention of natural disasters".

Through its cooperation projects, the programme's aim was to foster sustainable spatial development in the Alpine Space. The implementation of 58 projects in the above-mentioned working fields provided an opportunity to test strategies and approaches for European spatial development and to develop transnationally effective solutions. The cooperation projects have been co-financed $50: 50$ by the ERDF and by national funds. In total the available budget for 2000-2006 was $€ 118$ million.

One of the key topics tackled by the programme is climate change, which is affecting the Alps faster and rather more severely than the rest of Europe. Coping with the effects of climate change and its related impacts on settlements, infrastructure, cultural heritage and human life is a major challenge for the cooperation area. Transnational cooperation produces necessary joint solutions.

- As a strategic project, ClimChAlp („„ Climate Change, Impacts and Adaptation Strategies in the Alpine Space") examines the potential impacts of climate change in the Alpine Space, e.g. on the landscapes, and intends to elaborate basic adaptation strategies. Based on screening historical and future climate change scenarios, the forthcoming impacts of and on natural hazards, spatial development and key econo- mic sectors (e.g. tourism, agriculture, forestry) are evaluated and assessed in four thematic work packages. Strategic recommendations will be laid down in a synthesis work package as an input for policy-makers and public administrations on national and regional levels.

The partner states also focused on the protection and promotion of the Alpine cultural heritage. This was done through diverse approaches.

- The Alpine area is known worldwide for its natural characteristics but not for its cultural heritage, which actually deserves the same attention. This was the starting point for the project CulturALP (, Knowledge and Enhancement of Historical Centres and Cultural Landscapes in Alpine Space"). The project's aim has been to preserve and promote historic mountain settlements. The historic settlement system of the Alpine areas constitutes a heritage relevant to local cultures and European identity alike. In order to safeguard this cultural heritage and enhance its potential, the project has taken into account natural aspects as well as characteristics and qualities of historic, artistic, cultural and territorial resources - all in relation to Alpine cultural heritage. Moreover, CulturALP is focused on rules, regulations and instruments for integrated policies, to be able to combine sustainable and long term protection with the enhancement and promotion of cultural heritage in a far-flung territorial framework.

- Alpter ( „Terraced landscapes of the Alpine arc“) deals with a different aspect of cultural heritage, i.e. terraced landscapes. Within this project synergies were developed with the actions and programmes on terraced landscapes by international organisations such as UnESCO and FAO. Terraced areas can be conceived as intermediate landscapes from several points of view, e.g. between artificial spaces and natural environments, or between household horticulture and mechanised monoculture. The current development of such landscapes is a range of processes leading towards opposite extremes: intensification versus abandonment. The AlPTER project was developed to counteract the abandonment of terraced areas in Alpine regions. It is a widespread phenomenon with negative consequences in terms of loss of productive land and biodiversity, increasing hydro-geological hazards and depletion of cultural heritage. The project focuses on three possible ways of managing terraced landscapes: productive recovery and promotion of regional agrarian products; valorisation of tourist appeal by enhancing tourist demand and supply; strengthening their social value and the local communities' sense of territorial identity. 
Finding innovative and shared solutions to face socioeconomic decline and its consequences in peripheral rural areas of the Alps is another challenge the Alpine Space Programme has tackled effectively. The migration of young and dynamic people and the resulting rising proportion of ageing alpine populations, often leads to the dismantling of public services and existing spatial structures in many areas of the Alps.

- The project AlpCity („Local endogenous development and urban regeneration of small Alpine towns") fosters the creation of a polycentric urban system and a sustainable urban-rural relationship in fragile natural environments of the Alps. It aims to raise awareness of the revitalisation of small towns in the Alpine Space area by sharing and improving common knowledge and understanding on key issues. The project promotes and supports local innovative actions and approaches by developing case-studies in the following four topic areas: economic development, services and quality of life, urban environment and cooperation among towns. AlpCity endorses collection, exchange and search of good and best practices in these areas. Lessons learned represent the basis for the formulation of recommendations and policy guidance.

Various projects, networks and institutions in the Alpine Space are dealing with similar Alpine problems. In order to bundle and make available existing data, knowledge and best practice experiences, several projects have developed shared indicators and tools for regional development.

- In the context of Diamont („Data Infrastructure for the Alps: Mountain Orientated Network Technology"), a network of specialists on Alpine development has elaborated an Alp-wide information system, and performed a selection of relevant Alp-wide indicators for regional development. This process includes concrete testing of the usefulness and relevance of selected regional development instruments. In this perspective, workshops are held aiming to ascertain the main stakeholders' opinions on instruments provided. The workshops promote public participation in policy making by involving stakeholders and citizens and thus raising their awareness. These workshops are currently being held within the test regions; the results will be presented in autumn 2007.

\section{The Alpine Space Programme 2007-2013}

In the programming period 2000-2006, the partners and regions developed stable networks, witnessing the strong commitment of projects to fulfill the programme's major target of a common sustainable development strategy. The cooperation continues in the Structural Fund period running from 2007 to 2013. The INTERreg Community Initiative has been upgraded to European Territorial
Cooperation Objective of the European Cohesion Policy, which underlines the importance the European Commission and the Member States attach to the added value of transnational cooperation.

The overall aim of the Alpine Space Programme 20072013 is to increase competitiveness and attractiveness of the cooperation area. The programme has identified three thematic working fields, „competitiveness and attractiveness of the Alpine Space", "accessibility and connectivity" and "environment and risk prevention".

In the new programming period, the projects to be approved will receive ERDF co-funding of no more than $76 \%$. The programme budget - national and EU funding combined - amounts to almost $€ 130$ million. Following approval of the Operational Programme (the official programme document and implementing framework setting the programme strategy) by the Commission, a first call for project proposals will be launched end 2007/early 2008.

For further information, please contact the Joint Technical Secretariat, jts@rosenheim.de and visit the programme website at www.alpine-space.eu. 


\section{Poster presentations}

\section{Sweet chestnut - landscape development by means of a traditional fruit tree in the Alps}

Oliver Bender (Mountain Research: Men and Environment, Austrian Academy of Sciences, Innsbruck, Austria)

\section{Keywords:}

Alps, chestnut culture, cultural landscape, landscape conservation, sustainable development

Since Roman times vast areas of Southern and Western Europe have been covered by groves and coppices of sweet chestnut trees (Castanea sativa MILL.). Having replaced the original broad-leaved forest, they used to play an important role in traditional agriculture. Chestnut cultivation was even more important as providing a substitute for cereals (bread) than for the production of timber. With changing economic conditions and the appearance of the chestnut blight caused by Cryphonectria parasitica in the 20th century, particularly in south-western Europe, the sweet chestnut lost almost all of its economic and cultural significance.

In the last 10 to 15 years, there has been a renewed interest in the preservation and re-planting of chestnuts. This currently comprises marketing strategies, landscape conservation and cultural history aspects ( „Chestnut Festival“"). As chestnut cultivation is widespread, especially in the Southern part of the Alps, it links cultural landscape and regional geographic research with respect for sustainable development. The poster describes different aspects of the importance of the revaluation of an endogenous rural resource.

\section{Remoteness in the southern Swiss Alps - an opportunity for hiking tourism}

Florian Boller (Eidg. Forschungsanstalt für Wald, Schnee und Landschaft WSL, Berne, Switzerland)

Co-authors: Patrik Krebs (Swiss Federal Research Institute WSL, Bellinzona, Switzerland); Marcel Hunziker (Swiss Federal Research Institute WSL, Birmensdorf, Switzerland); Hans Elsasser (Department of Geography, University of Zurich, Switzerland)

Remote areas are defined as valleys that can only be accessed and traversed by foot - a rarity in the highly developed Swiss Alps. This master thesis analysed the supply and demand for hiking tourism in remote areas of the southern Swiss alpine regions of Sopraceneri and Moesano.
The first step was to create a GIS-based inventory and classification of all 67 remote areas larger than $5 \mathrm{~km}^{2}$. In a second step, two case studies were carried out in the moderately remote Val Cama (canton Grisons) and the extremely remote Val di Lodrino (canton Ticino).

A questionnaire-based survey of hikers in these two areas during summer 2006 provided 230 answers with 120 variables each

According to 18 answers concerning attitudes towards preferred extent of human influence in remote areas, hikers could be classified into three types of visitors on a „purism scale" (Stankey 1973, Fredman 2000): purists, neutralists and non-purists. Purists prefer as little human influence as possible while non-purists are looking for infrastructure and security rather than „pure" wilderness. The share of purists in the extremely remote Val di Lodrino was 45 per cent, significantly higher than in the moderately remote Val Cama (24 per cent)

Looking at the visitor's landscape valuation, it was determined that elements of traditional cultural landscape reach highest preference values. Reafforestation of agricultural land is regarded as something positive only by a minority of hikers ( 22 per cent), while as many as 67 per cent regret this development. 11 per cent are ambiguous; they do not have strong feelings either way.

For the management of remote areas it is important to know that the preservation of existing infrastructures (e.g. paths, huts, cultural landscape elements) and "soft" measures (e.g. more information, better signposting) are regarded positively by all types of visitors, whereas the construction of new huts and tracks is very controversial; construction of new road access is clearly refused by all types.

Results also show that sensitivity towards over-use of remote valleys is high: 74 per cent of visitors in Val di Lodrino and 53 per cent in Val Cama prefer to encounter fewer than 10 people a day.

\section{Qualitative determination of erosion by stable and radiogenic isotopes}

Monika Brodbeck (Institut für Umweltgeowissenschaften, University of Basel, Switzerland)

Co-author: Christine Alewell (Institut für Umweltgeowissenschaften, University of Basel, Switzerland)

Soil degradation and nutrient export severely affect mountain slopes. An early warning tool to detect degradation 
before it is visible is urgently required. This project aims to determine soil degradation by analysing the deviation of stable isotope signals in erosion source and sink sites in comparison to non-degraded sites. The study area is located in the Urseren valley in the southern part of Central Switzerland (Canton Uri). Samples were collected at four sites on a south exposed hillslope. The sites correspond in altitude, exposition and land use, but differ in the intensity of visible soil erosion.

Transects in stable isotope dynamics of carbon and nitrogen were determined from upland soils (oxic environment and erosion source) to lowlands (predominantly anoxic environments and sink of erosion material). Oxic upland soils with a predominantly assimilatory metabolism differed significantly from anoxic wetland soils and riparian zones with dissimilatory metabolism. Differences are detectable but are rather small, especially for ${ }^{13} \mathrm{C}$. Soil erosion could be traced in wetlands with ${ }^{13} \mathrm{C}$ and $\partial^{15} \mathrm{~N}$. However, fertilizing with manure changes $\partial^{15} \mathrm{~N}$ values and masks a possible influence of soil erosion on $ð^{15} \mathrm{~N}$.

As a second approach, the same sites were tested on soil erosion by Cs-137. Various studies applied Cs-137 to trace soil erosion, mainly for agricultural areas. Measurements of Cs-137 concentrations can provide important information on soil erosion and redistribution processes of the last 20 years (since deposition of Cs-137 following the Chernobyl nuclear reactor accident in 1986).

\section{Vegetational succession on abandoned terraced land in the Vallée de la Roya (Alpes- Maritimes, France) and its perception by local people}

\section{Conradin Burga (Physical Geography, University of Zürich, Switzerland)}

Co-authors: Sébastien Boillat (Institute of Integrative Biology, ETH Zürich, Switzerland), Andreas Gigon (Agroecologia Universidad Cochabamba, Bolivia), Norman Backhaus (Geographisches Institut, University of Zürich, Switzerland)

\section{Keywords:}

Terraced land, secondary vegetation succession, abandonment, limestone grassland, olive groves, depopulation, landscape perception, neo-rurals, Alpes-Maritimes

The study aims to show the connection between the ecological state of abandoned terraced land in the middle section of Roya valley and socio-cultural values linked thereto.

Fourteen vegetation types were identified and grouped in a succession model. At present, maintained terraces are characterised by olive groves or limestone grasslands. If left unused, the terraces have been colonised by Brachypodium pinnatum grassland, to be followed by scrubland (maquis), and finally by forest. Spatial mapping of different vegetation types show that the largest percentage of maintained terraces is to be found in regions with the highest population density and easy access to terraces.

Interviews with 21 inhabitants allowed for information to be collected on local opinions concerning land abandonment and future prospects of the valley. The opinion spectrum ranges from neo-rurals, who consider the rediscovery of traditional agriculture as a development perspective, to local villagers who see industry and tourist development as the only realistic prospects for the future.

Based on these results, four scenarios for the valley's future were elaborated and discussed, with particular attention being paid to the consequences of each scenario for the preservation of terraced land.

\section{Experiencing landscape - Climate Change and Austrian farmers' risk perception}

Hemma Burger-Scheidlin (Department of Sustainable Agricultural Systems, University of Natural Resources and Applied Life Sciences ВокU, Vienna, Austria)

Co-authors: Anja Christanell and Christian Vogl (University of Natural Resources and Applied Life Sciences BокU, Vienna, Austria)

Changes in weather and climate lead to changes in landscape, which can be observed by farmers. Questions arising are whether these landscape changes lead to a different use of landscape and/or a different attitude towards climate change. Objectives of our work are to present

1) farmers' perception of landscape changes caused by climate change;

2) associations, relations and reactions to these landscape changes;

3) climate-related use of landscape; and

4) risk perception of weather and climate change.

To analyse the perception of landscape and climate change a 15-month field study was conducted in the regions Großes Walsertal and Western Styria, Austria. This poster is based on interviews with 36 farmers / 7 experts (Großes Walsertal) and 38 farmers/ 3 experts (Western Styria) and participant observation. Results from the field study were analysed according to different approaches, such as landscape research (Hirsch \& O'Hanlon 1995), risk \& hazard studies (Boholm 2003) and ethnoclimatology (Strauss \& 
Orlove 2003) to obtain a wide range of findings.

Farmers observe various changes in weather and climate. Hot temperatures, strong winds, les rain and less snow lead to decreasing soil moisture and soil erosion, diminished headstreams and changes in vegetation, flora and fauna. Farmers slowly adapt land-use to the changing climate. For example, cattle-grazing periods in the Großes Walsertal are extended, farmers cut hay earlier - on the shady side more frequently than they used to, on the sunny side less. Further, the observation of climate change causing less snow and more rain in winter-time is slowly leading to a change in risk perception and behaviour towards avalanches. In Großes Walsertal, only recently were new houses constructed in (former?) avalanche-prone areas.

Extreme weather events such as storms and heavy rainfalls also leave their footprints in landscape through uprooted trees and landslides, for example. Although the impact of climate change is visible in the landscape and farmers are confronted with it every day, farmers do not really reflect upon own their own contribution to climate change. As local explanations for climate change are dominated by prevailing media discourses and rarely based on farmers' own conclusions, farmers rarely relate climate change to their own actions.

While climate change leads to different land-use, and landscapes serve as a mirrors of human impact on climate, risk perception concerning climate change is very low and does not lead to re-thinking possible own responsibilities. It rarely leads to active, self-initiated commitment to mitigating climate change impacts.

\section{Biological agriculture, rural tourism, participatory approach. The case of Gresta Valley - Trentino (Italy) - in preserving traditional cultural landscape}

Mirtis Conci (Centro di Ecologia Alpina, Garniga Terme, Italy)

Co-author: Alessandro Grettler (Centro di Ecologia Alpina, Garniga Terme, Italy)

Italy is the world's fourth largest producer of organic products, and is Europe's leader. In Italy organic agricuIture has gained importance in past years, not only for commercial but for conservation reasons as well. The case presented here recalls this function of agriculture, applying organic and organic-dynamic approaches to the preservation of a traditional landscape.

The Gresta valley is renowned for open-field cultivation of fresh vegetables (22 species from cabbage to carrot) in a unique location. Fields are cultivated between 700 and 1'300 $\mathrm{m}$ asl. This became possible through the introduction of organic agriculture by some young farmers in 1980 and widely adopted in 1986, with small-scale enterprises working under a „brand" promoted by a cooperative. In the Gresta Valley, where there are four times as many part-time farmers as there are full-time ones, and agriculture is culturally perceived as part of landscape preservation, there is a need for alternative activities to enable people to earn a sustainable income.

For the past few years, preservation of traditional landscape has been supported by an administrative and financial tool of participation called Patto Territoriale ( „Pact of territorial development"). During 7 years, in an area of only 1'300 hectares, over $€ 30$ million $€$ was invested, of which $€ 17$ million directly financed by private stakeholders. The latter chiefly invested in rural tourism (the development project's key area) and upgrading of agricultural firms and infrastructures.

Apart from the large private financial involvement and the capacity of working with different stakeholders, the involvement and commitment of young people and women is the main achievement of this Pact

The Territorial Pact has helped to increase awareness and involvement of the local population in the management and development of its native land (even if the percentage of delegation is still high), turning a marginal area into a highly attractive part of the valley, and into a „living space".

\section{Dating of soils and high Alpine landscape evolution in Val di Sole (Trentino, Italy) during the Holocene based on charcoal, soil chemistry and mineralogy}

Filippo Favilli (Physical Geography, University of Zïrich, Switzerland)

Co-authors: Markus Egli (Geographisches Institut, University of Zürich, Switzerland), Paolo Cherubini (Swiss Federal Research Institute WSL, Birmensdorf, Switzerland), Aldo Mirabella (Institute for Soil Study and Conservation, C.R.A., Firenze, Italy), Giacomo Sartori (Museo Tridentino di Scienze Naturali, Trento, Italy), Daniele Giaccai (Institute for Soil Study and Conservation, C.R.A., Firenze, Italy)

The investigation of the Holocene period gives precise insight into the sensitivity of Alpine areas regarding fast changing environmental conditions. Alpine areas are highly sensitive to climatic change. Corresponding effects can be seen in soil evolution. Our investigation generally focuses on dating selected Alpine sites of distinct landform surfaces with numerical and relative methods. The 
aim is to establish an absolute chronology of surfaces. The investigation area of Val di Sole (Trentino, northern Italy) was covered by ice during the last glaciation. Soil evolution began as soon as glaciers retreated. We investigated 5 soil profiles, located short distances apart, developed in subalpine and alpine zones on different morphological aspects with respect to the development of clay minerals and the determination of well and poorly crystallised Al and Fe phases. The investigated soils developed on similar parent materials (granitic, paragneiss). Two soils were on a morainic deposit under a natural Larix decidua forest at 2'100 m asl, one on an alpine moraine at 2'380 m asl, and two on different inactive rock glaciers at $2^{\prime} 230$ and 2'370 m asl, respectively. Soil chemistry and mineralogy already provided relative age estimation.

These results were further compared with radiocarbon dating of old and stable organic matter (SOM) and of naturally buried charcoal fragments. In the oldest soil, radiocarbon dating of charcoal fragments produced increasing ages with soil depth, from 3'300 y calBP in the upper horizon to 10'500 y calBP in the lower one. Extraction and dating of the oldest and most stable organic matter, carried out in one of the most developed profiles by oxidation of "fresh" OM by 10 per cent $\mathrm{NaOCl}$, followed by dissolution of minerals by 10 per cent $\mathrm{HF}$ and radiocarbon dating of the residues, showed ages between 5’000 y calBP and 9`000 y calBP, confirming the chemical and mineralogical data.

Vegetation and soil development show that the surface can be attributed to an Egesen equivalent. The eluviation and illuviation of Fe and Al, typical for podzolisation process, were greater in the soils near the timberline and in the soil developed on the rock glacier at 2'230 m asl. Soil development was also confirmed by the ratio $\mathrm{Al}_{d} / \mathrm{Fe}_{d}$ in the $\mathrm{B}$ horizon. The older the soil, the higher this ratio. The development of clay minerals and especially of smectite, investigated with XRD and DRIFT, also reflects weathering intensity. Smectite was discernible in surface horizons at all sites, however in different quantities, except for the soil developed on the rock-glacier in the alpine zone $\left(2^{\prime} 370 \mathrm{~m}\right.$ asl). This profile showed a buried soil with a repetition in the sequence of soil horizons. This could be due to a recent activity of the rock glacier (Little Ice Age?), or erosion and accumulation processes. The clay mineral assemblage (hydroxy-interlayered vermiculite and mica) indicated a very young stage of weathering.

The landforms were analysed by means of relative age dating methods based on soil chemical and mineralogical aspects and by the ${ }^{14} \mathrm{C}$ technique. The radiocarbon dating of charcoals in the subsoils provided a good estimate of the surface age. This age was confirmed by extraction of the oldest possible organic matter in soils (tightly bound to soil minerals and consequently protected from biological decay). Together with soil chemical and mineralogical analyses, a differentiation of surface ages is rendered possible. The oldest surfaces developed for about 11'000 years (since the Egesen equivalent). Chemical and mineralogical analyses, however, showed the dynamics of Alpine landscape within a relatively small area where permafrost activities locally disturbed the evolution until recently.

\section{Geoheritage and geomorphosites in the Blenio valley (Ticino, Switzerland)}

\author{
Georgia Fontana (Institut de Géographie IgUL, Université \\ de Lausanne, Switzerland)
}

Co-authors: Sibilla Ambrosetti-Giudici \& Cristian Scapozza (Institut de Géographie IGUL, Université de Lausanne, Switzerland)

Within the context of landscape and nature degradation, a new interest in their management has developed in Switzerland since the 1960s. Several laws and protection instruments have been adopted, but they often focus on ecological and aesthetic values. The value of geoheritage in general and of geomorphosites in particular is not much considered.

This situation has pressed us to study geoheritage management in the context of a project for the creation of a new Swiss National Park, the "Parc Adula". Attention was concentrated on the Blenio valley. Only few recent studies concerning the geomorphology of the region have been realized and the importance of geoheritage is not emphasised. An inventory of geomorphosites was therefore carried out to make information on geomorphology available to the Park's promoters. The inventory was realized according to the assessment method developed at the Institute of Geography of the University of Lausanne. This method allows the integration of scientific and additional (ecological, cultural, aesthetic, economic) values in the assessment of a geomorphosite (Reynard et al. 2007).

The assessment allowed the selection of 20 geomorphosites that represent the diversity of major processes (glacial, karstic, periglacial, fluvial, gravitative, organic and anthropic) that have left their marks on the Blenio landscape. The localisation of the geomorphosites in the Blenio valley is quite uniform. In general, the dominant additional value is ecological in the upper part of the valley (Lucomagno and Greina regions), while it is cultural on the valley floor where human presence is of greater relevance.

In conclusion, this realisation of a geomorphosites inventory has allowed us to demonstrate that the Blenio valley has an interesting geoheritage that merits to be better conserved and promoted. The presence of geomorphosites with high ecological value is interesting in 
the context of the creation of a protected area to show connections between abiotic and biotic domains (Reynard et al. 2007); the cultural value of some geomorphosites is also of interest in the context of the region's promotion as a tourist destination.

\section{Biotic and abiotic interactions on short-term recruitment of larch and spruce in a subalpine pasture: a field experiment}

\section{François Freléchoux (Wetland Research Group, Swiss Federal Research Institute WSL, Birmensdorf, Switzerland)}

Co-authors: Sibilla Ambrosetti-Giudici \& Cristian Scapozza (Institut de Géographie IGUL, Université de Lausanne, Switzerland)

For several decades, decrease in grazing pressure at the subalpine belt has been followed by a natural reafforestation in the central Swiss Alps. We hypothesised that a sudden decrease in grazing intensity strongly favoured establishment of larch (a pioneer species) followed by spruce (a successional one). Indeed, recruitment of larch is favoured by gaps in the field layer, while negative effects of cattle disappear. By a factorial sowing experiment, we tested how the canopy of larch (shade under canopy vs full light) and the presence of herbaceous neighbours (with neighbours vs neighbours removed) influenced seed germination and seedling survival of two tree species (larch vs spruce). Light and soil water content were measured in sowing places. We also tested the effect of cattle activity on seedling survival after one growing season. Light was reduced by 40 per cent under larch and by 57 per cent in presence of herbaceous neighbours.

Because the spring of 2006 was dry and hot, germination of both species was higher under larches than in the full light, higher without neighbours for larch (trade-off between humidity and light / competition), but higher with neighbours for spruce (higher humidity, tolerance to shade). Survival decreased from 56.5 per cent without cattle to 19.4 per cent due to cattle activity. Without cattle, survival of larch was strongly reduced in presence of neighbours, stressing that larch does not tolerate competition in the field layer. In subalpine pastures, in open and well lit environment, reduced competition from herbs due to trampling by cattle and a sudden decrease in grazing intensity can strongly accelerate larch establishment and forest dynamics.

\section{Impacts of Climate Change on ecosystems in mountain landscapes}

Rüdiger Grote (Institute for Meteorology and Climate Research, Research Center Karlsruhe GmbH, Germany)

The poster presents a new project submitted for funding as a large-scale collaborative project within the EU $7^{\text {th }}$ Framework Programme. Research institutes, NGOs, private and public organizations from Germany, Austria, Switzerland, France, Italy, Spain, Slovakia, the United Kingdom, Finland, and Norway have combined their expertise in order to present a scientifically sound basis for adaptation to climate change impacts to be expected in mountainous regions.

The project will contribute to the mitigation of disastrous impacts and evaluation of economic opportunities under new environmental conditions. This will be done for the socio-economic sectors "Agriculture and Forestry", "Nature Preservation Management", „Civil Protection", "Water and Hydropower-Management", and "Tourism".

Vulnerability of ecosystem services such as yield, biodiversity, protection of infrastructure, water and energy supply, as well as recreational potential will be investigated for 6 regions in 4 European mountain areas (Eastern, Central, and Western Alps, Central Norway, High Tatra, and Sierra Nevada). Changes will be quantified throughout the $21^{\text {st }}$ century with special emphasis on the period up to 2030. The strong points of this proposal are innovative approaches to determine climate and land use scenarios accounting for small-scale heterogeneity in mountain landscapes, integration of different sectors for consideration of feedbacks, and strong stakeholder participation.

The project is presented because it will provide valuable decision support not only for explicitly assessed regions, but also for other mountainous regions in Europe, especially the Alps, and worldwide.

\section{Dry grasslands of Switzerland: an overview}

Christian Hedinger (Atelier für Naturschutz und Umweltfragen UNA, Berne, Switzerland)

Co-author: Christine Gubser (Federal Office for the Environment FoEN, Berne, Switzerland)

On behalf of the Swiss Federal Office for the Environment (FOEN), dry grasslands are being surveyed in Switzerland. The aim is to preserve and promote sites of national importance within the framework of a biotope inventory. From 1996-2006, 23'712 ha of dry grassland have been valuated as of national importance. Implementation of this inventory is based on a sustainable form of agricul- 
ture. Land management subsidies provide farmers with the motivation for appropriate land use. The legal base, the ordinance of dry grassland, will be decided in 2008

Further information: www.umwelt-schweiz.ch/tww

\section{Investigating and analysing spatial patterns of site-related factors in mountainous areas based on remote sensing}

Kati Heinrich (Gebirgsforschung: Mensch und Umwelt, Österreichische Akademie der Wissenschaften, Innsbruck, Austria)

Mountainous landscapes are characterised by specific small-scale changes of sites. The objective of this thesis is to survey such spatial patterns by means of remote sensing including airborne and terrestrial laser scanning as well as aerial photography. The pattern represents a specific interaction especially between the factors of relief, soil and vegetation. By assigning typical distribution patterns in combination with expert knowledge and modelling approaches, it is possible to deduce characteristics of individual geo-factors. Survey of soil properties therefore seems to be feasible, for which to date extensive mapping was required. Soils can be defined as a function of the soil-forming factors, i.e. parent material, relief, climate, vegetation, human presence and time. In a first step, these factors are ascertained by means of remote sensing and GIS. In a next step, data are used to define/deduce soil properties. Test sites are various distinctive areas in mountainous regions of Tyrol.

\section{Finding methods for the quantification of soil erosion in an Alpine environment in Switzerland}

Nadine Hohwieler (Institut für Umweltgeowissenschaften, University of Basel, Switzerland

Co-authors: Volker Prasuhn (Swiss Federal Research Station for Agrorcology and Agriculture, Agroscope Reckenholz, Switzerland); Christine Alewell (Institut für Umweltgeowissenschaften, University of Basel, Switzerland)

Because soil degradation in mountainous regions has been of increasing concern to scientists, policy makers and society, this project aims at quantifying soil erosion on plot scale at different land use sites in an Alpine ecosystem. Reliable information on soil erosion rates is an essential prerequisite for the design of targeted erosion and sediment control strategies.
To quantify soil erosion in alpine environments with different land use types, two methods were applied in the Urseren valley. Erosion measurements with sediment traps at nine plots (three different land use types with three replications each) were compared with Cs-137 measurement along transects. The land use types investigated were meadow, pasture with dwarf shrubs, and pasture without dwarf shrubs. With sediment traps it is possible to detect short term erosion (two weeks up to a few months) whereas the Cs-137 measurements provide medium-term soil erosion and redistribution rates for the last 20 years.

From July to November 2006 the average erosion rate measured by sediment traps was $51 \mathrm{~g} / \mathrm{ha}$ for grassland, $70 \mathrm{~g} / \mathrm{ha}$ for pasture with bushes and $83 \mathrm{~g} / \mathrm{ha}$ for pasture without bushes. Thus, our preliminary results indicate that land use significantly influences erosion. However, for reliable results, a measuring period of several years is necessary because of high temporal heterogeneity. Our first results of the measured erosion seem to be very low in comparison to visible damages.

Our first working hypothesis at the moment is that the maximum erosion takes place in springtime during snowmelt. Furthermore, high infiltration rates might be the reason for the low erosion rate during the summer of 2006. A second working hypothesis is that the visible damages are the results of the accumulation of erosion over several years. This hypothesis can be confirmed by measurements that were done in the Austrian Alps.

\section{Alpine research in Austria}

Günter Köck (Österreichische Akademie der Wissenschaften, Vienna, Austria)

The Austrian Academy of Sciences' (ÖAW) Alpine Research programme is aimed to promote Alp-wide and interdisciplinary cooperation in the fields of alpine research and the transfer of scientific results into practice and to the public. The programme administered by a national committee established at the ÖAW is financed by the (Austrian) Federal Ministry for Science and Research. Eleven research projects are currently running in the context of this programme, on a wide range of basic and applied research topics.

Additional alpine research projects are also funded by the ÖAW programmes Global Change, Man and Biosphere, International Strategy for Disaster Reduction (ISDR), International Geoscience Project (IGBP), Hydrology of Austria and Geophysics of the Earth's Crust. Research topics for the period of 2007-2009 are: effects of climate warming on alpine permafrost; global change impacts on species 
composition of mountain biota; the impact of neobiota; land use change (the impact of agro-industrial practices on traditional mountain farming/Almnutzungen); hydrological processes in a changing environment, predictability; and global change effects in alpine and Arctic areas (as contribution to the IPY-International Polar Year). Further details can be found at http://www.oeaw.ac.at/deutsch/ forschung/programme/programme.html.

Alp-related online publications and project reports can be downloaded from the homepage of the Austrian Academy of Sciences Press. (http://epub.oeaw.ac.at/forschungsprogramme)

\section{Long-term development and spatial differentiation of agriculture in Austria, with particular regard to the alpine space. Essential characteristics of regional changes in rural and forestry populations and enterprises, as well as cattle rearing}

\author{
Elisabeth Lahn Gärtner (Institut für Geographie, \\ University of Innsbruck, Austria)
}

Agricultural production has increased over the past 50 years (1951-2001), while the rural population, the total number of agricultural, forestry and cattle-rearing enterprises has seen a continuous decrease. Agriculture that had remained unchanged over centuries has changed beyond recognition due, on the one hand, to technological innovations introduced since the 1950s. Productivity has increased significantly; workers became free for employment in other sectors. Another reason is that agricultural policies have favoured large-scale farming over small and medium-sized farms, which has forced numerous farms out of business for purely economical reasons. "Flourish or perish" (Wachsen und Weichen) was the infamous 1970's motto.

In Austria a great many small farms without cultivation handicaps (Bearbeitungserschwernis) in favourable areas of the alpine foreland and inner-alpine basins and valleys were affected, as well as alpine farms with reduced cultivation handicaps in areas of West Tyrol and Vorarlberg with traditionally equal land inheritance practices (Rea/teilungsgebiete). Farms with great cultivation handicaps, however, were able to hold out well, especially in eastern Tyrol and western Salzburg, as well as farms with extreme cultivation handicaps in the Realteilungsgebiet. Prior to accession to the EU, Austrian mountain farmers' allowances, and EU income support as well as the Austrian Environmental Programme (ÖPUL) since Austria's accession to the EU, have been targeted policies of Austrian ecosocial agricultural policy that have provided effective support to mountain farmers with high handicaps and low incomes. These policies are intended to prevent farm abandonment and depopulation of mountain areas. By farming and managing extremely sensitive mountain ecosystems, the mountain populations provide valuable services to the general public, such as avalanche and landslide protection, as well as tourist services.

If in the future, neo-liberal tendencies as proclaimed in Agenda 2000 gain the upper hand over against ecosocial concerns, it will become difficult to provide the kind of support to mountain farming areas they have received so far. These tendencies will reinforce agrarian structural change (Flourish or perish), the number of mountain agricultural and silvicultural enterprises will decrease further, which will entail all the negative regional, ecological and social impacts and aspects. Abandonment will critically threaten a unique cultural landscape, a traditional biosphere for local populations and a recreational area for humans from agglomerations north and south of the Alps.

\section{Meanings of nature in land use practices and narratives}

Karina Liechti (Centre for Development and Environment CDE, Institute of Geography, University of Berne, Switzerland)

"Human beings act toward things on the basis of the meanings that things have for them" (Blumer 1969). Based on this perspective, the study has reflected on the question of how human actions are influenced and guided by certain understandings of nature and, therefore, how a dynamic ecological system, associated with many different meanings, guides land use practices. The different actors' meanings of nature - in the Sokuluk region in Kyrgyzstan and in the Jungfrau-Aletsch-Bietschhorn World Heritage Site (WHS) region in Switzerland - were deduced by highlighting narratives about the past and the present, and future land use, and by focusing on current land use practices. Semi-structured interviews, field observations and a detailed media analysis were carried out to generate relevant data.

First results have proved the importance to learn about different meanings of nature underlying debates on sustainable regional development. They directly influence positions taken by actors involved when negotiating land use. In the context of the Jungfrau-Aletsch-Bietschhorn WHS, we have learned that statements both by proponents and opponents of the WHS might be similar to each other in wording (e.g. to care for coming generations), but that underlying meanings are diametrically opposed to each other. Similar patterns could be observed in research carried out in Kyrgyzstan. In the case of pasture 
issues, the narratives concerning degradation or non-degradation of pastures are highly dependent on individual meanings of nature (e.g. unlimited vs. limited availability of resources), which in turn are related to former (Soviet), current, or envisaged land use practices, and strategic positioning in relation to other actors.

\section{InTERREg Project AlPTER - terraced landscapes of the Alpine arc}

\author{
Luca Lodatti (Urban Planning Department, Regione \\ Veneto, Venezia, Italy)
}

Co-author: Laura Fagarazzi (University of Padua, Italy)

The AlPTER project, co-funded by the European Union in the context of the INTERREG IIIB Alpine Space programme, was conceived to counteract terraced farmland abandonment in alpine regions, a process with various negative effects in terms of loss of productive land and biodiversity, increasing hydro-geological hazards and depletion of cultural heritage. The disregard often shown towards this particular issue in the context of mountain landscape development is mostly due to a lack of information on the distribution and features of terraced landscapes.

This is why detailed mapping is of fundamental importance to acknowledge the pivotal role of terraced sites and to plan effective intervention strategies targeted at such sites. The AlPTER project aims at developing and testing a methodology able to provide regional maps showing extent, distribution and density of terraced sites. This methodology implies four main steps:

1) simple localization of terraced sites;

2) detailed monitoring and gathering of historical and current data by means of specific data-forms designed by project partners;

3) implementation of a GIS structure for terraced landscapes;

4) classification of terraced landscape units.

Such a methodology is being applied in the AlPTER pilot areas throughout the Alpine arc. The poster reports some of the results so far obtained, with particular regard to the Venetian (Brenta River Valley), the Austrian (Ulrichsberg) and the Slovenian (Goriška Brda) study areas.

For further information please visit the project website www.alpter.net .

\section{Sustainable development processes in the marginal Alpine communities of Trentino}

Claudia Marchesoni (Centro di Ecologia Alpina, Garniga Terme, Italy)

Co-authors: Michela Zucca \& Alessandro Gretter (Centro di Ecologia Alpina, Garniga Terme, Italy)

Keywords:

Alps, depopulation, marginal communities, cultural identity, fragmented society

In recent years, alpine populations have faced the challenge of balancing quality of life with preservation of cultural identity. Most rural settlements have a small number of inhabitants, whose income level is lower than that of urban areas, and entrepreneurship is weak. In addition, self-esteem of rural people is generally low; hence, they tend to emigrate from their birthplaces.

To study in depth the phenomenon of depopulation, we have conducted anthropological fieldwork in socio-economically peripheral alpine communities. In particular, the focus has been on negative aspects more likely to induce residents to emigrate. From a methodological point of view, we have opted for participatory action-based research.

Problems almost invariably associated with mountain communities are not merely of an economic nature. By and large, what is most conspicuous is the widespread distrust towards the territory itself, and the unravelling of family networks. As a result, local services close down, which increases the marginality of these areas as it becomes increasingly difficult for both residents and local administrations to venture into new business enterprises. Therefore, the original contribution of our project lies in its focus on procedures to detect, analyse, and diagnose experiences of marginality in alpine communities, and to identify a combination of elements and conditions most likely to ensure a self-sustaining process of development based on local values and opportunities.

\section{InTERREG IIIB Alpine Space, DiAmont project: instruments for regional land resource management}

Stefan Marzelli (Ifuplan, Munich, Germany)

Why is land resource management an issue at regional level?

There are two main developments which call for efficient land resource management: 
- Regions / settlements with an increasing conversion of agricultural areas into settlement and traffic infrastructure due to population increase, increasing demand of living space per person, changing economic needs and household patterns (more singles - young people and seniors; fewer two-parent-families; more single parents; etc.). The challenge is to mitigate land conversion and push inner-urban development instead.

- Regions / settlements with population decline, overaged populations or declining agricultural sector face the problem of increasing inner-urban vacancies of buildings, and buildings in various phases of decay, with various negative effects on the economic value of the whole quarter and, occasionally, even on the social sphere. The challenge is to find ways to revitalise inner-urban land resources to escape a vicious circle of decline.

Individual municipalities are often overly challenged to deal with dynamic changes in land resource demand and development. Solutions might often be more easily achieved at regional level, offering win-win situations for all municipalities in the region.

\section{What instruments are available for land resource management?}

DiAmont focuses on instruments to be implemented autonomously by municipalities and regions.

In a first step, instruments available in Austria, Switzerland, France, Italy, Slovenia and Germany are collected and documented in a database. This establishes a platform of exchange for project partners and will be an outcome of the DIAMONT project. To enrich this collection of instruments, best practice examples will also be presented and made available through the database.

In a second step, collected instruments will be analysed in terms of feasibility, transferrability between Alpine countries, success factors and also estimation by stakeholders derived from an alpine wide questionnaire of mayors, conducted by EURAC.

\section{Nutritive value and herbage selection by suckler cows on subalpine pastures}

\author{
Marco Meisser (Agroscope RAC Changins-Wädenswil \\ ACW, Nyon, Switzerland)
}

Co-author: François Freléchoux (Swiss Federal Research Intitute WSL, Laboratory of Ecological Systems ECOS, EPF Lausanne, Switzerland)

\section{Introduction}

Because of decreasing grazing pressure, land use changes often lead to reafforestation, which is especially visible in the subalpine belt. In order to maintain an open landscape with high biodiversity, it is important to improve our knowledge of the nutritive characteristics of the pastoral resource and to better understand the feeding behaviour of cattle.

\section{Materials and methods}

\section{Grazing management}

The experiment was conducted in 2006 on the pastures of Le Larzay, above Sembrancher (Valais, Switzerland). The herd comprised 9 suckler cows with their calves, and 9 dry suckler cows. All animals grazed together in a rotational system on a total surface of 27 ha. Two complete rotations were made during the grazing season.

Vegetation survey and herbage selection

Botanical composition of the vegetation was determined according to Daget \& Poissonet's (1969) point-quadrant method along 34 transects distributed in 4 paddocks. The relevés were made two or three days after the animals arrived in each paddock. A Correspondence Analysis was performed with the relative species frequency recorded in all 34 relevés in order to visualise the main vegetation gradients. The mean ecological indicator values for each relevé were calculated by weighting the Landolt values (1977) of each specie according to its relative frequency. To assess herbage selection by the animals, we recorded hit species as "browsed" or "not browsed" at each contact point. The selection index of a certain functional group was obtained by dividing its proportion among all consumed plants by its proportion in the herbage.

Herbaceous biomass and digestibility of standing herbage Standing crop samples were collected in 42 small exclosures located close to the transects on the same day that we carried out the vegetation survey. During the first rotation, samples were taken in all 4 paddocks. During the second rotation, samples were collected only in the paddocks located on the northern aspect because regrowth in the paddocks on the western aspect was nil. For each exclosure, biomass was determined by harvesting vegetation of $1 \mathrm{~m}^{2}$ and drying the herbage samples during 18 hours at $60^{\circ} \mathrm{C}$. Digestibility was assessed according to Tilley and Terry's (1963) method. Mean values for herbaceous biomass and digestibility were calculated for each CA analysis group of relevés.

\section{Results}

Ordination of the 34 transect relevés along the two first axes indicated three main vegetation types. Passive projection of ecological values revealed that the first axis could be explained by nutrient $(\mathrm{N})$ and humidity $(\mathrm{F})$, and the second axis by light $(\mathrm{L})$ and temperature $(\mathrm{T})$.

Selection index of graminoids was always higher than 1 . Surprisingly, it was lower than 1 for legumes.

Herbaceous biomass was virtually identical for North $1+2$ 
and West 2, which was in a shady location, under larches. Exposed to full light, West 1 was less productive. The first early use of the lower paddocks made it possible to obtain a good regrowth, both in terms of quantity and in terms of quality.

\section{Conclusions}

Our results confirm that early grazing helps to draw the best advantage from the pastoral resource. Selection indexes reveal that the most browsed species are often not those regarded as more palatable. Further research is needed on other herbage characteristics, such as chemical composition (volatile organic compounds), in order to better understand cattle's selection processes on speciesrich pastures.

\section{The effect of land use change on soil stability of an alpine catchment}

Katrin Meusburger (Institut für Umweltgeowissenschaften, University of Basel, Switzerland

\author{
Co-author: Christine Alewell (Institut für \\ Umweltgeowissenschaften, University of Basel, \\ Switzerland)
}

Even though changes in climate and land-use pose a risk to stability of alpine soils, recent studies rarely considered these dynamic factors but concentrated on quasi-static catchment characteristics such as geology, soil type or topography. The underlying assumption of multivariate statistical approaches to predict landslide risk is that catchment characteristics leading to landslides in the past will also trigger landslides in the future. The latter approach neglects the temporal variability of landslide triggering factors, which may result in erroneous risk predictions (Guzzetti et al., 1999).

In this study, we explicitly considered the influence of dynamic factors such as precipitation characteristics, avalanche density and land-use change on stability of slopes and the quality of risk prediction. We chose the Urseren Valley in the Central Alps as investigation site for two reasons: 1) the valley is dramatically affected by soil erosion and 2) land-use history is well documented.

Our hypothesis was that if changes in land-use and climate have a significant influence on the occurrence of landslides, we would see a change over time. Time series (for 45 years) of precipitation characteristics, avalanche density, cattle stocking and pasture maps were compared to a sequence of seven landslide investigation maps between 1959 and 2004. We found that the area affected by landslides from 1959 to 2004 increased by 92 per cent. The progression of the increase could only partly be explained by the rise of cattle stocking and increased frequency of torrential rain events. Detailed spatial analysis of the land-use with GIS and interviews with farmers confirmed the strong influence of land-use management practises on slope stability.

We set up a logistic regression model based on the landslide inventory map of the year 2000 to assess the risk caused by static factors. Of 21 static variables, the most significant were geology, slope and stream density, which could correctly classify 70.4 per cent of the validation dataset. In addition, the resulting risk zones were compared to the inventory map of 2004 to assess quality and limitation of the model for future predictions. Overall classification was still good. However, many of the new landslides in 2004 occurred in zones which the model only classified as medium risk. The latter were also zones where we assumed the highest influence of changed land-use management practices. We visualised spatial information on where erosion risk increased due to land-use change by comparing regressions of 1959 with 2000 . The result was a parameter map for land use that could predict the new landslides of 2004. Consequently, natural susceptibility to landslides was decisively influenced by land use, which highlights the urgent need for sustainable management guidelines for alpine regions.

\section{Landscape perceptions in alpine valleys of the Valais central - what landscape preservation? For whom? For what purpose?}

Valérie Miéville-Ott \& Yaëlle Berrebi (AGRIDEA, Lausanne, Switzerland

The decrease of farming activities is a real problem in the Alpine region. It induces bush and forest progression in abandoned surfaces. Project PAsto aims to test and develop an extensive breeding system in order to link two functions: beef meat production and landscape preservation. Study area is the central Valais (Switzerland).

Generally, the notion of landscape preservation is poorly developed and analysed. More often, it tends to be associated with cultivated, well-kept and humanised landscape, and to be a consensual notion, i.e. a social expectation shared by everyone, assessments are not validated by sociological studies. Our aim is precisely to investigate this notion, answering the following questions:

- Is landscape preservation a shared and univocal notion?

- What does a well-kept landscape mean? How is a well-kept landscape perceived according to the different profiles of survey participants? What functions of a well-kept landscape are prioritised (leisure, habitat, 
production, etc.)?

- Where is it necessary to maintain a well-kept landscape?

In addition to analysing the notion of landscape preservation, we will also identify landscape preferences now and in a prospective trend.

Our approach combines two methods: a questionnaire and qualitative interviews with a representative sample of the population (farmers, foresters, residents, tourists, administrative people, members of NGOs, etc.). Some prospective points will also be discussed in focus groups.

Theoretically speaking, we consider the landscape as a relative notion. It results from an interaction between a subjective view and perceived physical space. There is no one landscape but several landscapes, weighted with emotions, values and projections. How landscape is weighted varies according to social background and individual identity. But in order to analyse how landscape is perceived, qualified and expected, it is necessary to refine the notion of social group. Landscape representations depend on the complex identity of social actors. Every individual alternates between different identity contexts and cannot be reduced to one of them. The notion of attitude expresses this identity flexibility better. Landscape representations depend on mobilised attitudes and on values that inform them. Everybody sees different stakes and values in one landscape according to his or her own experience, competencies and social identity. For example, residents very highly value the identity and habitat values of a landscape. On the other hand, biologists attribute greater importance to a landscape's environmental and spiritual values.

Our objectives are to more precisely define values inherent in the different attitudes, more particularly in relation with landscape preservation. We will also analyse compatibility or exclusivity between these different values. Finally, we will propose different landscapes scenarios to the appreciation of a representative sample of the population. These different results aim to foster public debates about landscape management, and to provide valid elements to facilitate decision making by public authorities.

\section{The CulturALP Project - knowledge and enhancement of historical centres and cultural landscapes in Alpine space}

\section{Luisa Pedrazzini (Regione Lombardia, Milano, Italy}

Today, living in mountains territories is no easier than in the past and the historical settlement system mirrors the adaptation of local communities, who by choice or from necessity have lived in these territories during by trying to improve quality of life in the face of difficulties presented by these areas.

The Alpine area is known worldwide for its natural characteristics, but the same is not true for its cultural heritage, which should deserve the same attention. This is the starting point for the CulturALP project, which aims to promote the importance and the enhancement of the mountain historical settlements.

The project is addressed to the historical settlements system of the Alpine areas, which constitute an heritage of importance for both local culture and for European identity.

In order to safeguard cultural heritage values, the project has taken into account the nature, characteristics and quality of historical, artistic, cultural and territorial resources incorporated as a whole in the alpine cultural heritage.

\section{Connecting mountain and Alpine people: collective identity and cultural heritage}

Mathieu Petite (Départment de Géographie, Université de Genève, Switzerland)

This study seeks to analyse forms of cooperation between mountain communities for the promotion of cultural heritage. It is based on four field cases: construction and social use of a Bhutanese suspension bridge in Valais (Switzerland); renovation of hamlets in Val d'Hérens (Valais); an ecologist NGO's dismantling of obsolete installations in some mountain regions; and the construction of a Walser cultural network throughout the Alps.

First, this study explores the symbolic role of cultural and natural heritage and its importance in the process of collective identity building. Numerous traditional buildings or natural/cultural landscapes tend to be considered as a heritage by local communities in the Alpine regions.

Second, we observe that numerous mountain communities (municipalities or associations) are engaged in social networks (oriented, for instance, in cultural exchange or know-how transfers) linking distant communities, occasionally in an interregional and/or international context. Thus, this study aims to show that the cultural and natural heritage should enable social groups to be connected with other communities.

Generally speaking, this study tries to understand how cultural and natural heritage is constructed and used by different social groups. Analysing written and oral texts as well as pictures and images, the study deals with processes in which these groups give meanings to heritage 
objects. Particularly, it shows that the latter are conceived as emblematic representations of Mountains, the Alps, Nature and Tradition.

\section{Influence of policy instruments on landscape development in the Bavarian Alps: a case study of the "Isarwinkel"}

\section{Thomas Probst (Alpenforschungsinstitut gGmbH, Garmisch-Partenkirchen, Germany)}

The study, an ongoing dissertation at the University of Erlangen-Nuremberg (D), examines the influence of policy instruments in the fields of spatial planning, nature protection, agriculture and forestry on cultural landscape development from 1950 to 2000 in the Isarwinkel region (7 municipalities in the Bavarian Alps, 37'000 inhabitants, $530 \mathrm{~km}^{2}$ ). The main intention is to clarify whether these instruments have achieved their formal objectives which are intended to preserve scenery and specific landscape elements such as mountain forests, flood plains etc., while seeking to steer and reduce settlement and infrastructure development. The policy instruments analysed in detail are the Regional Development Programme on Bundesland level (Landesentwicklungsprogramm Bayern); the subordinate Regional Plan for the study region; the Forest Management Plan on regional level (Waldfunktionsplan); the Bavarian Cultural Landscape Programme KuLAP and compensatory allowances for agricultural enterprises in disfavoured regions (Ausgleichszulage); as well as nature conservation areas.

These instruments' specific landscape objectives concerning the Isarwinkel were extracted from legal documents and then contrasted with actual landscape development in 5 selected parts of the study region. Landscape development was analysed by means of a Geographic Information System (GIS) based on aerial photos from 1959, 1975 and 1999 (scale 1:25’000). The comparison of formal objectives and real development showed that the examined instruments were unable to prevent partially significant landscape changes, especially settlement expansion and urban sprawl in the central valley areas, or forest growth in the mountainous areas. However, some characteristic landscape elements (e.g. hedgerows) as well as peripheral areas have been preserved quite comprehensively. Thus, these instruments play an important role within the complex system of landscape development, but they have to be adapted and improved, especially in terms of implementation in order to better fulfil their steering function.

\section{A master program on Alpine environments at the University of Lausanne, Switzerland}

Emmanuel Reynard (Institut de Géographie IGUL, Université de Lausanne, Switzerland)

Since 2006, the Faculty of Geosciences and Environment of the University of Lausanne has provided a master program in Geography, specialised on alpine environments. The program is organised by the Institute of Geography and its duration is 3 semesters (beginning in September). The full program (90 credits EcTs) is organised in three modules of 30 credits each: a module common for all students of the master of Geography that has a second specialisation in urban studies; a specialised module on alpine environments; a master thesis. The "Alpine environment" module is divided in three blocks of 10 credits each. The first block, called "Periglacial environments" is oriented on the study of regions of high mountains, especially the sectors concerned with permafrost. The block aims at giving the students skills for studying the relationships "climate change - morphogenesis" and specific methods for studying ice and permafrost, as geophysics, GPS, thermal measurements, etc.). The second block, called "Quaternary geomorphology", concerns the evolution of geomorphology during the last millennia in the Alps. It aims at giving the students a basis for understanding the complex deposition and erosion processes that have modelled the alpine landscapes. The last block, called "Landscape and resource management" is dedicated to the study of the profound transformations that have concerned the alpine landscapes and environments during the two last centuries. A large part of the courses are organised in the field. The public targeted by this master is made of persons that want to work in public administration and private companies active in the Alps and in the alpine development. Language of the master is French.

\section{Local and scientific perspectives on the management of natural hazards}

Franziska Schmid (Centre for Development and Environment CDE, Geographisches Institut, University of Bern, Switzerland)

Hazard assessment and evaluation provide the basis for so-called hazard maps. Experts consider these analyses as indispensable elements of dealing with natural hazards. The Swiss cantons and communes are legally obliged to have this instrument and to consider it in land-use planning. After the disastrous floods of August 2005, the Federal Council confirmed its prevention strategy by claiming that these hazard maps have to be produced and implemented in all regions soonest. 
However, actual implementation has been found to be fraught with difficulties. At the community level, where the policies have to be applied, various forms of knowledge conflict with each other: objective, analytical knowledge displayed in hazard maps clashes with local, context-based knowledge and experience.

The research project thus focuses on various perspectives and forms of knowledge in the field of natural hazards with the aim to contribute to building an effective and successful risk dialogue. It explores local conceptions and meanings of natural hazards, and protection strategies as well as the importance of scientific expertise for the local situation. A further focus is set on power relations: What form of knowledge, what kinds of interpretation will prevail? Who possesses normative power?

Qualitative interviews are conducted with experts, with local decision makers and with other inhabitants of alpine municipalities. Preliminary results indicate that authorities do not sufficiently communicate the need for risk-management instruments. Although local actors are aware of the existence of hazard maps, they hardly know its content or function and therefore demonstrate little ownership. This may be illustrated by the statement that practical knowledge and experience of hazards is available on the spot because "we live here and see if something happens". A hazard map therefore is seen to be unnecessary and perceived as an imposition by the state. Experts, on the other hand, assume that science-based risk information can be transferred into practice and lead to appropriate actions. They are often unaware that communication efforts are required that meet the specific local context.

\section{Landscape-perception by local populations in two Alpine landscapes: Diemtigtal valley (Switzerland) and Krakau valley (Austria)}

\section{Sonja Völler (Vienna, Austria)}

For the sustainable development of landscapes in the Alps it is important to consider the needs and perceptions of local inhabitants towards their landscape. Understanding local communities' perceptions will thus help to involve local people and foster their participation in further planning processes, including nature conservation projects.

This poster illustrates the results of two diploma theses exploring the relation of local inhabitants to their landscapes as studied in two different Alpine landscapes: in the Diemtigtal valley in Switzerland, and the Krakautal valley in Austria. The results illustrate that landscapes are more than just the arrangement of their physical components. There is a complex and individual relatedness of inter- viewees with particular landscape features or locations in the valleys. Inhabitants attribute different meanings to landscape features, ranging from usage values such as agriculture, tourism and recreation, ownership and cultural esteem to personal experiences, feelings or childhood memories. Landscape elements and features bear different values and meanings, experiences and memories, both collectively and individually.

These elements and meanings connect to detailed mind maps and help produce a strong sense of place and identity within the respondents. Landscape changes in the past were not perceived as numerous and did not interfere with this sense of place. However, the inhabitants fear that foreseeable changes in the future might harm their identification with their living space.

\section{Agriculture in Ursern (Switzerland) during the second half of the twentieth century}

\section{Rahel Wunderli (Niederlenz, Switzerland)}

Using a broad historical approach, the dissertation on "Agriculture in Ursern during the second half of the twentieth century" intends to study the agrarian sector in the Ursern Valley (located between the Gotthard, Furka and Oberalp passes and the Schöllenen Gorge). The project asks how agriculture in this alpine valley, greatly affected by tourism and Swiss military facilities, has changed during the past 60 years.

Political, economic, ecological, technical and social aspects will be examined, and both internal and external factors analytically brought into a relationship with each other. The conclusion and synthesis address the question of how material status and functional importance of Ursern agriculture have been altered.

The corpus of available sources consists of archival records and oral history interviews with contemporary witnesses. 


\section{List of participants and contributors}

Albrecht Max Amt der Vlbg Landesregierung, Römerstrasse 16, A-6901 Bregenz; max.albrecht@vorarlberg.at

Alewell Christine, Prof. Institut für Umweltgeowissenschaften, Universität Basel, Bernoullistrasse 30, CH-4056 Basel christine.alewell@unibas.ch; +41(0) 612670477

Altorfer Jörg Frauenfelderstrasse 101, CH-8252 Schlatt; joerg_altorfer@gmx.ch; +41 (0) 764229493

Amstutz Marc, Dr. ITW Institut f. Tourismuswirtschaft, Hochschule für Wirtschaft, Rösslimatte 48, CH-6002 Luzern mamstutz@hsw.fhz.ch; +41 (0) 412284149

Anselmetti Flavio, Prof. Geologisches Institut, ETH Zürich, ETH Zentrum NO, Sonneggstr. 5, CH-8092 Zürich; flavio.anselmetti@erdw.ethz.ch; +41 (0) 446326569

Atmanagara Jenny, Dr. Geographisches Institut - Kulturgeographie, Universität Bern, Hallerstrasse 12, CH-3012 Bern atma@giub.unibe.ch, +41 (0) 316318838

Bacher Andreas, Dr. Amt für Wald und Raumentwicklung, Flüelistrasse 3, CH-6060 Sarnen andreas.bacher@ow.ch; +41 (0) 416666328

Bächler Martha Gemeinde Engelberg, Engelbergerstrasse 44, CH-6390 Engelberg; baechler.m@gde-engelberg.ch

Backhaus Norman, PD Dr., Geographisches Institut - Human Geography, Universität Zürich, Winterthurerstr. 190 - Irchel, CH-8057 Zürich; backhaus@geo.unizh.ch; +41 (0) 446355172

Baud Dominique Université de Savoie, F-73376 Le Bourget du Lac; dominique.baud@univ-savoie.fr

Bender Oliver, Dr. Mountain Research: Men and Environment, Österreichische Akademie der Wissenschaften, Technikerstr. 21a, A-6020 Innsbruck; oliver.bender@oeaw.ac.at, +43 (0) 5125074945

Bernbaum Edwin, Dr. Sacred Mountains Program, The Mountain Institute, 1846 Capistrano Ave., USA-Berkeley, CA 94707 ebernbaum@mountain.org,+1(0) 5105271229

Berrebi Yaëlle AgrideA, Av. des Jordils 1, CH-1000 Lausanne 6; yaelle.berrebi@agridea.ch; +41 (0) 216194439

Berthoud Anne-Claude, Prof., SAGw, Hirschengraben 11, CH-3001 Bern; anne-claude.berthoud@unil.ch; +41 (0) 313131440

Bertrand Nathalie, Dr. Division DTM, Cemagref, F-38402 St. Martin d'Hères; bertrand@lsv.ens-cachan.fr; +33 (0) 147407540

Bin Sara

Dipartimento di Geographia, Università degli Studi di Padova, Via del Santo, n. 26, I-35123 Padova sarabin76@gmail.com; +39049827 4090

Bissig Géraldine Institut de Géographie IGUL, Université de Lausanne, Bâtiment Anthropole, CH-1015 Lausanne geraldine.bissig@unil.ch; + 41 (0) 216923612

Björnsen Gurung Astrid, Dr., The Mountain Research Initiative, ETH Zentrum CHN G71, CH-8092 Zürich bjoernsen@env.ethz.ch; +41(0) 446325562

Blatter Michael, Dr. Historisches Seminar, Universität Luzern, Kasernenplatz 3, PF 7455, CH-6000 Luzern 7; michael.blatter@unilu.ch; +41(0) 412287807

Blättler Richard Tiefbauamt Nidwalden, Breitenhaus, CH-6370 Stans; richard.blaettler@nw.ch; +41 (0) 416187220

Boesch Martin, Prof. Forschungsstelle für Wirtschaftsgeographie und Raumordnungspolitik, FWR, Universität St. Gallen CH-9011 St.Gallen; martin.boesch@unisg.ch; +41 (0) 712242582

Boller Florian WSL, Greyerzstr. 50, CH-3013 Bern; florian.boller@wsl.ch; +41 (0) 313315642

Bollier Regula

Böni Rosa Scuol Tourismus, Stradun, CH-7550 Scuol; r.bollier@engadin.com; +41 (0) 818612428 Fällmisstrasse 35, CH-8832 Wilen; rosiboeni@yahoo.com; +41 (0) 447845907

Borsdorf Axel, Prof. Institut für Geographie, Leopold-Franzens-Univ, Innsbruck, Innrain 52, A-6020 Innsbruck axel.borsdorf@oeaw.ac.at; +43 (0) 15125075400

Bose Lisa

Botta Johanne Swiss Biodiversity Forum, Schwarztorstrasse 9, CH-3007 Bern; lisa.bose@scnat.ch; +41 (0) 313120275 14 Faubourg Reclus, F-73000 Chambéry; jocat.b@wanadoo.fr

Braun Ludwig , Dr.

Kommission für Glaziologie, Bayerische Akademie d. Wissensch., Alfons-Goppel-Strasse 11, D-80539 München ludwig.braun@kfg.badw.de; +49 (0) 89230311196

Braun Valerie, Dr. Institut für Geographie, Universität Innsbruck, Innrain 52, A-6020 Innsbruck valerie.braun@uibk.ac.at; +43 (0) 5125075412

Brendt Irene

Brodbeck Monika

Habichtsweg 4, D-93180 Deuerling; irene_brendt@yahoo.de; +49 (0) 9498906890 Institut für Umweltgeowissenschaften, Universität Basel, Bernoullistrasse 30, CH-4056 Base monika.brodbeck@unibas.ch;+41(0) 612670482

Brun Jean-Jacques, Dr. Equipe Ecologie Spatiale et Fonctionelle, CEMAGref, 2, rue de la papeterie, Domaine Universitaire - BP 76 F-38402 Saint Martin d'Hères; jean-jacques.brun@cemagref.fr; +33 (0) 476762779

Buffa Federica $\quad$ Università degli studi di Trento, Via Inama 5, I-38100 Trento; federica.buffa@economia.unitn.it; +39 (0) 461882146

Bugmann Harald, Prof. Departement Umwelt wissenschaften, ETH Zürich Universitätsstrasse 22, CH-8092 Zürich harald.bugmann@env.ethz.ch, +41(0) 446323239

Bundi Ulrich EAWAG, Überlandstrasse 133, CH-8600Ｄübendorf; bundi@eawag.ch; +41(0) 448235021

Burga Conradin, Prof. Geographisches Institut - Physical Geography, Universität Zürich, Winterthurerstr. 190 - Irchel, CH-8057 Zürich conradin.burga@geo.uzh.ch; +41(0) 446355168

Burger-Scheidlin Hemma, Department of Sustainable Agricultural Systems, University of Natural Resources and Applied Life Sciences, GregerMendelstrasse 33, A-1180 Wien; hemma.burger-scheidlin@boku.ac.at; +43 (0) 1476543771

Buzzi Giovanni Studi Associati SA, Via Zurigo 19, CH-6904 Lugano; buzzi@sasa.ch; +41 (0) 794050829

Caprez Riccarda Botanisches Institut - Pflanzenökologie, Universität Basel, Schönbeinstrasse 6, CH-4056 Basel riccarda.caprez@stud.unibs.ch 
Carestiato Nadia Dipartimenteo di Geografia, Universita di Padova, Via del Santo, I-35100 Padova; nadia.carestiato@unipd.it

Castiglioni Benedetta, Dr., Dipartimento di Geografia, Università di Padova, Via del Santo, 26, I-35123 Padova etta.castiglioni@unipd.it; +39049827 4278

Clivaz Christophe, Dr. Institut Economie \& Tourisme, Sierre University of Applied Sciences Western Switzerland, TechnoArk 3 CH-3960 Sierre; christophe.clivaz@hevs.ch; +41(0) 276069006

Conci Mirtis, Dr. C Centro di Ecologia Alpina, Viote del Monte Bondone, Loc. Caserme n. 2, I-38060 Garniga Terme euronet@cealp.it; +390461939573

Coutaz Denise

Coy Martin, Prof. NFP 48, Wildhainweg 48, CH-3012 Bern; dcoutaz@snf.ch; +41 (0) 313082345 Institut für Geographie, Universität Innsbruck, Innrain 52, A-6020 Innsbruck martin.coy@uibk.ac.at; +43 (0) 5125075420

De Nardi Alessia Dipartimento di Geografia, Università di Padova, Via del santo, 26, I-35123 Padova; alessia.denardi@unipd.it

Debarbieux Bernard, Prof., Dépt. de Géographie, Université de Genève, 40, bd Pont-d'Arve, CH-1211 Genève 4 bernard.debarbieux@geo.unige.ch; +41 (0) 223798338

Decrausaz Brigitte Office fédéral de l'agriculture, Mattenhofstrasse 5, CH-3003 Bern, brigitte.decrausaz@blw.admin.ch

De Kegel Rolf, Dr.

Del Barba Oscar Stiftsarchiv, Benediktinerkloster Engelberg, CH-6390 Engelberg; stiftsarchiv@kloster-engelberg.ch; +41 (0) 416396161 Agenzia Regionale per la Protezione dell'Ambiente / CIPRA Italia, Viale Francesco Restelli 3/1, I-20124 Milano o.delbarba@arpalombardia.it

Diamantini Corrado, Prof., Università di Trento, Via Mesiano 77, I-38050 Trento; corrado.diamantini@ing.unitn.it; +39 0461882663

Dusi Marco, Dr. Naturforschende Gesellschaft Ob- und Nidwalden, Sonnenbergstrasse 13, CH-6060 Sarnen dusi@bluewin.ch; +41 (0) 416601141

Eberle Joachim Institut für Geographie, Universität Stuttgart, Azenbergstrasse 12, D-70174 Stuttgart eberle@geographie.uni-stuttgart.de; +49 (0) 71168581474

Egerer Harald nterim Secretariat of the Carpathian Convention; United Nations Environment Programme - Vienna International Center A-1400 Wien; harald.egerer@unvienna.org; +43 (0) 1260604545

Ehinger Jacques Gymnase de Burier, Route de Brent 25, CH-1817 Brent; famille.ehinger@bluewin.ch; +41 (0) 219643522

Ehringhaus Barbara

ProMont-Blanc, Mountain Wilderness CIAPM European Mountain Forum, CH-1299 Crans barbara.ehringhaus@bluewin.ch; +41 (0) 227765722

Eulitz Christine ConTrac Berlin, Köpenicker Strasse 48/49, D-10179 Berlin; info@contrac-berlin.de; +49 (0) 3027593965

Fagarazzi Laura, Dr.

Fassi Driss, Dr.

Favilli Filippo

Ferrario Viviana

Ferret Florence

Finsterwald Marco

University of Padua, Via del Sano 26, I-35100 Padua; laura.fagarazzi@alpter.net; +39 (0) 3495335102

Institut Agronomique et Vétérinaire Hassan II, BP 6202-Instituts, MA-10101 Rabat idrissfassi@yahoo.fr; +212 (0) 37760102

Geographisches Institut - Physical Geography, Universität Zürich, Winterthurerstr. 190 - Irchel, CH-8057 Zürich favilli@geo.unizh.ch; +41 (0) 446355228

Università luav di Venezia, via Piave 10, I-30123 Venezia; ferrario@iuav.it; +39 (0) 3483106771

Fischer Markus, Prof.

Flückiger Bernadette

Flüeler Elsbeth

Boulevard de Grancy 5, CH-1006 Lausanne; floferret@hotmail.com; +41 (0) 216015888

Abt. Nationale Forschungsprogramme, SNF, Wildhainweg 21, CH-3012 Bern

Institut für Pflanzenwissenschaften, Universität Bern, Altenbergrain 21, CH-3013 Bern; markus.fischer@ips.unibe.ch

Roschistrasse 6, CH-3007 Bern; williblond@hotmail.com; +41 (0) 786026158

Mountain Wilderness Schweiz, Postfach 1622, CH-8040 Zürich

elsbeth.flueler@mountainwilderness.ch; +41 (0) 444613900

Flury Christian, Dr

Forschungsanstalt Agroscope Reckenholz-Tänikon, CH-8356 Ettenhausen christian.flury@art.admin.ch; +41 (0) 523683236

Fontana Georgia Institut de Géographie IGUL, Université de Lausanne, Bâtiment Anthropole, $\mathrm{CH}-1015$ Lausanne georgia.fontana@unil.ch; +41 (0) 216923077

Freléchoux François, Dr. Reserach Unit Ecosystem Boundaries, WSL, c/o EpFL Ecublens, CH-1015 Lausanne francois.frelechoux@wsl.ch; +41(0) 216935750

Gabrovec Matej, Dr. Anton Melik Geographical Institute, Scientific Research Centre of the Slovenian Academy of Sciences and Arts, Novi trg 2, SI-1000 Ljubljana; matej@zrc-sazu.si; +386 (0) 14706364

Ganguin Jean-Jacques Gymnase de Burier, Rte de Chailly, CH-1814 La Tour-de-Peilz; jjganguin@hotmail.com; +41 (0) 219210810

Gauchon Christophe Université de Savoie, F-73376 Le Bourget du Lac; christophe.gauchon@univ-savoie.fr; +33 (0) 479758138

Geiger Willy, Dr.

Gelinek Michael

Genoud Mathieu

Gentizon Caterina

Giorgetti Caroline

Golobič Mojca, Dr.

Grabherr Georg, Prof BAfu, Papiermühlestrasse 172, CH-3063 Ittigen; willy.geiger@bafu.admin.ch; +41 (0) 313222496 ConTrac Berlin, Köpenicker Strasse 48/49, D-10179 Berlin; info@contrac-berlin.de; +49 (0) 3027593965 Université de Lausanne, Couchirard 5, CH-1004 Lausanne; +41 (0) 774134736

Gymnase de Burier, rte de Chailly, CH-1814 La Tour-de Peilz; caterina.gentizon@hepl.ch; +41 (0) 213169337 Sites \& Paysages, 4 rue Buclée, F-38130 Echirolles; sites.paysages@wanadoo.fr; +33 (0) 476231466 Urbanisticni institut RS, Trnovski pristan 2, SI-1000 Ljubljana; mojca.golobic@uirs.si; +386 (0) 14201322 Faculty of Life Sciences, Universität Wien, Althanstrasse 14, A-1090 Wien grab@pflaphy.pph.univie.ac.at; +43 (0) 1427754370

Grêt-Regamey Adrienne, Dr., Landscape and Environmental Planning LEP, ETH Zürich, Wolfgang-Pauli-Strasse 15, CH-8093 Zürich gret@nsl.ethz.ch; +41 (0) 446333002

Grote Rüdiger, Dr. Institute for Meteorology and Climate Research, Research Center Karlsruhe GmbH, Kreuzeckbahnstr. 19, D-82467 Garmisch-Partenkirchen; ruediger.grote@imk.fzk.de; +49 (0) 8821183124

Gulič Andrej Urban Planning Institute RS, Trnovski pristan 2, SI-1000 Ljubljana; andrej.gulic@uirs.si; +386 (0) 14201317 
Geographisches Institut - Centre for Development and Environment CDE, Universität Bern, Steigerhubelstrasse 3 , CH-3008, Bern; thomas.gurtner@gmx.ch; +41(0) 787437787

Haber Wolfgang, Prof. Lehrstuhl für Landschaftsökologie, Technische Universität München, in Weihenstephan, D-85350 Freising wethaber@aol.com; +49(0) 8161714140

Haeberli Wilfried, Prof. Geographisches Institut - Physical Geography, Universität Zürich, Winterthurerstr. 190 - Irchel, CH-8057 Zürich haeberli@geo.unizh.ch; +41(0) 446355120

Hagedorn Horst, Prof. Geographisches Institut, ,Universität Würzburg, Am Hubland, D-97074 Würzburg horst.hagedorn@mail.uni-wuerzburg.de; +49 (0) 9318885555

Haltmeier Katrin Am Zopfbach 4, CH-8804 Au; katrinha@bluewin.ch; +41 (0) 797202466

Haug Roman Markt Bad Hindelang, Marktstrasse 9, D-87541 Bad Hindelang; rathaus@hindelang.net; +49 (0) 832489231

Hausner Isolde, Dr. Institut für Österreichische Dialekt- und Namenlexika, Österreichische Akademie der Wissenschaften, Postgasse 7, A-1010 Wien; isolde.hausner@oeaw.ac.at; +43 (0) 1515813496

Hedinger Christian Atelier für Naturschutz und Umweltfragen, UNA, Mühlenplatz 3, CH-3011 Bern hedinger@unabern.ch; +41 (0) 313122937

Heeb Johannes, Dr. Heinrich Kati seecon international, Bahnhofstrasse 2,CH-6110 Wolhusen; johannes.heeb@seecon.ch; +41 (0) 793666850 Gebirgsforschung: Mensch und Umwelt, ÖAW, Technikerstr. 21a, A-6020 Innsbruck kati.heinrich@oeaw.ac.at; +43 (0) 5125074947

Herzog Felix, Dr. ART Standort Reckenholz, Agroscope Reckenholz-Tänikon ART, Reckenholzstr. 191, CH-8046 Zürich felix.herzog@art.admin.ch; +41 (0) 443377445

Hiltbrunner, Erika, Dr. Botanisches Institut - Pflanzenökologie, Universität Basel, Schönbeinstrasse 6, CH-4056 Basel erika.hiltbrunner@unibas.ch; +41 (0) 612673511

Hirschmugl Manuela Institute of Digital Imaging Processing, Joanneum Research, Steyrergasse 17, A-8010 Graz manuela.hirschmugl@joanneum.at; +43 (0) 3168761707

Hohwieler Nadin

Institut für Umweltgeowissenschaften, Universität Basel, Bernoullistrasse 30, CH-4056Basel nadine.hohwieler@unibas.ch; +41(0) 612673631

Hostert Patrick, Prof. Institute of Geography, Humboldt-Universität zu Berlin, Unter den Linden 6, D-10099 Berlin patrick.hostert@geo.hu-berlin.de; +49 (0) 3020936905

Husi Stefan, Dr. Imhof Regula SNF, Wildhainweg 21, CH-3012 Bern; shusi@snf.ch; +41 (0) 313082222 Ständ. Sekretariat der Alpenkonvention, Herzog-Friedrich-Strasse 15, A-6020 Innsbruck regula.imhof@alpconv.org; +43 (0) 512588589

Jiricka Alexandra Jost Silvia Universität für Bodenkultur Boku, Peter-Jordan-Strasse 82, A-1190 Wien; alexandra.jiricka@boku.ac.at Internationales, Bundesamt für Raumentwicklung ARE, Mühlestrasse 2, CH-3063 Ittigen; silvia.jost@are.admin.ch; +41 (0) 313224060

Kaufmann Vera Geschäftsstelle ICAS \& IsCAR, Kommission Alpenforschung, Schwarztorstrasse 9, CH-3007 Bern icas@scnat.ch; +41 (0) 313187018

Kaufmann-Mattli Susy Stiftung „Lebensraum Gebirge”, Herrenhaus Grafenort, CH-6388 Grafenort; info@grafenort.ch; +41 (0) 41639533

Kienast Felix, PD Dr Kirchgesser Magali Abt. Landschaft, WSL, Zürcherstrasse 111, CH-8903 Birmensdorf; felix.kienast@wsl.ch; +41 (0) 447392366 Joint Technical Scretariat INTERREG IIIB Alpine Space Programme, D-83013 Rosenheim magali.kirchgesser@rosenheim.de; +49 (0) 8031362773

Kiser Karl, Dr. Präsidium Plattform KRG, Landenbergstrasse 11, CH-6060 Sarnen

Kissling-Näf Ingrid, Dr. Kocherhans Yvonne Köck Günter, Dr. SCNAT, Schwarztorstr. 9, CH-3007 Bern; kissling@scnat.ch; +41 (0) 313104030 FHnw Institut Architektur, Gründenstrasse 40, CH-4132 Muttenz; yvonne.kocherhans@fhnw.ch; +41 (0) 788258609 Nationale und internationale Forschungsprogramme, Österreichische Akademie der Wissenschaften ÖAW, Dr. Ignaz Seipel-Platz 2, A-1010 Wien; guenter.koeck@oeaw.ac.at; +43 (0) 151581271

Kohli Lukas, Dr. Kohte Maya Hintermann \& Weber AG, Marzilistr. 8a, CH-3005 Bern; kohli@hintermannweber.ch; +41 (0) 313128272 Institut für Landschaftsarchitektur, ETH Zürich, ETH Zentrum, HIL H 57.2, CH-8092 Zürich kohte@forumlandschaft.ch; +41 (0) 446332989

Kozak Jacek, Dr. Institute of Geography and Spatial Management, Jagiellonian University, Gronostajowa 7, PL-30-387 Krakow jkozak@gis.geo.uj.edu.pl; +48 (0) 126645300

Kräuchi Norbert, Dr. Forschungsprogramm target Forstwirtschaft und Klimawandel, WSL, Zürcherstrasse 111, CH-8903 Birmensdorf norbert.kraeuchi@wsl.ch; +41 (0) 447392595

Kretz Stephanie Expert EC, Grosser Kesselweg 25, D-75223 Niefern; mail@stephaniekretz.eu; +49 (0) 7233943835

Kuss, Patrick, Dr. Institut für Pflanzenwissenschaften, Universität Bern, Altenbergrain 21, CH-3013 Bern fhpk1@uaf.edu; +41(0) 316314992

Lahn Gärtner Elisabeth Institut für Geographie, Universität Innsbruck, Innrain 52, A-6020 Innsbruck elisabeth.gaertner@uibk.ac.at; +43 (0) 5125075416

Lange Eckart, Prof. Department of Landscape, University of Sheffield, Floor 3, Arts Tower, Western Bank, GB-Sheffield S10 2TN e.lange@sheffield.ac.uk

Lauber Guido Niederlassung Spiez, Emch + Berger AG, Seestrasse 7, CH-3700 Spiez guido.lauber@emchberger.ch; +41 (0) 336507571

Legaz Amaia Université de Savoie, F-73376 Le Bourget du Lac; amaya.legaz@univ-savoie.fr

Lehmann Bernard, Prof. Institut für Agrarwirtschaft IAW, ETH Zürich, Sonneggstr. 33, CH-8092 Zürich; lehmann@ethz.ch; +41 (0) 446325391

Lenhard Vera Christine, Dr., Altweg 18, CH-8047 Zürich; vera@freesurf.ch; +41 (0) 438114168

Liechti Karina

Geographisches Institut - Centre for Development and Environment CDE, Universität Bern, Steigerhubelstrasse 3, CH-3008 Bern; karina.liechti@cde.unibe.ch 


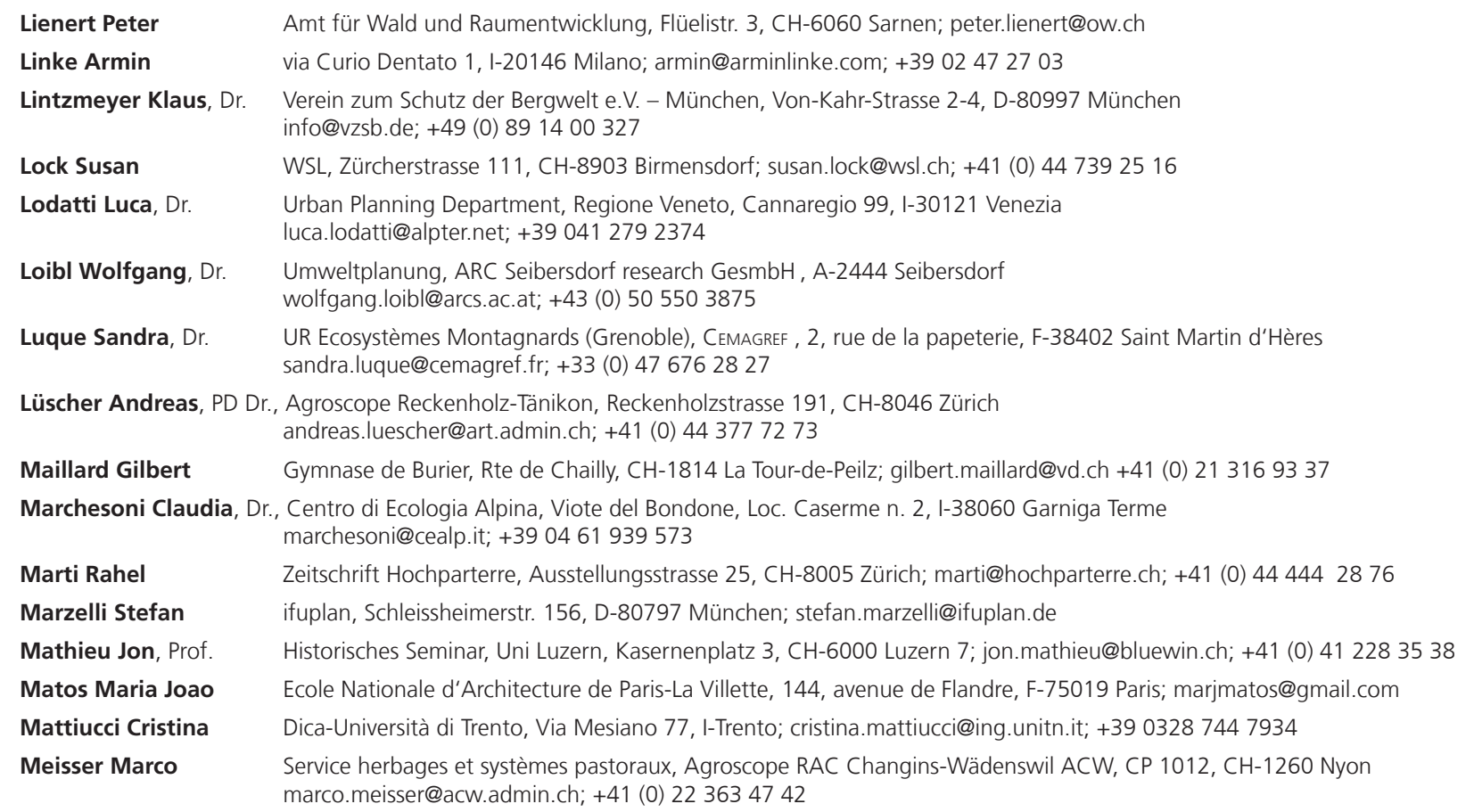

Messerli Bruno, Prof. em., Geographisches Institut - Physische Geographie, Universität Bern, Hallerstrasse 12, CH-3012 Bern bmesserli@bluewin.ch; +41(0) 318193381

Messerli Paul, Prof. Geographisches Institut - Kulturgeographie, Universität Bern, Hallerstrasse 12, CH-3012 Bern mep@giub.unibe.ch; +41(0) 316318886

Meusburger Katrin Institut für Umweltgeowissenschaften, Universität Basel, Bernoullistrasse 30, CH-4056 Basel katrin.meusburger@unibas.ch; +41(0) 612670483

Miéville-Ott Valérie AgrideA, Jordils 1, CH-1010 Lausanne 6; valerie.mieville@agridea.ch; +41 (0) 216194458

Monard Denis, Prof. $\quad$ Friedrich Miescher Institut, Maulbeerstr. 66, CH-4058 Basel; denis.monard@fmi.ch; +41 (0) 616976658

Müller Eduard Büro für Denkmalpflege, Eidgenössische Kommission für Denkmalpflege EDK, Treibstrasse 10, CH-6377 Seelisberg denkmalpflege@msn.com; +41(0) 418206850

Müller Wahl Priska, Dr. Abt. Umwelt und Natürliche Ressourcen, Hochschule Wädenswil, Grüental / Postfach 335, CH-8820 Wädenswil p.mueller@hsw.ch; +41 (0) 447899582

Neuenschwander-Gindrat Sylviane, Sozialanthropologisches Institut, Universität Bern, Jubiläumsstr. 43, CH-3005 Bern sylviane.neuenschwander@hispeed.ch; +41 (0) 313525910

Niederberger Beat Naturforschende Gesellschaft Ob- und Nidwalden, Zürichstr. 9, CH-6004 Luzern; beat@speleo.ch

Odermatt Martin

Omlin Sibylle, Prof.

Panizza Mario, Prof. Gemeinde Engelberg, Engelbergerstrasse 44, CH-6390 Engelberg; odermatt.m@gde-engelberg.ch Offenburgerstrasse 1, CH-4057 Basel; sybille.omlin@fhnw.ch; +41 (0) 616666112 Dipartimento di Scienze della Terra, Università degli Studi di Modena e Reggio Emilia, Largo S. Eufemia 19, I-41100 Modena; pit@unimore.it; +39 0592055840

Pecci Massimo, Dr.

Pedrazzini Luisa

Perlik Manfred, Dr.

Petek Franci, Dr.

Petite Mathieu

Pfefferkorn Wolfgang

Powell-Joss Margret

Praper Sergeja

Preiswerk Christian

Probst Thomas

Pröbstl Ulrike, Prof.

IMONT, Piazza dei Caprettari 70, I-00186 Roma; massimo.pecci@imont.gov.it; +39066 8192366

Regione Lombardia, piazza IV Novembre, 5, I-20124 Milano; luisa_pedrazzini@regione.lombardia.it; +390267653735 Gebirgsforschung: Mensch und Umwelt, Forschungsstelle der Österreichischen Akademie der Wissenschaften , Technikerstr. 21a, Otto Hittmair-Platz 1, A-6020 Innsbruck manfred.perlik@oeaw.ac.at; +41 (0) 616934365

Anton Melik Geographical Institute, Scientific Research Centre of the Slovenian Academy of Sciences and Arts, Novi trg 2, SI-1000 Ljubljana; franci.petek@zrc-sazu.si; +386 (0) 14706351

\section{Dépt. de Géographie, Université de Genève, 40, bd Pont-d'Arve, $\mathrm{CH}-1211$ Genève 4} mathieu.petite@geo.unige.ch; +41 (0) 223799896

Rosinak\&Partner ZT GmbH, Schlossgasse 11a, A-1050 Wien; pfefferkorn@rosinak.at; +43 (0) 15440707

Powell-Joss Translations, Muesmattstrasse 28, CH-3012 Bern; info@powelltrans.ch; +41 (0) 313026162

Urbanisticni institut RS, Trnovski pristan 2, SI-1000 Ljubljana; sergeja.praper@uirs.si

ScnAT, Schwarztorstrasse 9, CH-3007 Bern; preiswerk@scnat.ch; +41 (0) 313104022

Alpenforschungsinstitut AFI, Am Kurpark 21, D-82467 Garmisch-Partenkirchen probst@alpenforschung.de; +49 (0) 88219431630

Institute for Landscape Development, Recreation and Conservation Planning, BoKU - University of Natural Resources and Applied Life Sciences, Peter-Jordan-Strasse 82, A-1190 Wien; ulrike.proebstl@boku.ac.at; +43 (0) 1476547207

Pruckner Gerald, Prof. Sozial- und wirtschaftswissenschaftliche Fakultät, Johannes Kepler Universität Linz, Altenberger Strasse 69 , A-4040 Linz gerald.pruckner@jku.at; +43(0) 7024688213

Prutsch Andrea

Department für Raum, Landschaft und Infrastruktur, Universität für Bodenkultur Boku, Peter-Jordan-Strasse 82 , A-1190 Wien; andrea.prutsch@boku.ac.at; +43 (0) 1476547247

Psenner Roland, Prof. Institut für Ökologie, Leopold-Franzens-Universität Innsbruck, Technikerstr. 25, A-6020 Innsbruck roland.psenner@uibk.ac.at; +43 (0) 5125076130 
Quaglia Tiziana

Rampl Gerhard, Dr.

Regione Veneto, Cannaregio 99 Pal. Linetti, I-30123 Venezia; tiziana.quaglia@regione.veneto.it; +390412792086 Österreichische Akademie der Wissenschaften ÖAW, Postgasse 7, A-1010 Wien gerhard.rampl@the-office.at; +43 (0) 6509381789

Reynard Emmanuel, Prof., Institut de Géographie IGUL, Université de Lausanne, Bâtiment Anthropole, CH-1015 Lausanne emmanuel.reynard@unil.ch; +41 (0) 216923065

Rinaldi Renato

Risi Marius

Località lesizza 94, I-33040 San Leonardo; oreledigneur@libero.it; +390432 723537 marius.risi@unibas.ch; +41(0) 612670528

Röthlisberger Markus

Rechtsdienst, Schweizerischer Nationalfonds SNF, Wildhainweg 3, CH-3001 Bern mroethlisberger@snf.ch; +41 (0) 313082255

Samuel-Eckerle Eva

Kommission für Glaziologie, Bayerische Akademie der Wissenschaften, c/o Geographisches Institut, Universität Würzburg, Am Hubland, D-97074 Würzburg; eva.samuel-eckerle@mail.uni-wuerzburg.de; +49 (0) 9318885555

Savelli Nicolas

Schaaf Thomas, Dr. Faubourg Reclus, F-73000 Chambéry; nicolas.savelli@free.fr

Schaffner Ruth, Dr. Man and the Biosphere Programme MAB, Unesco, 1, rue Miollis, F-75732 Paris Cedex 15 t.schaaf@unesco.org; +33 (0) 145684065

Schenker Franz, Dr.

U.+R. Schaffner \& Associates, Allmendweg 15, CH-3653 Oberhofen; ruth.schaffner@gmx.ch; +41 (0) 332434973

Geologische Beratung, Schenker Korner \& Partner GmbH, Büttenenhalde 42, CH-6006 Luzern

franz.schenker@fsgeolog.ch; +41 (0) 413756100

Scheuerer Silvia

Scheurer Thomas, Dr. Geschäftsstelle ICAS \& IsCAR, Kommission Alpenforschung, Schwarztorstrasse 9, CH-3007 Bern scheurer@scnat.ch, +41 (0) 313187018

Schlumpf Hans-Ulrich, Dr., Mühlegasse 5, CH-8001 Zürich; info@film-schlumpf.ch; +41 (0) 442518668

Schmid Franziska Geographisches Institut - Centre for Development and Environment CDE, Universität Bern, Hallerstrasse 12 , CH-3012 Bern; fschmid@giub.unibe.ch; +41 (0) 316318390

Schmid Christian Professur für Agrarwirtschaft, ETHZ, Sonneggstrasse 33, CH-8092 Zürich; christsc@ethz.ch; +41 (0) 446327930

Schnellmann Michael, Dr., Geologisches Institut, ETH Zürich, ETH Zentrum NO, Sonneggstr. 5, CH-8092 Zürich

Schüpbach Ursula Managementzentrum, UnEsco Weltnaturerbe Jungfrau-Aletsch-Bietschhorn, Jungfraustrasse $38, \mathrm{CH}-3800$ Interlaken ursula.schuepbach@weltnaturerbe.ch; +41(0) 338216176

Senn Maria

Sektion Siedlung und Landschaft, ARE, Mühlestrasse 2, CH-3063 Ittigen maria.senn@are.admin.ch; +41 (0) 313223382

Sgard Anne Institut de Géographie Alpine, Laboratoire Pacte-Territoire, 14 bis avenue M. Reynoard, F-38000 Grenoble anne.sgard@upmf-grenoble.fr; +33 (0) 476822070

Sitko Izabela Institute of Geography and Spatial Management, Jagiellonian University, Gronostajowa 7, PL-30-387 Krakow isitko@gis.geo.uj.edu.pl; +48 (0) 126645302

Smoliner Christian, Dr. Bundesministerium für Bildung, Wissenschaft und Kultur, Rosengasse 4, A-1010 Wien christian.smoliner@bmbwk.gv.at; +43 (0) 1531206353

Spalinger Nika, Prof. Sentimatt 1, CH-6003 Luzern 5; nspalinger@hgk.fhz.ch; +41 (0) 412285770

Spehn Eva, Dr. Botanisches Institut - Pflanzenökologie, Universität Basel / GMBA, Schönbeinstrasse 6, CH-4056 Basel gmba@unibas.ch, +41(0) 612673511

Spiegelberger Thomas, Dr., Cemagref Grenoble, 2, rue de la Papeterie - BP 76, F-2800 Saint-Martin-d'Hères cedex thomas.spiegelberger@cemagref.fr, +33(0) 476762819

Spielmann Max, Prof. FHnw/HGK Institut HyperWerk, Totentanz 17, CH-4057 Basel; max.spielmann@fhnw.ch; +41 (0) 793217279

Stalder Andreas

Stalder Ulrich Natur und Landschaft, BAFu, Worblentalstr.68, CH-3063 Ittigen; andreas.stalder@bafu.admin.ch; +41 (0) 313229375 Abt. Kantonsplanung, Amt für Gemeinden und Raumordnung AGR, Nydeggasse 11/13, CH-3011 Bern ueli.stalder@jgk.be.ch; +41 (0) 316337305

Stäuble Sabine Institut de Géographie IGUL, Université de Lausanne, Bâtiment Anthropole, CH-1015 Lausanne sabine.stauble@unil.ch; +41 (0) 216923077

Steiger Urs Pilatusstrasse 30, CH-6003 Luzern; u.steiger@bluewin.ch; +41 (0) 412200676

Stöcklin Jürg, PD Dr. Botanisches Institut - Pflanzenökologie, Universität Basel, Schönbeinstrasse 6, CH-4056 Basel; juerg.stoecklin@unibas.ch; +41(0) 612673501

Stremlow Matthias, Dr. BAfu, Papiermühlestrasse 172, CH-3063 Ittigen; mstremlow@freesurf.ch; +41 (0) 313248401

Strobl Margit, Dr.

Stucki Silvio

Kulturverein Grand Hotel Toblach, Beda Weberstr. 3b/8, I-39100 Bozen; margitstrobl@web.de; +3903336769700

Birdlife CH - Schweizer Vogelschutz SVS, Wiedingstrasse 78, $\mathrm{CH}-8036$ Zürich silvio.stucki@birdlife.ch; +41 (0) 444577027

Tamburelli Gianfranco Institute for International Legal Studies ISGI, Consiglio Nazionale delle Ricerche CNR, Via dei Taurini, 19, I-00185 Roma RM Lazio; gtamburelli@pelagus.it; +39 0649937660

Tappeiner Ulrike, Prof. Alpine Environment, Europäische Akademie Bozen, Drususallee 1, I-39100 Bozen ulrike.tappeiner@uibk.ac.at; +3904 71055301

Tasser Erich, Dr. Troll Mateusz, Dr. Europäische Akademie Bozen, Drususallee 1, I-39100 Bozen; erich.tasser@uibk.ac.at; +39 0471055311 Institute of Geography and Spatial Management, Jagiellonian University, Gronostajowa 7, PL-30-387 Krakow mtroll@gis.geo.uj.edu.pl; +48 (0) 126645300

Ullrich Aurelia

Urbanc Mimi CIPRA International, Im Bretscha 22, FL-9494 Schaan; aurelia.ullrich@cipra.org; +423 (0) 2374033

Anton Melik Geographical Institute, Scientific Research Centre of the Slovenian Academy of Sciences and Arts, Gosposka ulica 13, SI-1000 Ljubljana; mimi@zrc-sazu.si; +386 (0) 14706354 
Vancutsem Didier IsOCARP, Valpichlerstr. 49, D-80686 München; info@vancutsem.de; +49 (0) 8974370442

Vanpeene-Bruhier Sylvie, Ecosystème montagnards, CEMAGreF, BP 76, F-38402 St.-Martin-d'Hères cedex sylvie.vanpeene@cemagref.fr; 33 (0) 476762787

Veit Heinz, Prof. Geographisches Institut - Physische Geographie, Universität Bern, Hallerstrasse 12, CH-3012, Bern veit@giub.unibe.ch; +41(0) 316318561

Völler Sonja O Oskar-Spiel-Gasse 6/2/1, A-1190 Wien; sonja.voeller@gmx.de; +43 (0) 19240755

Vonlanthen Corinne, Dr., Plant Science Center, ETH Zürich, Universitätsstrasse 2, CH-8092 Zürich; cvonlanthen@ethz.ch

Wallner Astrid, Dr. Geographisches Institut - Centre for Development and Environment CDE, Universität Bern, Steigerhubelstrasse 3, CH-3008 Bern; astrid.wallner@cde.unibe.ch; +41 (0) 316313059

Walser Urs Wasserbau, Amt für Wald- und Raumentwicklung Obwalden, Flüelistr. 3, CH-6060 Sarnen urs.walser@ow.ch; +41(0) 416666286

Walter Felix ECOPLAN, Thunstr. 22, CH-3005 Bern; walter@ecoplan.ch; +41 (0) 313566161

Walter François, Prof. Dépt. d’Histoire générale, Université de Genève, 5, Rue St. Ours, CH-1211 Genève 4 francois.walter@lettres.unige.ch; +41 (0) 227057093

Walz Ariane Institut für Schnee- und Lawinenforschung, SLF, WSL, Flüelastrasse 11, CH-7260 Davos Dorf walz@slf.ch; +41(0) 814170283

Weber Thomas Schweiz. Stiftung für Alpine Forschung SsAF, Stadelhoferstr. 42, CH-8045 Zürich; mail@alpinfo.ch; +41 (0) 442531200 Weber Michael, Dr. Institut für Agrarwirtschaft IAW, ETH Zürich, Sonneggstr. 33, CH-8092 Zürich; miweber@ethz.ch

Weber Sandra Kantonsschule Oerlikon, Birchstrasse 107, CH-8050 Zürich; s.weber@ksoe.ch

Weck-Hannemann Hannelore, Prof., Institut für Finanzwissenschaft, Universität Innsbruck, Universitätsstrasse 15, A-6020 Innsbruck hannelore.weck@uibk.ac.at; +43(0) 5125077153

Weissen Andreas Termerweg 22, CH-3900 Brig; +41 (0) 442972253

Weixlbaumer Norbert, Prof., Institut für Geographie und Regionalforschung, Universität Wien, Universitätsstrasse 7, A-1010 Wien norbert.weixlbaumer@univie.ac.at; +43 (0) 1427748624

Werlen Iwar, Prof. Institut für Sprachwissenschaften, Universität Bern, Länggassstrasse 49, CH-3000 Bern 9 iwar.werlen@isw.unibe.ch; +41(0) 316318004

Wiesinger Georg, Dr. Bundesanstalt für Bergbauernfragen, Federal Institute for Mountainous and Less-favoured Areas, Marxerg. 2/M, A-1030 Wien; georg.wiesinger@berggebiete.at; +43 (1) 504886920

Wohler Urs EngADIN / Scuol Tourismus AG, Stradun, CH-7550 Scuol; u.wohler@engadin.com

Wozniak Marie 7 av. M. Berthelot, F-38100 Grenoble;marie.wozniak@wanadoo.fr

Wunderli Rahel Wildeggerstrasse 4, CH-5702 Niederlenz; rahel.wunderli@stud.unibas.ch; +41 (0) 628911612

Wytrzens Hans Karl, Dr., Institut für nachhaltige Wirtschaftsentwicklung, Universität für Bodenkultur Boku Wien, Feistmantelstrasse 4, A-1180 Wien; wytrzens@boku.ac.at; +43 (0) 1476543572

Zanini Piero Via Romana 6, I-38016 Messocorona; pierozanini@wanadoo.fr; +39 03391242129

Zbinden Marlis SAGw, Hirschengraben 11, CH-3001 Bern; marlis.zbinden@sagw.ch; +41 (0) 313131440

Zebisch Marc Area Sustainable Development, Eurac.Research, Drususalle 1, I-39100 Bolzano marc.zebisch@eurac.edu; +390471055 312 